\title{
Ning
}

\section{The future of car ownership}

August 2017 
Better road and transport infrastructure has been a core focus of the $\bigcirc$ NRMA since 1920 when our founders lobbied for improvements to the condition of Parramatta Road in Sydney. Independent advocacy was our foundation activity, and it remains critical to who we are as we approach our first centenary.

We've grown to represent over 2.4 million Australians, principally from New South Wales and the Australian Capital Territory. We provide motoring, mobility and tourism services to our Members and the community.

Today, we work with policy makers and industry leaders, advocating for increased investment in road infrastructure and transport solutions to make mobility safer, provide access for all, and deliver sustainable communities. By working together with all levels of government to deliver integrated transport options, we give motorists real choice about how they get around.

We firmly believe that integrated transport networks, including efficient roads, high-quality public transport and improved facilities for cyclists and pedestrians, are essential in addressing the challenge of growing congestion and providing for the future growth of our communities.

The NRMA acknowledges the work of Sam Rutherford on

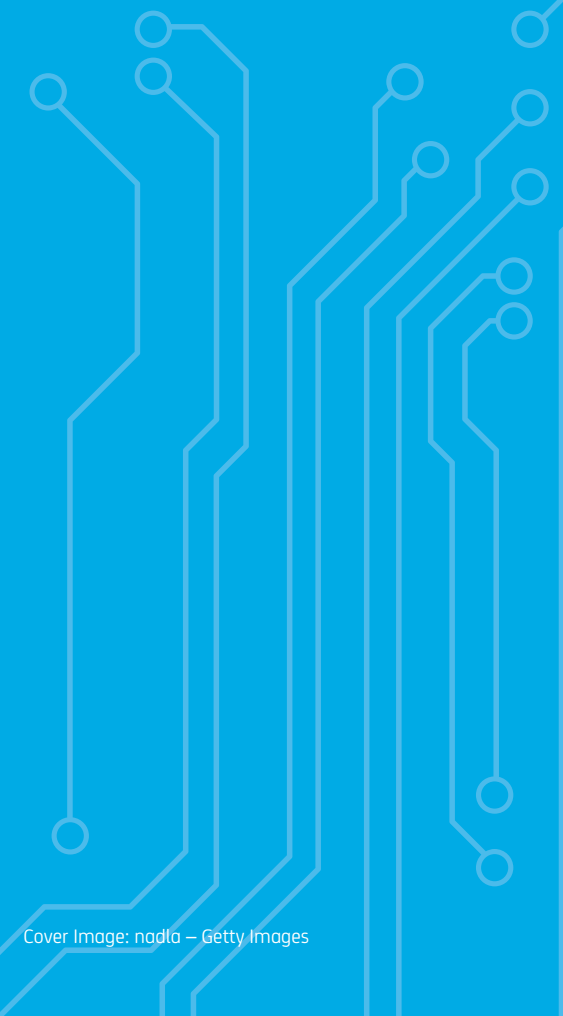
this report.

\section{Comments and queries}

\section{Ms Carlita Warren}

Senior Manager - Public Policy and Research

\section{NRMA}

PO Box 1026, Strathfield NSW 2135

Email: Public.Policy@mynrma.com.au

Web: mynrma.com.au 


\section{Executive summary}

\section{Recommendations}

Introduction

\section{Setting the scene}

The established mindset of 'auto mobility'

The mobility challenge

Population growth and urbanisation

Congestion

Funding challenges

\section{Growing alternatives to car ownership}

The mindset of the millennial

Changing attitudes towards driving

Car share

Ride share

Door-to-door public transport (Mobility-as-a-Service)

The Silicon Valley effect

\section{The cars of the future}

Alternative drive train technology

Electric vehicles

Fuel cell

Autonomous vehicle

Connected car

Service investments

\section{Future car ownership}

Issues with estimating declines in ownership

Solving the hassle-premium: car or no car?

Consumer surplus

Convenience and better choice

Who will still own a car?

What type of car-use services can we expect?

How autonomous vehicles

interact with wider transport policies
2 Challenges and opportunities

The impact of door-to-door public transport

(Mobility-as-a-Service)

48

Competition from the outside 49

New preferences

50

\section{The benefits of new mobility}

51

Improved safety

53

Environment 54

Congestion $\quad 55$

Productivity $\quad 56$

What change is required? 57

What questions need to be asked?

Public and consumer acceptance $\quad 60$

Road rules and regulations 61

Infrastructure 64

Taxation and funding $\quad 66$

Road access pricing $\quad 67$

Other considerations $\quad 70$

Concerns to be addressed $\quad 71$

Displacement and job losses 72

Do autonomous vehicle trials require a driver? 73

Insurance and liability

Security and privacy

Beyond autonomous vehicles $\quad 77$

Hyperloop 79

Flying cars $\quad$.

Conclusion 81 


\section{Executive summary}

Car ownership is traditionally seen as something of a birth-right in Australia. The motor vehicle has been part of the Australian family now for at least three generations. As our cities are comparatively new in the march of time, they have been planned and have grown around the concept of auto mobility. Our suburbs and homes are designed for the use of our privately owned motor vehicle as our primary mode of transportation.

But the world is changing, and Australia will change with it. Population growth and the greater densification of our urban environment is throwing up enormous challenges.

Congestion, pollution and the impacts they have on the liveability of our urban environments will push government and industry to find new solutions. Indeed, urban congestion is one of the greatest challenges facing Australia today. Already we are seeing some urban environments trying to explicitly limit the use of private motor vehicles altogether. For example, Helsinki in Finland is planning to end private motor vehicle use by 2025 .

But the solution to this mobility conundrum may have already begun to occur in the great upheaval taking place in the mobility industry.

Car manufacturers are now locked in a great battle of creative disruption. Revolutions in autonomous vehicles, electric vehicles, car sharing, ride sharing and connected vehicle technology will radically alter the concept of how we move around in urban environments. A traditional vehicle manufacturer can no longer solely rely on manufacturing the vehicles we know today. While we have seen a significant shift in thinking, manufacturers will have to continue to focus on a broadening concept of mobility.
In a changing world, these great trends are converging to a point where, in all likelihood, the private ownership of a car will become unnecessary for many. It may even become highly unusual to drive a vehicle on a public road if autonomous vehicle technology becomes widespread.

We estimate that high level autonomous vehicles will arrive in Australia as early as 2020. While there will be fundamental changes to vehicles and associated mobility services, we expect that some level of human interaction with a vehicle will still remain the norm within Australian society up until 2025.

After that, car ownership will no longer be a necessity, but a choice. Once autonomous vehicles begin to increase their share of the road fleet, we expect car ownership will decline relative to population growth.

This does not mean that car use will decline. A decrease in personal car ownership may actually correspond with an increase in the use of cars as a mobility choice. This may exacerbate the need for public policy decisions to be made sooner rather than later on issues like road user charging and infrastructure investment.

A low personal ownership, fully autonomous car future is dependent on many stars aligning. Options for personal mobility will increase with the advent of autonomous technology, and mobility will be safer, cheaper and more comfortable than it is today.

But one thing is sure, whatever the future of mobility holds - the NRMA will continue to keep its Members moving. 


\section{Recommendations}

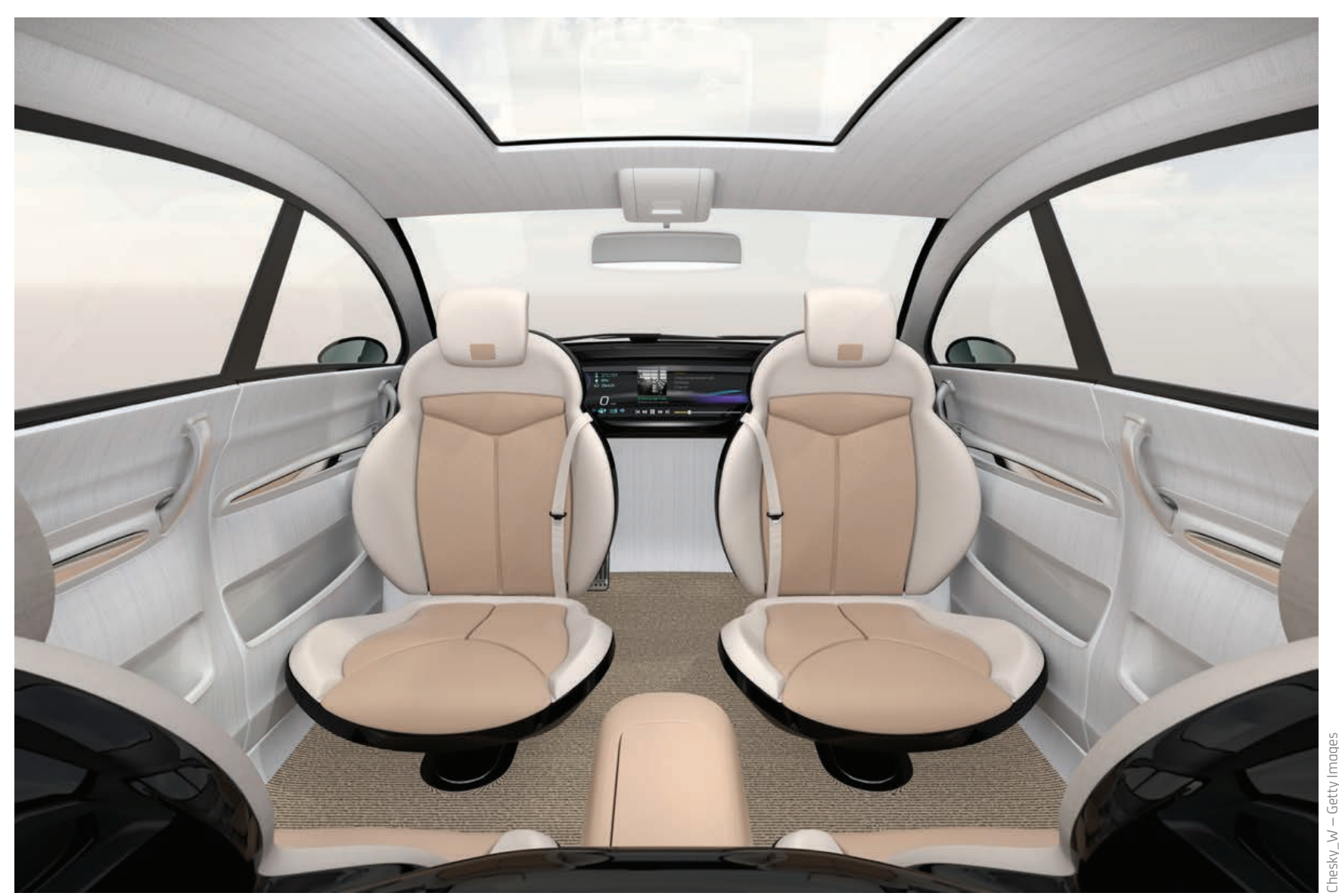

Given that much is uncertain, it is important for the community to keep an open mind about technological developments, and for Australian governments to provide flexibility for the trialling of autonomous technologies. More can be done to promote the development and advancement of electric vehicles and autonomous vehicles in Australia. With our population increasing rapidly and our urban areas becoming denser, the cost to society of doing nothing is significant. The following recommendations are aimed at breaking down existing barriers which may inhibit the benefits that an autonomous vehicle future promises:

\section{Mobility}

\section{All Australian governments should begin to develop holistic mobility policies for the future.}

There will still be a need for mass public transport and road infrastructure in the future, and governments should not prioritise the spending of one over the other. Instead, governments should ensure that investment is aimed at reducing congestion and maximising mobility choice which can be delivered at an efficient price.

All major road projects that are planned should incorporate smart infrastructure systems or, at the very least, be designed with the ability to easily retrofit future technology. The next generation of roads need to be intelligent and flexible enough to accommodate a future transition to fully autonomous vehicles. 


\section{Trials}

\section{All Australian governments should finalise legislation for trials of autonomous vehicles. Once these are finalised the implementation of trials should begin as soon as practicable.}

All states and territories should settle trial arrangements as soon as possible. Trials should be facilitated in a range of driving environments, including in rural, regional and urban settings.

Trials have the capacity to provide new and improved information to further our understanding of what is ultimately required for a fully autonomous future. With many of our congested cities and precincts struggling with transport demands, it is vital for our states and territories to play a leading role in the advancement of autonomy.

\section{The Australian Government should actively} promote Australia as a destination of choice for autonomous vehicle trials. It should should invite Original Equipment Manufacturers (OEMs) to run citizen focused autonomous vehicle trials, such as the Volvo Drive Me project, in order to grow societal acceptance of autonomous vehicles.

Broad acceptance of autonomous vehicles will only happen if consumers deem them to be safe and useful to their everyday needs. This has been realised by companies such as Volvo, who are planning on trialling autonomous vehicles on commuter routes using members of the public.

OEMs should be invited to conduct trials in specifically defined areas (sandboxing) to demonstrate the benefits of autonomous vehicles, and to increase collaboration and knowledge.

State governments should also promote autonomous vehicle trials focused on citizens that at present have high mobility inequalities such as the elderly, people with disabilities, and those living in remote areas.

\section{Services and sharing}

\section{State capitals and transport agencies should open up transport options to Mobility-as-a-Service (MaaS) companies in order to design end-to-end mobility options for citizens.}

Developments in MaaS - total door-to-door mobility solutions that are consumed as a service as opposed to privately-owned transport - have shown how integrated transport systems can give real mobility choice to citizens and allow them to compare and utilise different modes, including cycling and public transport against car use.

\section{Local governments should trial or promote car} sharing based on the success of current schemes (such as Go-Get).

Car sharing has the ability to take approximately 10 private vehicles off the road for every one shared car used. An expansion of car sharing would free up car parking capacity in our inner cities and provide significant financial savings for inner city residents.

\section{Electric vehicles}

\section{The Australian Government should remove impediments to the purchasing of electric vehicles.}

Australia has a low uptake of electric vehicles compared with our global counterparts. Less than one per cent of Australian vehicles currently possess electric or hybrid technology. The Australian Government should abolish the luxury car tax for electric vehicles as it provides a disincentive to buying certain electric models. 


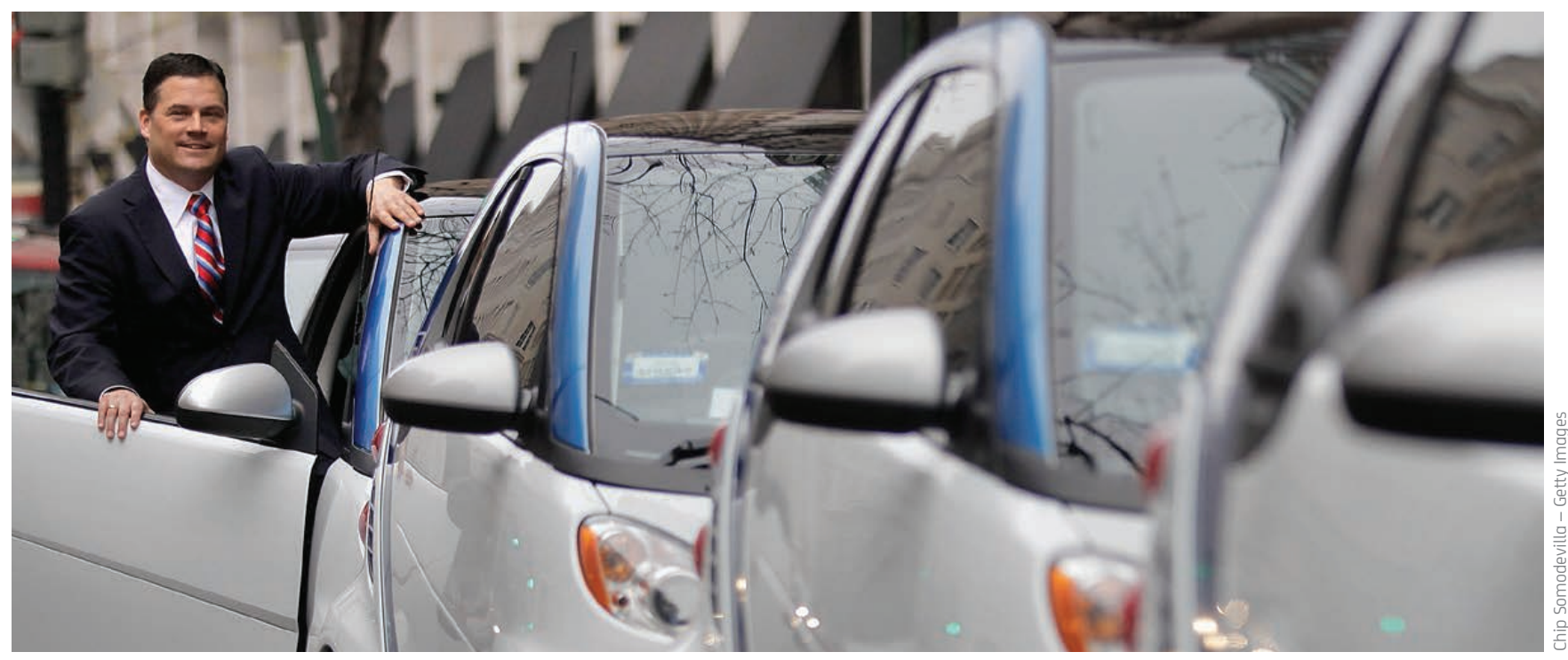

\section{Progression}

7. Road safety agencies across Australia should work together to examine whether alternative driver licensing schemes are needed in the short term, including better training with semi and fully autonomous technology.

While licensing schemes may currently be fit for purpose, there is a significant gap between current skill requirements and those needed in order to transition to an autonomous vehicle future. A discussion around future licensing requirements should be seen as a priority.

8. All Australian governments should begin to develop arrangements to implement an efficient road user charging scheme, with a view to move towards more integrated MaaS schemes within the decade.

Electric vehicles and autonomous vehicles that do not contribute to fuel excise will only exacerbate the need to have efficient road pricing mechanisms in order to pay for our future road infrastructure needs.
9. A skills and vocational training review should be conducted into all automotive related courses to ensure graduates are equipped for an electronic, connected and autonomous vehicle future.

Mechanics and the vocational education system that supports their training should be reviewed regularly to ensure there is an able workforce ready to service an autonomous vehicle fleet.

\section{All Australian governments should seek to implement legislation to support autonomous vehicles, and consider changes to longer term transport and land-use policies. Concurrently, a national approach to raising public awareness and confidence in autonomous technology should be pursued.}

In the short term, legislation should be implemented to support trials and consumer adoption of new autonomous technology. Governments should also give consideration to how an autonomous future integrates with current transport and land-use policies significant reforms will likely be necessary. Additionally, a national public awareness campaign should be pursued to educate consumers about the benefits of an autonomous vehicle future. 


\section{Introduction}

"In the future, many people won't own a car. But they can all be a customer in one way or another, because we will serve a much broader concept of mobility than today"

Matthias Mueller, CEO Volkswagen

As populations increase and cities become denser, congestion continues to place greater demands on transport networks. The cost to society of doing nothing will exacerbate transport and mobility issues and place even greater strain on public services and budgets.

It is clear to the NRMA that a major shift in mobility technology is upon us. The private motor vehicle has been an expensive convenience for many decades, but it now sits idle for 95 per cent of the time 1 - it is an extremely lazy and inefficient asset.

Growing trends around the world point to increasing levels of ride sharing, bike sharing, carpooling, ondemand services and public transport use. Interestingly, driver licence uptake has declined and the age of applicants has increased, suggesting that for younger generations, the private motor vehicle does not command the need it once did.

Autonomous technologies have been around for decades, but it is only recently that we have seen them enter the private vehicle fleet. Self-parking, autonomous braking and lane guidance are just a few examples of current technology. With technological advances occurring almost daily, over the next decade we can expect to see higher levels of automation enter the market. If current estimates are correct, the humble steering wheel may well be a thing of the past by as early as 2025.

Given our rapidly changing environment, private car ownership as we currently know it will more than likely decline as time progresses. Mobility will no longer be a privately-funded undertaking, but an evolving and efficient service supported by interconnected modes of transport. This shift presents significant challenges for current automakers, but also significant opportunities. Many major players from diverse sectors such as automotive, mass transit and technology are already well advanced in their thinking and are presently working to support future mobility concepts.

Removing the privately-owned motor vehicle from the mobility equation provides society with a myriad of benefits, including greater safety, convenience and productivity, reduced costs and congestion, and improved access for the elderly and disabled.

Autonomous technological advances, however, are not immune to barriers. Presently, no international standards exist to guide the use of autonomous vehicles, and regulators around the world are seeking more information so that informed decisions can be made. In addition, there are ethical, insurance and consumer issues to address, none of which will be easy.

"The automobile industry is at an inflection point for massive change, not just evolutionary change" Tim Cook, CEO Apple

Regulators need to understand legal implications, data issues, cross-border operability, insurance ramifications and consumer perceptions.

However, with the right framework in place, and a holistic approach to autonomy and transport interconnectivity, governments around the world have the opportunity to significantly improve access to safe and reliable mobility services that represent good value for money.

With a number of autonomous vehicle trials currently underway in Australia, and technology companies focused on ways to advance capabilities, new and improved information will assist in the adoption of autonomy, and will progress our understanding of what is achievable. 
Setting the scene 
"We just can't keep adding cars to the road" Graeme Whickman, CEO Ford Australia

The vehicle industry, one of the largest and most globally integrated industries in the world, is undergoing drastic reform. It is on the edge of even greater changes.

At the outset, if you looked only at sales data there remains a healthy demand for new vehicles both globally and within Australia. While this is set to continue for the foreseeable future, diverse industries are gearing up for an autonomous vehicle and transport future where mobility is an on-demand or subscribed service.

\section{"Mobility-as-a-Service and autonomous} vehicles are among the ten most significant issues for global executives"

KPMG

This change in thinking is best illustrated by the KMPG Global Auto Executive Survey, widely considered as a leading marker on the trends and views within the industry. In the 2009 survey, the term 'autonomous vehicle', 'self-driving vehicle' or 'driverless vehicle' were not mentioned; fast forward to 2017 and
'Mobility-as-a-Service/car sharing' and 'autonomous and self-driving cars' have appeared at eight and nine respectively in the top 10 issues list.

Technological developments in electric vehicles and autonomous vehicles are just one trend. There is also a growth in the use of car share services and ride share services, which makes it more convenient and cost effective to get around than owning a car. Autonomous technology will eventually make these services even cheaper.

With congestion continuing to worsen, infrastructure backlogs increasing, and some statistics showing 35 per cent of millennials forgoing obtaining their driver licence, we can start to see an emerging convergence that may give an insight into the future of mobility. This chapter seeks to set the scene of this convergence, and explains how OEMs are beginning to transition themselves from car manufacturers to complex mobility organisations in order to survive and compete in the new world.

\section{"The next 10 years will bring more change than the last 30"}

Dr Christoph Grote, Senior Vice President Electronics BMW

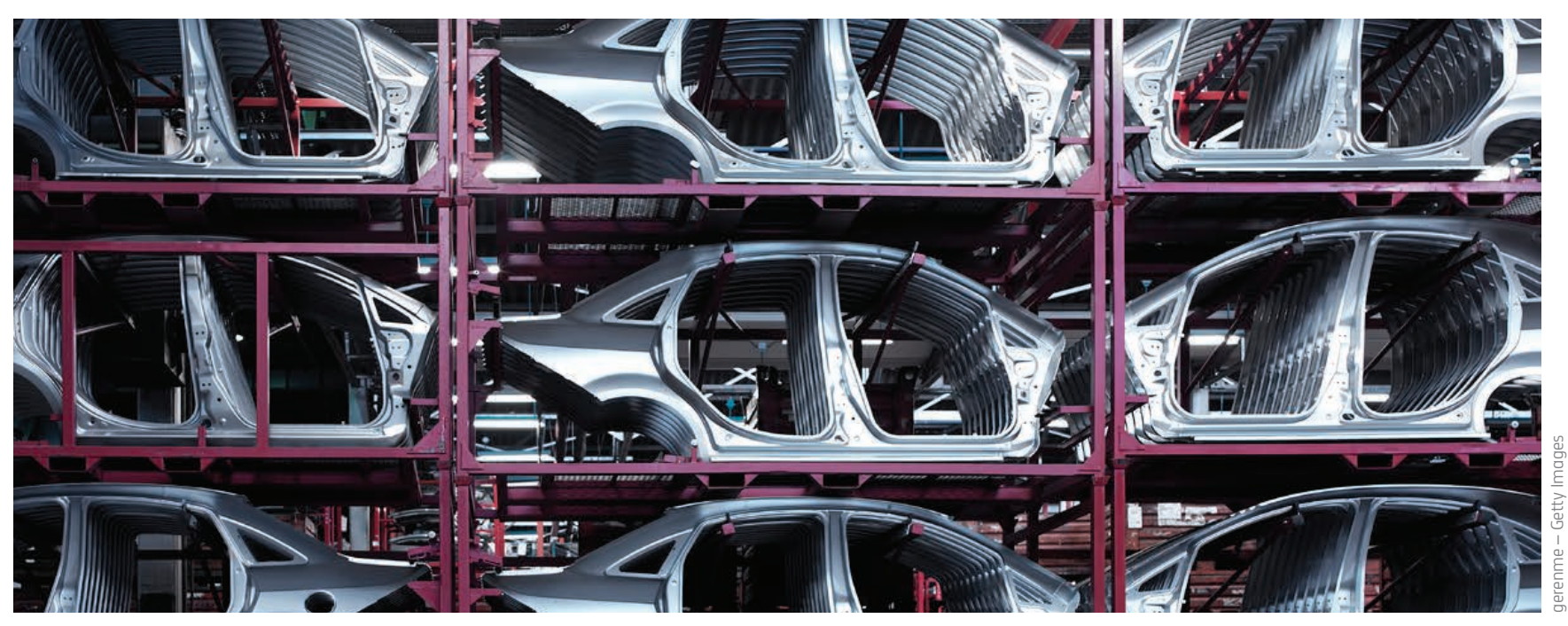




\section{The established mindset of 'auto mobility'}

Private car-based mobility is the preferred form of transport for most Australians. The ownership and usage of your own car is viewed as safe, comfortable and peaceful compared to active or public transport. Private car ownership also represents the pinnacle of personal freedom. Having a car parked in your garage or on the street gives you the ability to go anywhere you want at any time. There is no waiting for the bus or train, or walking in the rain or humidity. You can simply get in your car and drive in comfort to your destination.
This sense of freedom is a powerful and entrenched ideal within Australian society.

This mindset can be referred to as 'auto mobility'. Auto mobility has been central to the development of our cities, suburbs, homes, and many of the services and goods we use every day. Auto mobility has become so entrenched in our society that it can be difficult to imagine a scenario where you may not own a vehicle in the future.

\section{FIGURE 1: PERCENTAGE OF HOUSEHOLDS IN GREATER SYDNEY WITH CARS}
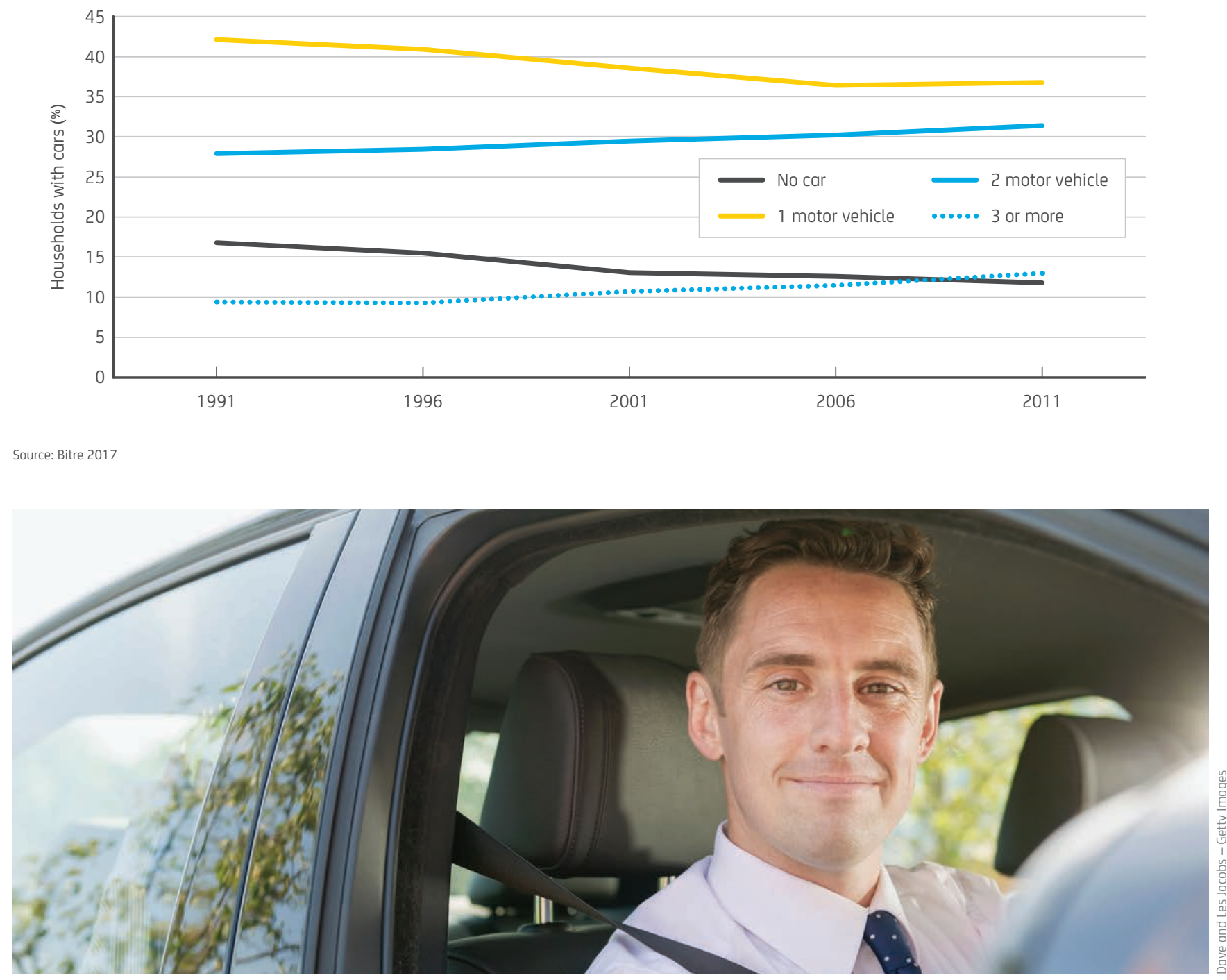


\section{FIGURE 2: REGISTERED MOTOR VEHICLES IN AUSTRALIA (000S)}

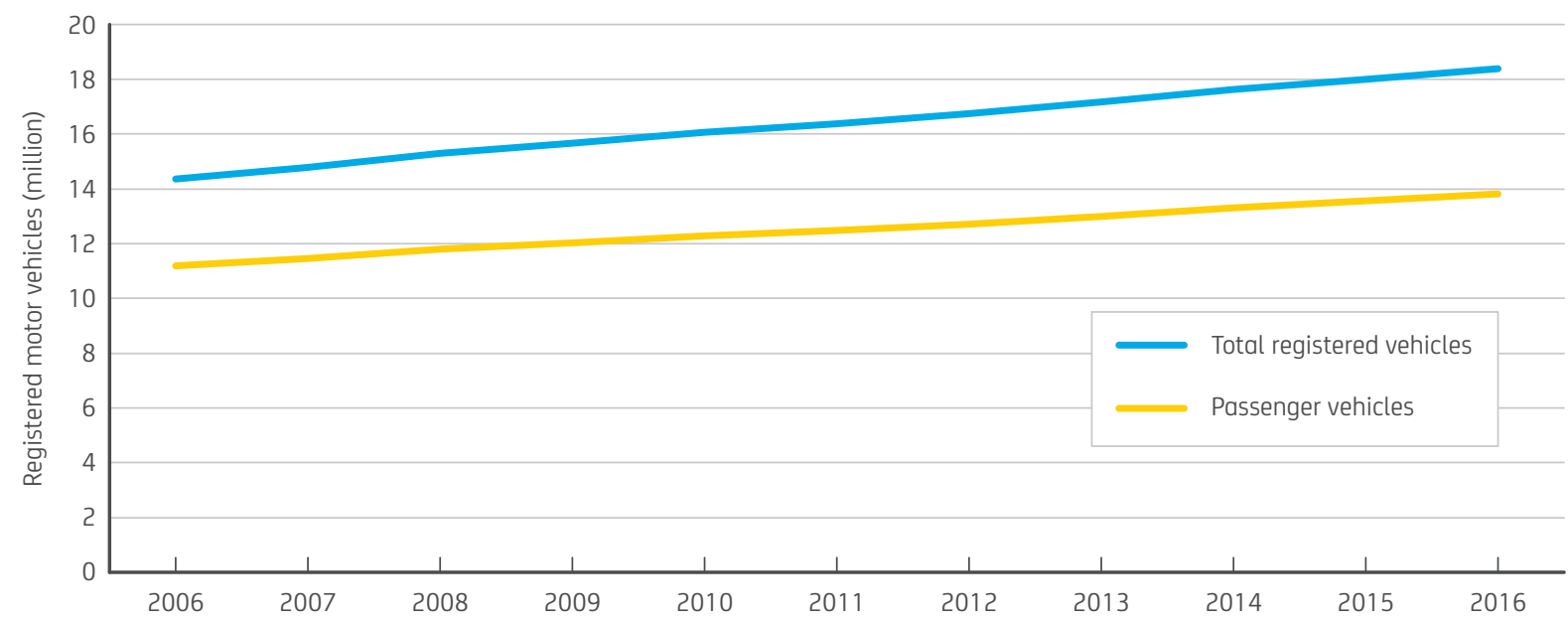

Source: Bitre 2017

\section{FIGURE 3: NEW MOTOR VEHICLES SALES, EXCLUDING MOTOR CYCLES, BY VEHICLE TYPE}

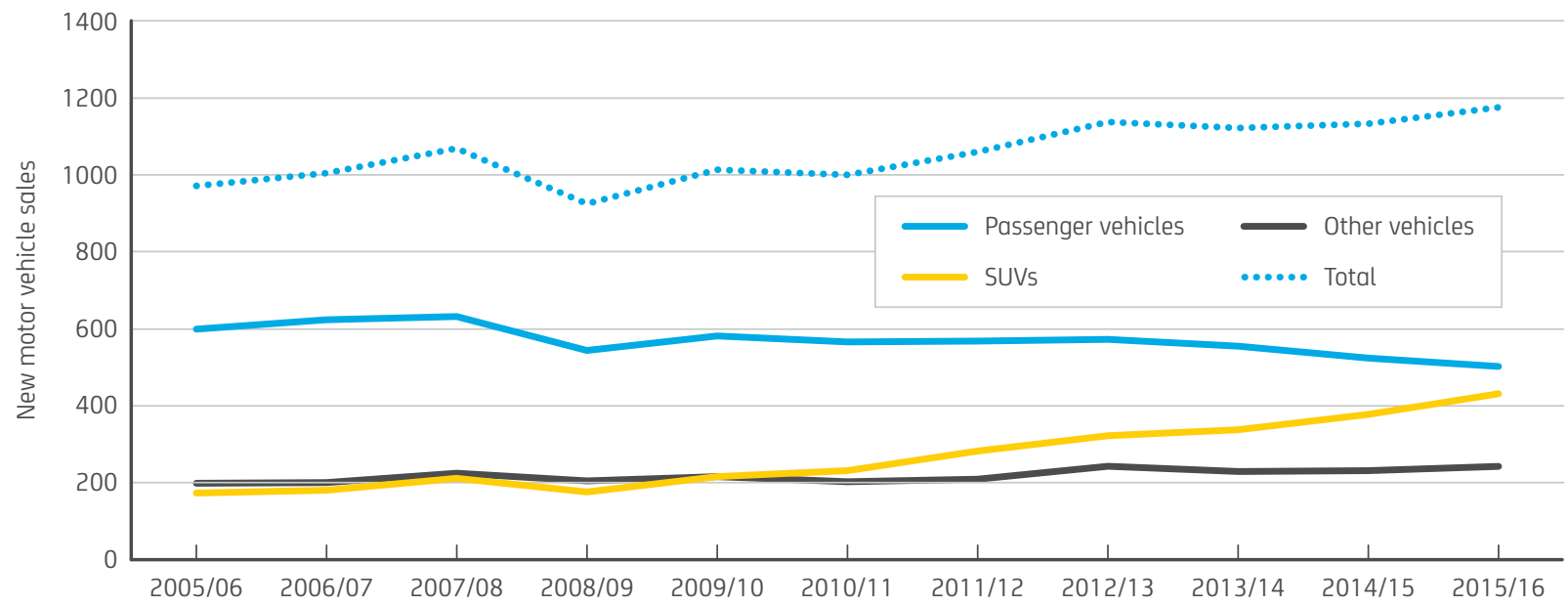

Source: Bitre 2017 


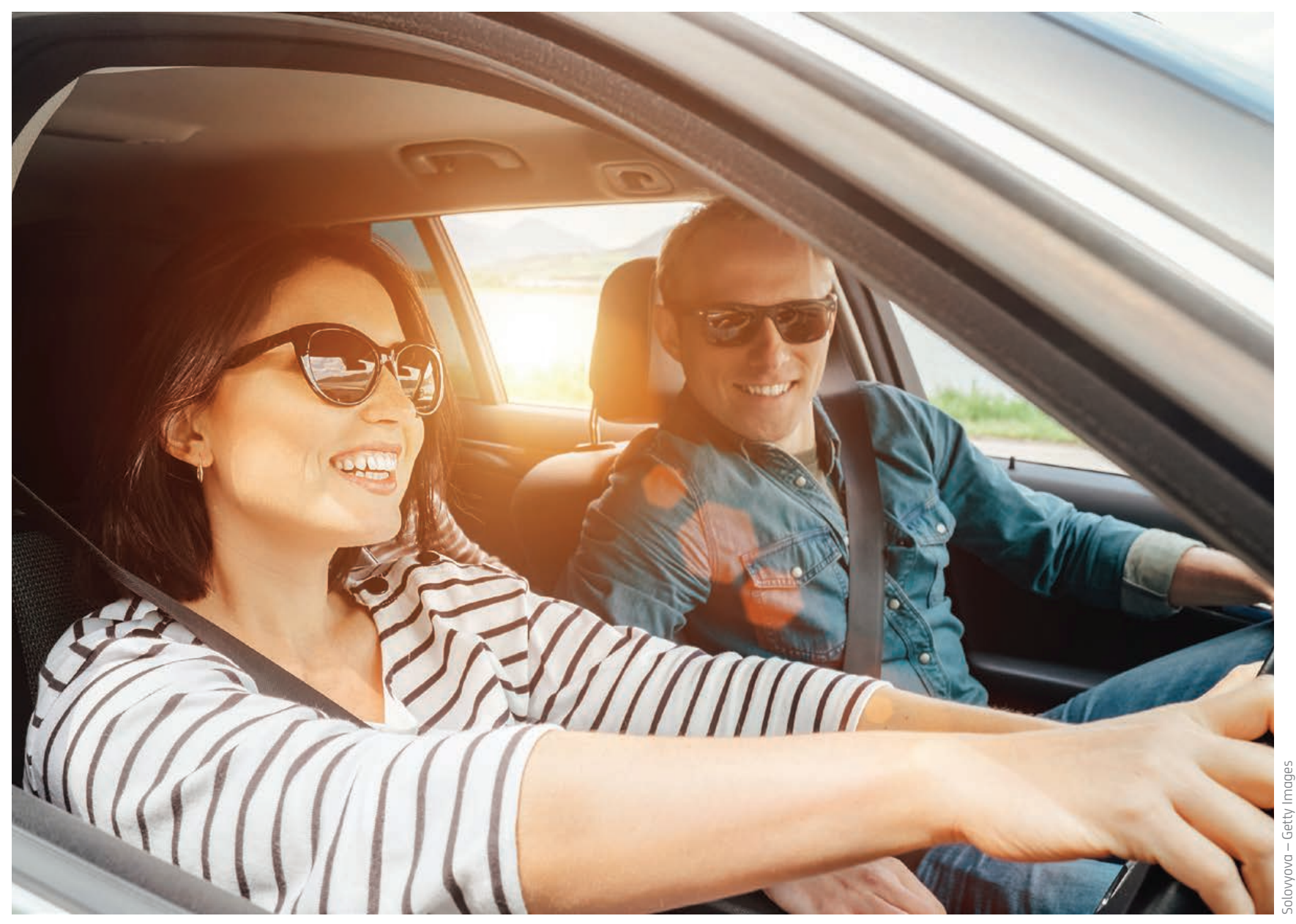

Remarkably, despite widespread news reports about the development of smaller, more fuel efficient or alternative fuelled vehicles, SUV sales have outgrown those of standard passenger vehicles for the first time in 2017.

Car sales and car registrations, however, are not great indicators of whether people will own cars in the future. Growth in car sales does not necessarily mean growth in car ownership. More cars can be bought and registered but fewer may be owned privately. A relevant comparison is to compare home ownership against new dwellings built.

The Boston Consulting Group have illustrated this point when looking at the growth of car sharing. They believe that car sharing will expand relatively quickly and widely, but will have only a minimal effect on new car sales, with one of the reasons being that some share of lost car sales will be partially offset by sales into carsharing fleets in large urban areas.?

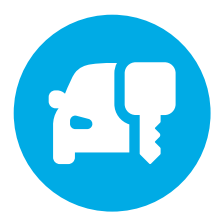
The private car sits
idle for $95 \%$ of the
time - it is a lazy and
inefficient asset 


\section{The mobility challenge}

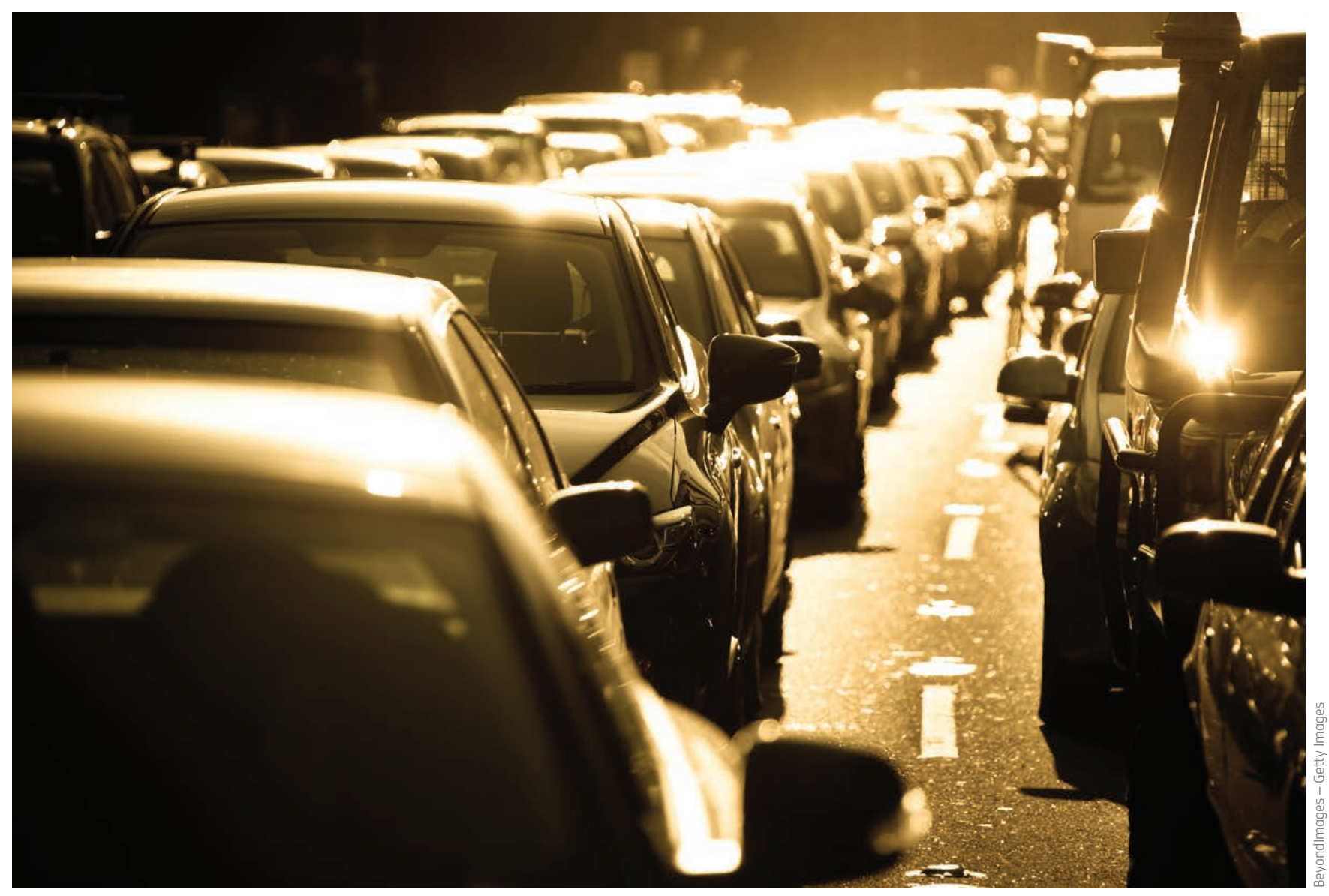

In 2017, auto mobility is still the predominant means of mobility.

However, despite auto mobility being so prevalent in western society, and particularly in Australia, it is under threat. Technological and societal change is transforming our world immeasurably, and its effect perhaps will be felt the greatest in the way we move around, getting from $A$ to $B$.

While the concept of auto mobility is powerful and firmly entrenched in the Australian mindset, there are problems with its long term practicality. Population growth, urbanisation, densification, individualised service expectations and increasingly complex travel patterns are leading to growing congestion and a lack of supporting infrastructure.
Existing forms of mobility, both cars and public transport, present very large costs to governments. On average, little more than 30 per cent of the costs of public transport are met by users. This has led to chronic under investment in mass transit. Conversely, taxes and charges on cars and motorists outstrip investment.

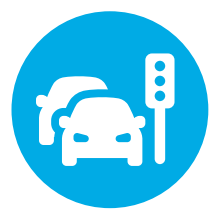

Denser cities, higher transport demand and congestion are altering the dynamics of private car ownership 


\section{Population growth and urbanisation}

The world's population is growing, and at the same time that population is moving into rapidly-expanding urban areas. Presently, just over half of the world's population lives in urban areas, but by 2050, this will have climbed to 66 per cent. $^{3}$

\section{FIGURE 4: GRAVITATIONAL PULL - GLOBAL POPULATION, PERCENTAGE OF TOTAL}

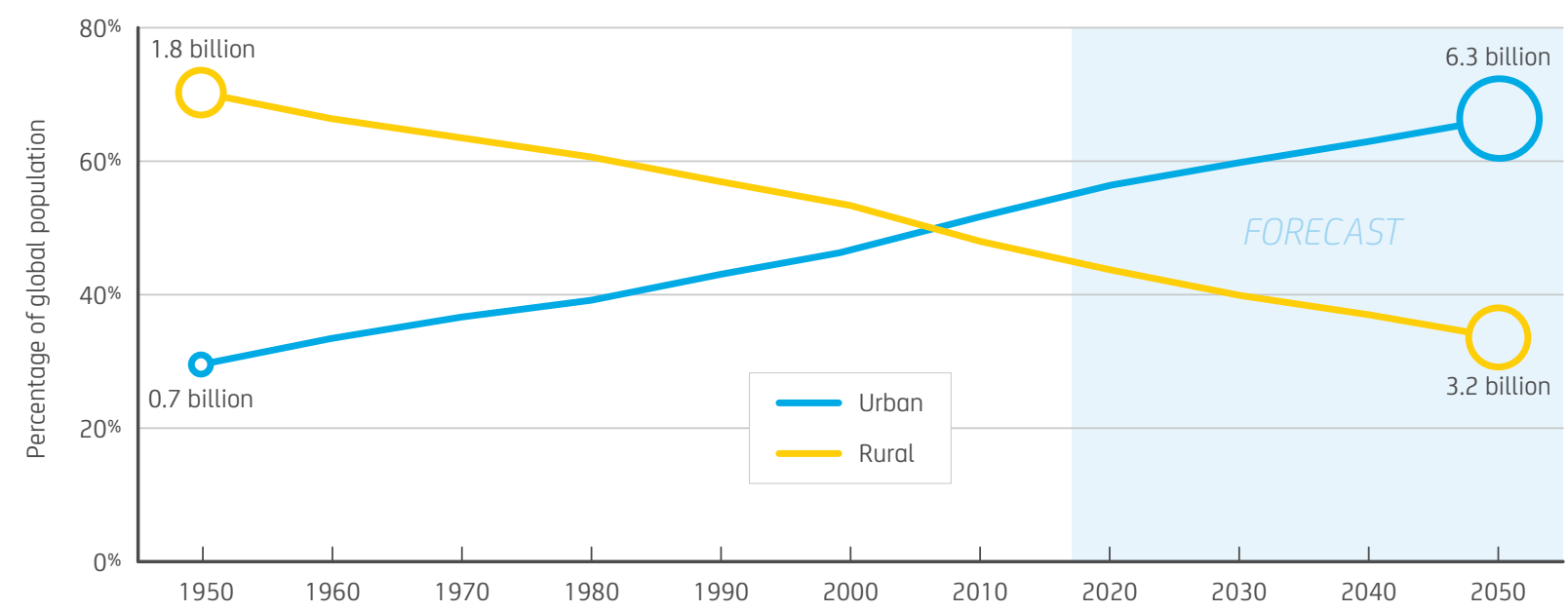

Source: Economist.com 2016

This growing trend is also replicated in Australia. Australia's population is projected to grow at an average of 1.3 per cent per year, with a projected population of 39.7 million by $2055 .^{4}$

By 2061, 11.5 million people are expected to make NSW home, an increase of 57 per cent from 2012. ${ }^{5}$ In the year to June 2015, more than 75 per cent of Australia's population growth occurred in just four cities: Sydney, Melbourne Brisbane and Perth.

Our low density suburbs, which have developed due to the rise of the motor vehicle, are becoming denser and this will only continue as older, larger blocks are bought up by developers and converted into denser apartment dwellings to cater for the growing population.
This presents a number of demands on the government's ability to deliver services, but also compounds the problems demanded of our infrastructure such as roads, public transport, telecommunications, water and electricity.

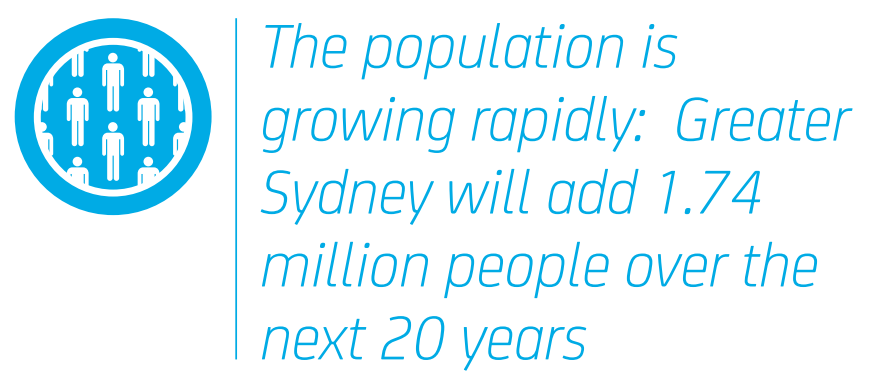




\section{Congestion}

Our growing population will need to move around. In a business as usual approach, we will need greater availability and capacity of transport and road infrastructure than our cities offer at present. Our roads are already severely congested, and the opportunity for widening is limited due to adjacent land uses.
Congestion in the Sydney basin will cost the NSW economy $\$ 6.9$ billion in 2017 and is expected to rise to $\$ 12.6$ billion by 2031.6

The OEMs are among the first to recognise this issue. Earlier this year, Ford Australia CEO Graeme Whickman made the statement that "we just can't keep adding cars to the road."

\section{FIGURE 5: CONGESTION LEVELS BY CITY}

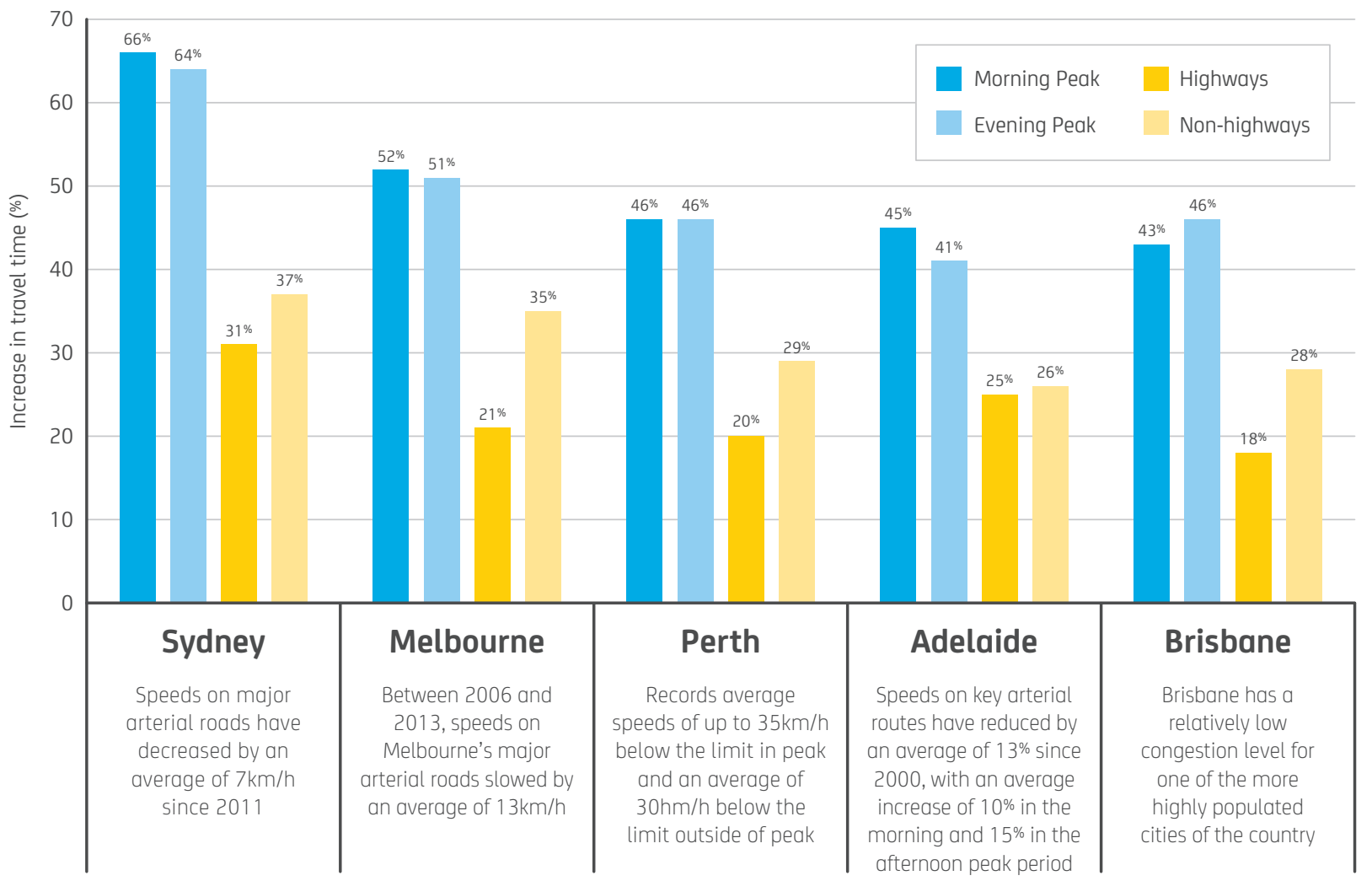

Source: The Australian, 29 April 2017 


\section{Funding challenges}

Despite the clear evidence that there needs to be major investment in our public transport and roads infrastructure, governments simply do not have the budgetary capacity to meet the infrastructure investment requirements alone.

Because of long distances, low population densities and widely separated major settlements, funding for roads in Australia has historically been a major fiscal issue for all levels of government - this has led to an ad hoc approach to funding roads in this country.

This ad hoc approach has contributed to a growing infrastructure deficit, as well as maintenance shortfalls, particularly on local roads. It has also led to a myriad of issues such as a lack of consistent long-term planning, the inability to undertake budget reform, and the implementation of a number of charging mechanisms that have no bearing on future investment and road maintenance requirements. The conflict between the economic policy debate associated with taxation and road user charging has also sent inefficient and confused price signals to road users.

Furthermore, with transport infrastructure critical to national productivity and economic growth, the current levels of investment have not kept pace with either current or projected demand. Without resolution, these capacity constraints will accelerate, imposing negative outcomes on national productivity.

The problem is most acute in road investment; roads are the least reformed of all infrastructure sectors, with institutional arrangements around funding and provision remaining much the same as they were 20 years ago. ${ }^{7}$

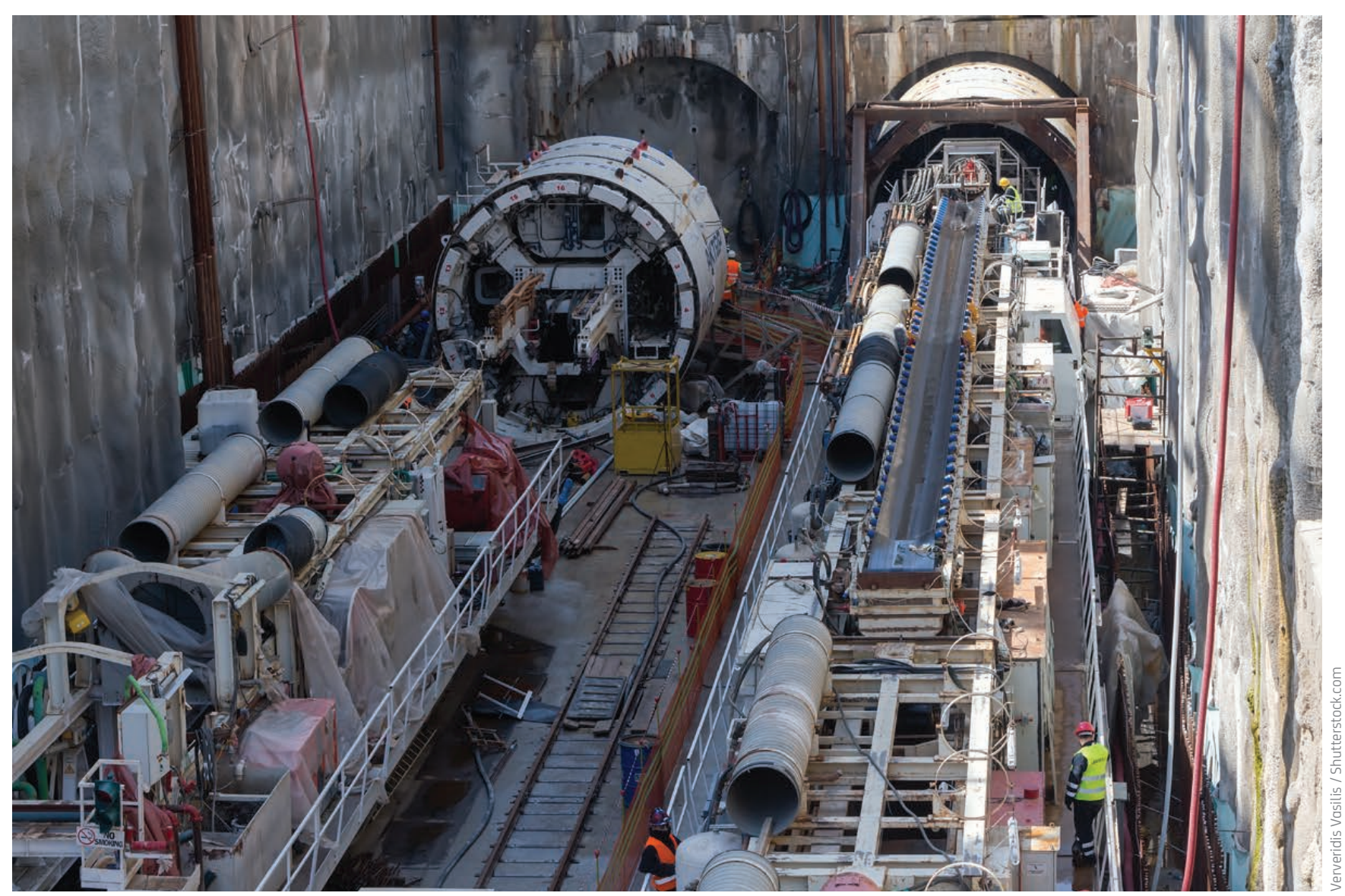


Infrastructure backlog is also a significant issue for NSW regional councils, which have limited capacity to raise revenue to meet their commitments. The infrastructure backlog for local councils is currently estimated at $\$ 2$ billion, with $\$ 1.6$ billion of this attributed to regional local councils. This deficit is unlikely to be addressed in the short to medium term as their revenue rates are capped by the NSW Government.

Falling population growth and decreasing revenues in some regions is making it difficult for regional councils to maintain existing assets, yet alone provide investment for the future. Conversely, many large regional centres and coastal councils are struggling to keep pace with growth.

We should also keep in mind the contestable nature of budget allocations between competing priorities. Every dollar spent on an urban motorway is a dollar not spent on a country road. Transport infrastructure (including roads) is also only one priority of government.

Compounding this, in the absence of road user pays reform, road funding will continue to be considered against funding for other services that governments provide. There are also major backlogs in health and education services in Australia. Not only do these important portfolios have capital allocation challenges, beyond the forward estimates period they have significant recurrent funding issues. For instance, Australian Government real health expenditure per person is projected to more than double over the next 40 years. ${ }^{8}$ Every dollar spent on any road is not spent on health or education.
It is clear that a national conversation needs to be held on how we fund our infrastructure now and into the future. While we will shortly discuss how developments in the industry may reduce some of the pressure on our infrastructure and the need for people to privately own their motor vehicle, autonomous vehicles and more on-demand systems of public transport will still require infrastructure to work efficiently.

The time to have this conversation is now. The NRMA has consistently described the need to move to a broad based user funding model for the road network. Once electric vehicles become more prevalent and fuel excise declines, the need for this conversation will become even more acute.

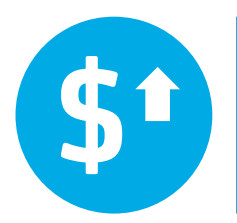

NSW has an infrastructure backlog of more than $\$ 100$ billion 


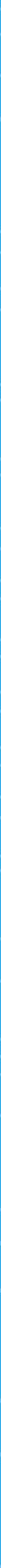




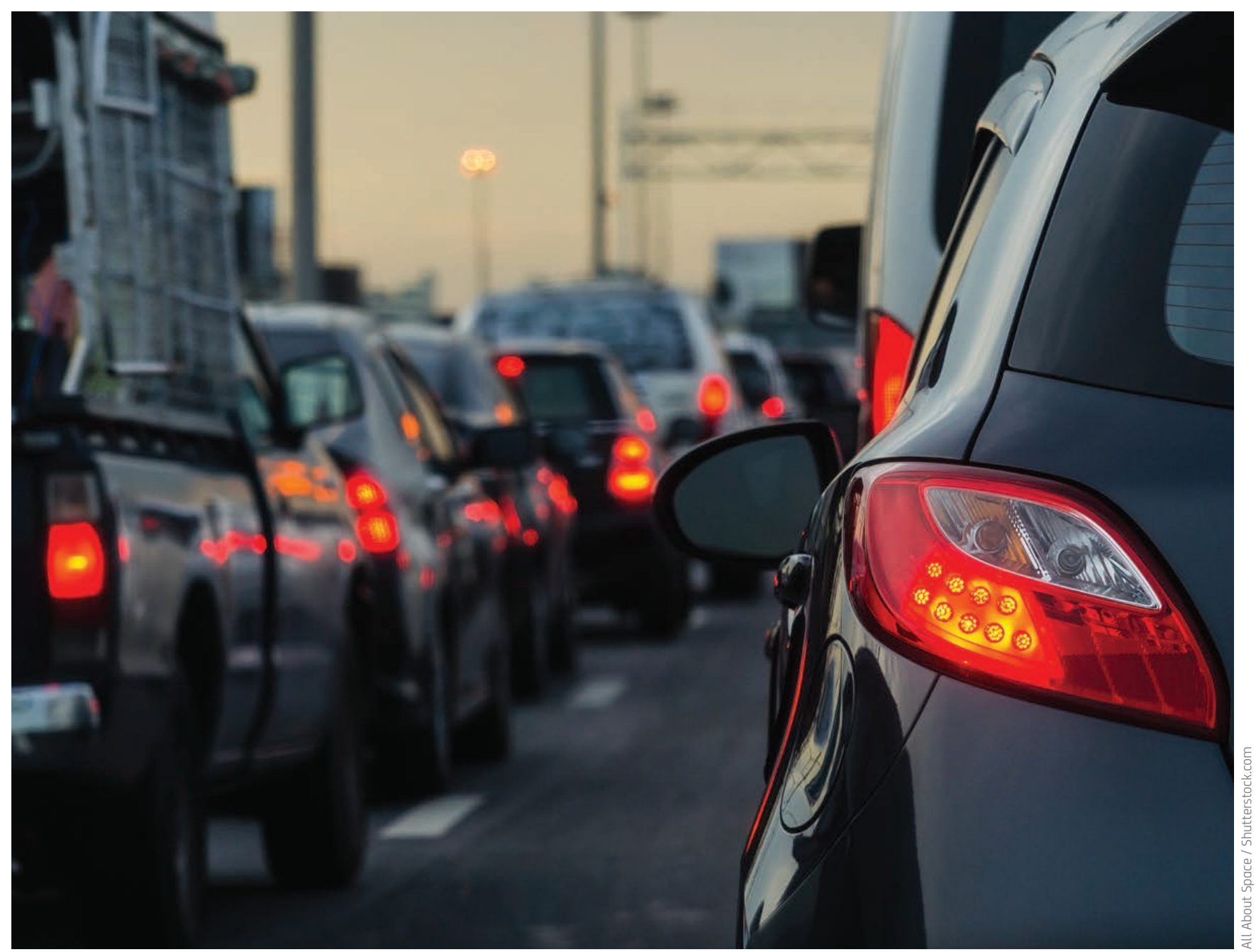

Greater urbanisation, growing congestion and the cost of owning a car means that sometimes it can be unattractive or impractical to own a vehicle. In our major cities, younger people are forgoing obtaining their driver licence and purchasing a car altogether. The car itself is also an incredibly inefficient asset - it is unused 95 per cent of the time.

While governments need to undertake reform in order to fund the critical infrastructure our society needs, developments in the wider mobility industry (including in the car industry) are seeking to change the way we think about mobility and challenge the concept of auto mobility as the best way to get around.
Australia does not exist in a vacuum and this challenge is reflected in most developed nations around the world. The main challenge is to solve mobility issues in our increasingly populous urban environments.

Breakthroughs in artificial intelligence, better mapping, cheaper materials and the growth of online and mobile phone delivered services are creating better, more convenient and cheaper ways for citizens to move around. We are no longer decades away from a new form of mobility, but instead are living through an age of disruption to mobility options. 


\section{The mindset of the millennial}

The mindset of the millennial (those born between 1982 and 2004) is is an important factor to understand as to why some of the changes that will be described in this section are occurring.

Businesses are doing what they always do - reacting to and anticipating the needs of consumers in order to develop products and services that meet the utility needs of society.

Driving this change is the demand for everything to be convenient, accessible and preferably orderable from a device that fits in the palm of your hand. This is what society is beginning to expect today, and the younger the generation, the greater the expectation.

Millennials have grown up with hand-held, mobilebased screen technology.

While it was launched in 2001, the iPod exploded in consumer hype and demand in 2004. It was a revolutionary way in which to listen to music, which was mainly down to the development of the screen interface and the on-demand content offered through iTunes. Prior to this, the mp3 player existed, but it had no real screen and was difficult to navigate.
When the iPhone was later launched in 2007, iPod sales flattened. ${ }^{9}$ The iPhone offered all of the capabilities of the iPod and more, and quickly became the latest smart accessory. The time taken to move through technological advancements is getting shorter and shorter.

Younger generations are leading the way towards pay-peruse mobility in place of owning a car; nearly 50 per cent of millennials like using a smartphone app to organise travel so that they can multitask on their journey. ${ }^{10}$

Affordability and high operational and maintenance costs are top reasons among millennials for not owning a vehicle. In addition, millennials generally feel that their lifestyle needs can be met by walking or by using public transport. ${ }^{11}$
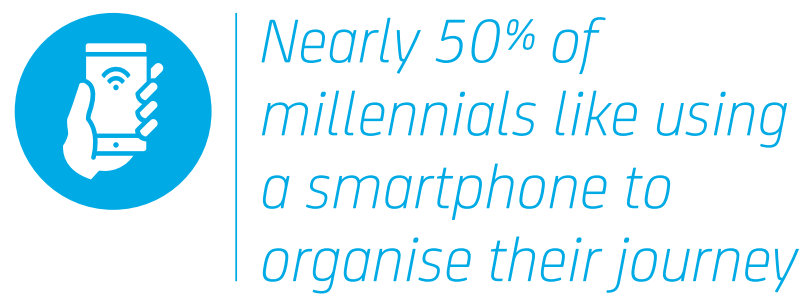

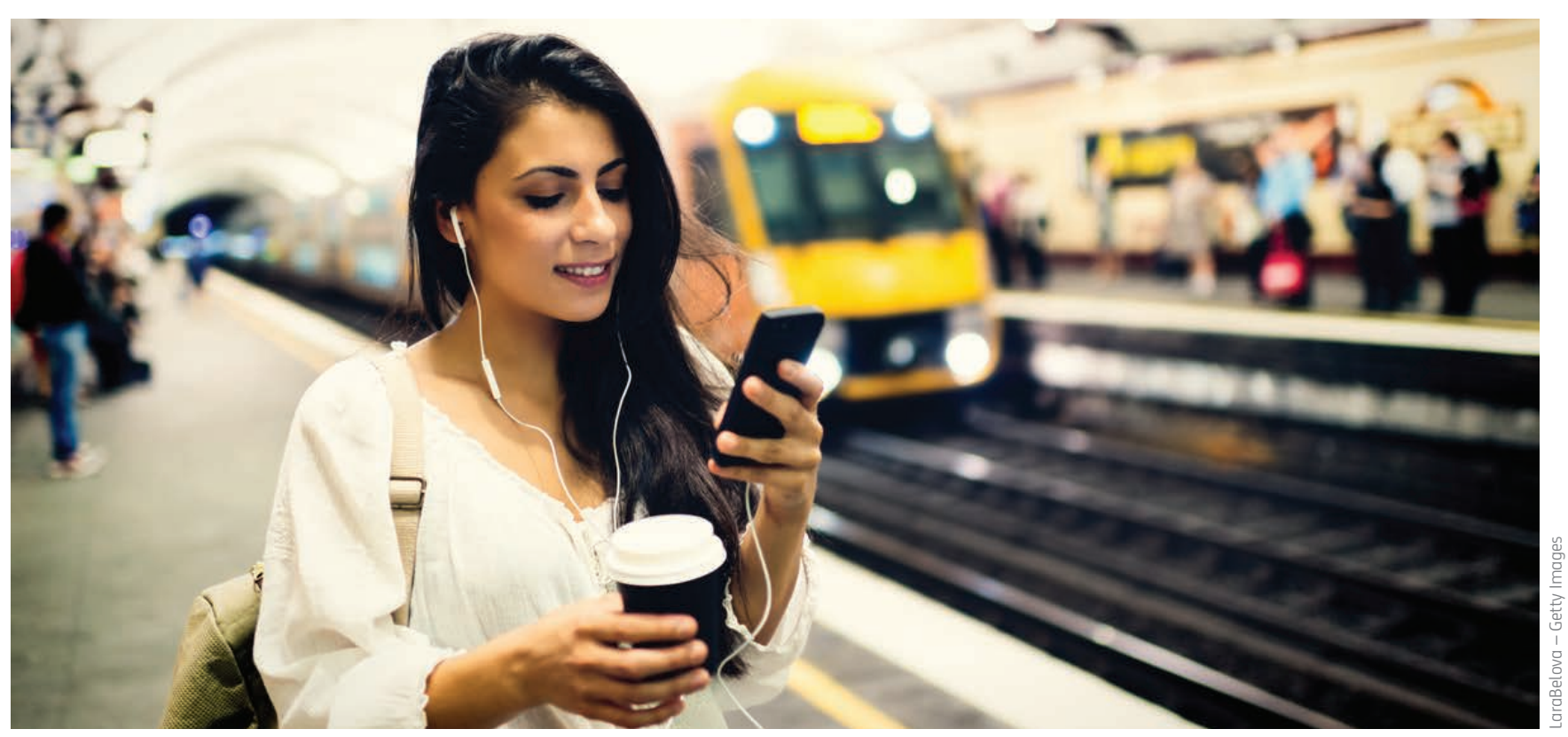

9. https://www.businessinsider.com.au/gadgets-the-iphone-killed-2012-7?r=US\&IR=T\#the-ipod-and-all-other-mp3-players-1

10. https://dupress.deloitte.com/dup-us-en/focus/future-of-mobility/transportation-technology.html?id=us:2el:3pr:dup1374:eng:dup:092315:fom

11. https://www2.deloitte.com/content/dam/Deloitte/us/Documents/manufacturing/us-auto-global-automotive-consumer-study-100914.pdf 


\section{Changing attitudes towards driving}

Are millennials even interested in cars? There has been much anecdotal commentary in the past few years that compared their views to previous generations:

- Younger people are driving less.

- Younger people are not owning cars as much.

- Younger people are not obtaining their driver licence.

This anecdotal chatter that seems so prevalent is difficult to substantiate.

In Victoria, the number of under 25s without a licence has grown by 10 per cent in the last 10 years to 35 per cent. In NSW, the proportion of young drivers has fallen by around 1 per cent per year. ${ }^{12}$ Similar trends exist around the world in developed nations such as the Canada, the United Kingdom and the United States.

An Australian authority on licensing trends, Monash University Senior Lecturer Alexa Delbosc, has noted that this means for the first time in Australia's history, young adults were becoming less likely to get a licence compared with their parents' generation.
In the United States, Brandon Scholettle and Michael Sivak from the Transportation Research Institute at the University of Michigan conducted a survey of a group of 618 persons between the ages of 18 and 39 who at that time did not have a licence.

The survey's top three responses indicate that in the United States at least, competing priorities, price, and alternate options are driving the decline in young drivers obtaining a licence.

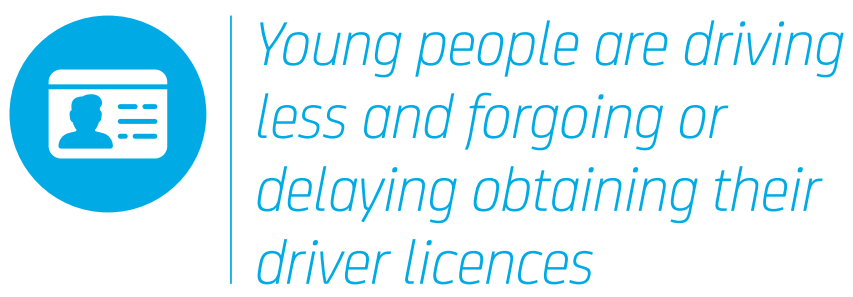

\section{FIGURE 6: SURVEYED REASONS FOR THE RECENT DECLINE IN YOUNG DRIVER LICENSING IN THE US (\%)}

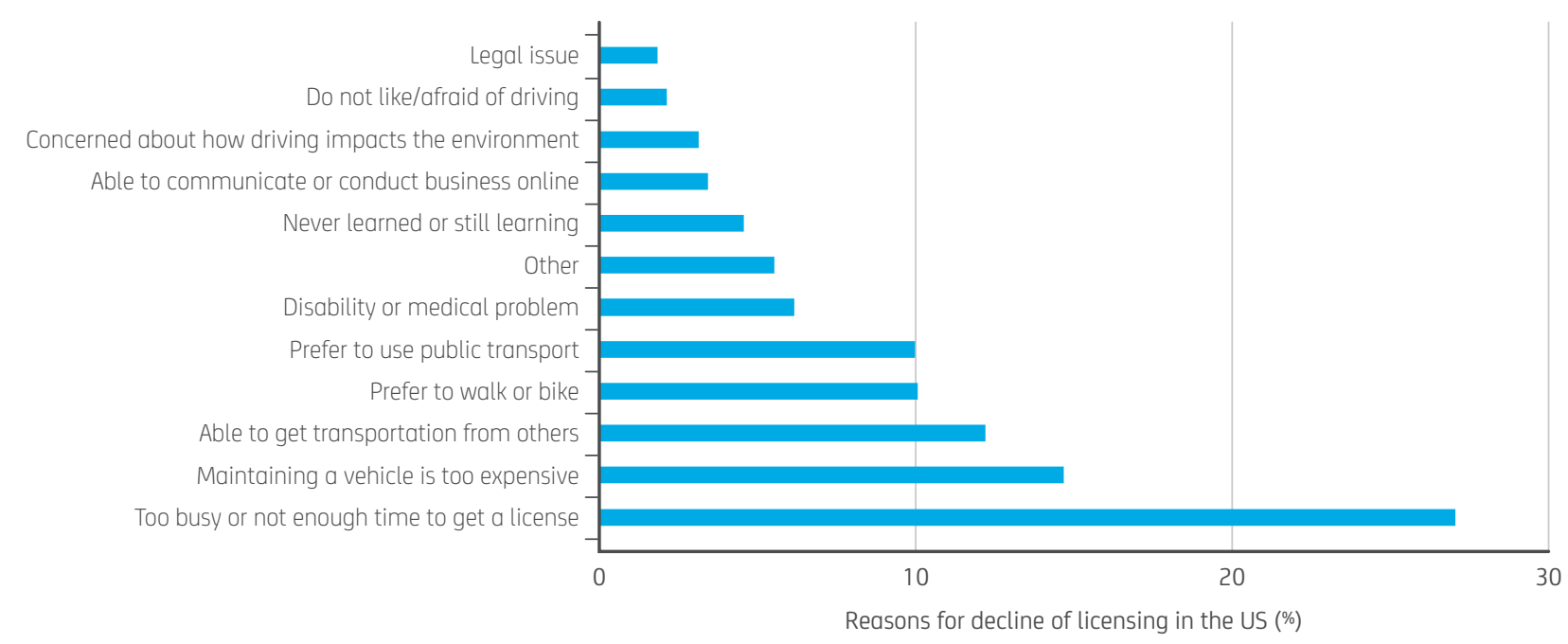

Source: Schoettle, B and Sivak, M, UMTRI

If millennials are not taking up their driver licence, how are they getting around? A growth in car share, ride share, and autonomous vehicles may be one such answer. 


\section{Car share}

Since the invention of the first keyless car sharing system in 1993, car sharing has become a quick way for inner city residents to access vehicles while negating many of the costs associated with ownership. Car sharing can be run by community organisations or a for-profit company, but the principle is the same: there is a pool of vehicles available to be used by members, and use is often charged by the hour, which is in addition to a monthly membership fee.

Car sharing owes its growing popularity to a model that capitalises on the inconvenience and costliness of owning a vehicle in an urban environment with limited on-street and off-street parking. Because the average vehicle represents a significant outlay in household expenditure, it presents a rather inefficient and costly way to access mobility.

In Australia alone, the average household spends around $\$ 332$ a week on car ownership, which is a lot of money for such an unproductive asset.

While car sharing has grown exponentially across the globe in the past five years, it is not an entirely new concept. In fact, car-sharing began in Zurich, Switzerland, in the 1940s, and progressed to other European cities over the ensuing decades.

Today, car sharing supports 66,000 users in Australia who have the ability to access 2,200 vehicles. ${ }^{13}$ Sydney is the centre of car sharing in Australia. In the City of Sydney alone, 31,000 residents and businesses have signed up to either GoGet or Hertz 24/7. Car sharing has enjoyed initial support from the City of Sydney as it meets the municipality's goals of reduced congestion and parking times, personal health improvements, and reduced greenhouse gas emissions.

In 2012, the City of Sydney commissioned SGS Economics and Planning to study the effects of car sharing in the city. The study found congestion and savings benefits of around $\$ 21$ million per year, which included savings of $\$ 18.5$ million per year in deferred car purchases.
In Sydney, GoGet began as a small car sharing initiative in the suburb of Newtown in 2003 and has since expanded to the wider Sydney area, Melbourne, Canberra, Brisbane and Adelaide. Despite this success, there is limited growth in outer suburbs.

However, as densification of housing becomes more prominent across Greater Sydney, there is an ability for car sharing to grow in popularity. The population of Greater Sydney is forecast to increase by 1.74 million people in the 20 years to $2036 .{ }^{14}$ With a focus on economic development in Western Sydney, there is an ability for regions to increase densification and further the capacity for car sharing to grow.

The NSW Government has also been supportive of car share, with the NSW Department of Finance and Services implementing a car share trial for employees in metropolitan areas using GoGet and Hertz 24/7. However, other operators (such as Car Next Door) have identified limited access to car spaces as a restriction on growth. The NRMA, through Thrifty, is trialling a car share service in Melbourne with our partner RACV.

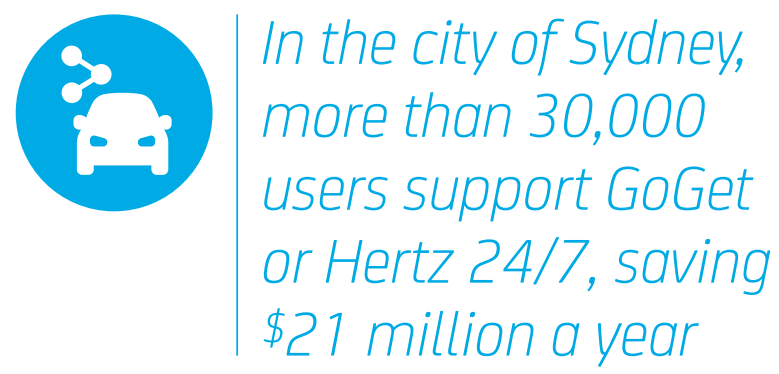


FIGURE 7: GLOBAL CAR SHARING MARKET TRENDS

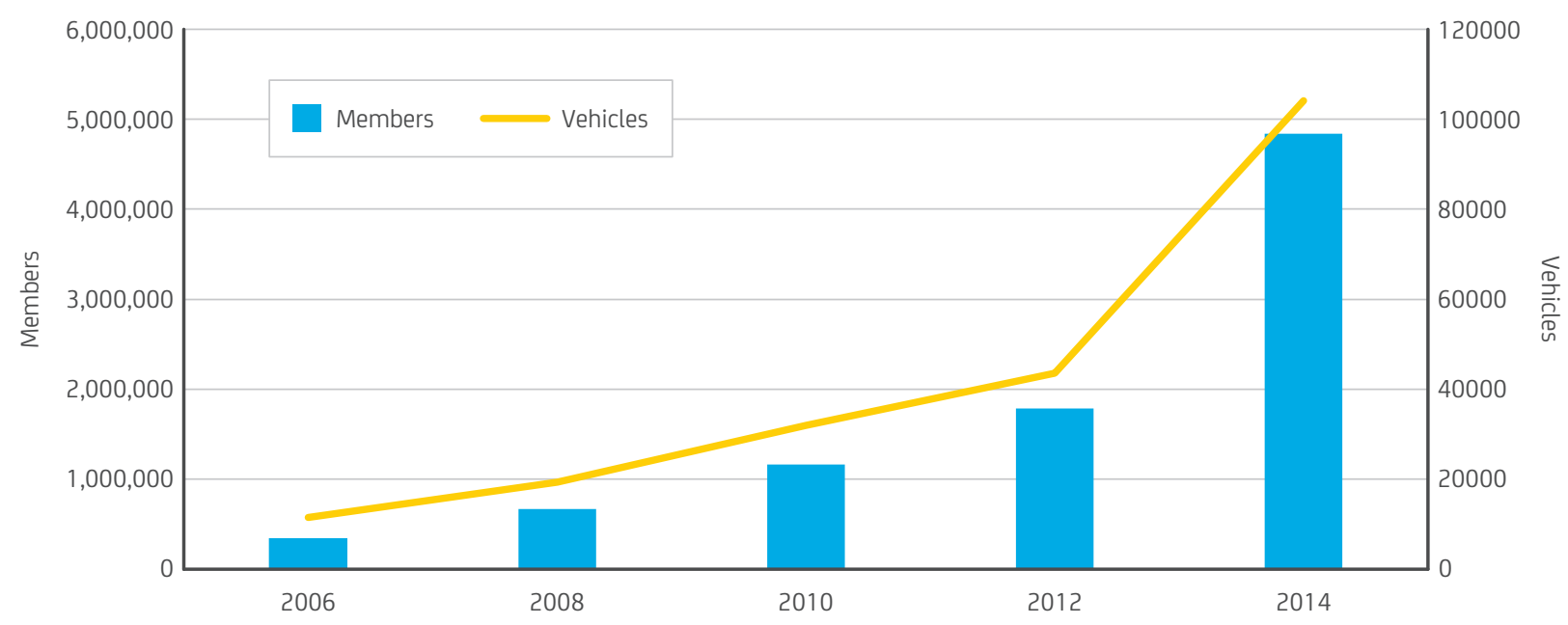

Source: Transportation Sustainability Research Centre - University of California, Berkeley

While car share is growing in Australia it is becoming even more popular around the world as seen in figure 7. Car sharing demonstrates that there is consumer demand for a viable alternative to car ownership.

Car sharing is cheaper for those who only need a car infrequently, and is not designed for someone who needs a vehicle every day. If you were to use a GoGet car every day for your commute to work over 48 weeks, it would cost around $\$ 17,760$ per year on the general rate for the GoFrequent plan at \$74 per day. ${ }^{15}$

Despite this enormous growth in car sharing around the world, it remains to be seen what the future of car sharing actually looks like. Car sharing is a userdrives service making its business model susceptible to developments in autonomous vehicle technology. It is possible that car sharing in the future will be consumed or merged with ride sharing.
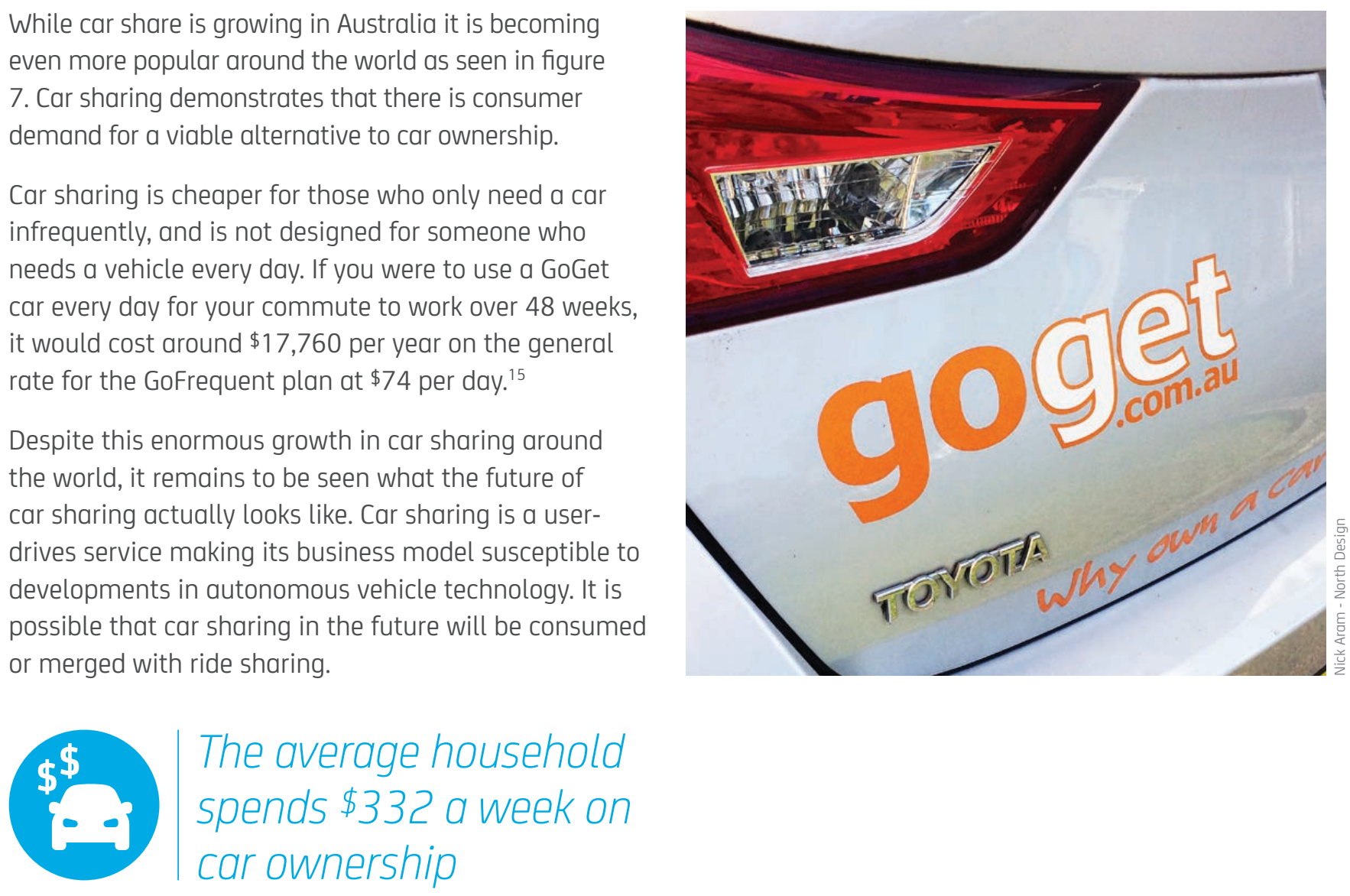


\section{Ride share}

Although much newer than car share, ride share has grown exponentially around the world. Ride share is a subset of the sharing economy, which uses technology to allocate underutilised resources efficiently.

Uber and Lyft are among the most well-known examples of ride share. Uber is looking to the future with driverless cars, and even has plans to introduce flying taxis in Dallas and Dubai by 2020.

Uber has a goal to end personal car ownership by driving down the cost of a ride so much that it makes financial sense to ditch your car. Uber began in San Francisco as UberCab after its founder had the idea of starting a shared premium ride service after spending nearly $\$ 800$ hiring a private driver on New Year's Eve. Uber is now valued at around US\$50 billion. ${ }^{16}$

Uber has evolved to become a challenger to all legacy taxi systems around the world. It has been recently reported that in Perth, Uber is more popular than taxis. Across the nation, 3.8 million Uber trips are being taken every month. ${ }^{17}$

In some circumstances, Uber is challenging the cost of car ownership altogether. In 2014, Kyle Hill, the founder of Los Angeles based start-up HomeHero, worked out that if you travelled less than 9,480 miles $(15,257$ kilometres) per year, it would actually be worth taking Uber for all your trips instead of owning a car.
Uber itself has entered into the autonomous vehicle race. They have recently undertaken to open an Advanced Technologies Center in Pittsburgh to test driverless cars and new mapping technologies. ${ }^{18}$ For Uber, they are supporting the development of driverless technology to drive down the cost of providing the service in order to meet their strategic objectives.

Uber's main rival in the United States, Lyft, is taking things a little slower. While Lyft only exists in the United States, it possesses global expansion aspirations, which includes Australia. The entry of Lyft into the Australian market would be a welcome addition for consumers who would benefit from the added competition to Uber and GoCatch.

In addition to these major companies that involve a large amount of capital and have experienced massive growth, localised and niche services are springing up all over the world by using technology to connect people who have the same needs.

Two examples in the United States include Carpool Kids and Voom, which lets parents connect and share rides. Zum is another company which coordinates transport for children, but also packages in babysitting and other child care services by matching customers with ondemand providers.

\section{Ride sharing is increasing}

One ride share vehicle can remove up to 13 private vehicles from the road
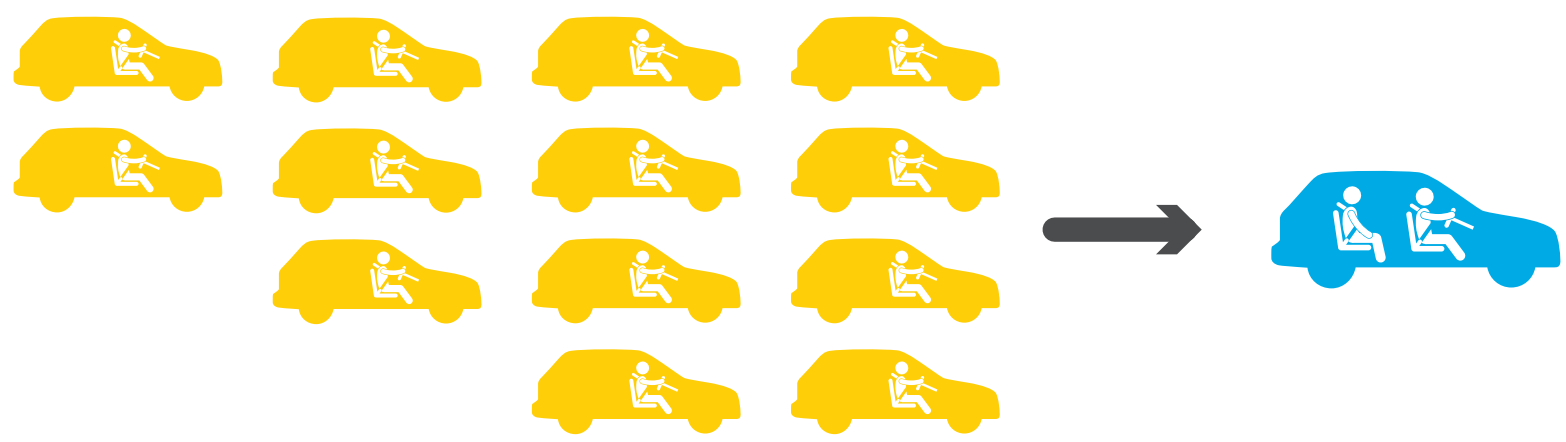

16. https://www.businessinsider.com.au/uber-is-officially-a-50-billion-company-2015-7? r=US\&IR=T

17. http://www.dailytelegraph.com.au/news/national/uber-is-more-popular-than-taxis-in-perth/news-story/7d5d815579919da2b1 eeec264b437ef0?csp=b670741309086a6ea0a6c0f071 b99aed

18. https://dupress.deloitte.com/dup-us-en/focus/future-of-mobility/transportation-technology.html 


\section{Door-to-door public transport (Mobility-as-a-Service or MaaS)}

Car share and ride share are just two modes of mobility that still retain a sense of auto mobility, but without the cost of ownership.

Many urban planners and cities believe that privatelyowned mobility, such as car ownership, can be phased out in favour of multi-mode mobility solutions that are consumed as a service.
This would see cars, through e-hailing platforms, work within a seamless door-to-door mobility solution with forms of public transport, such as on-demand or traditional buses, and light and heavy rail, as part of an efficient and cost-effective journey mix, paid for by either a monthly subscription or a pay-as-you-go service.

\section{Auto Mobility}

Owned automobiles are the major form of transportation
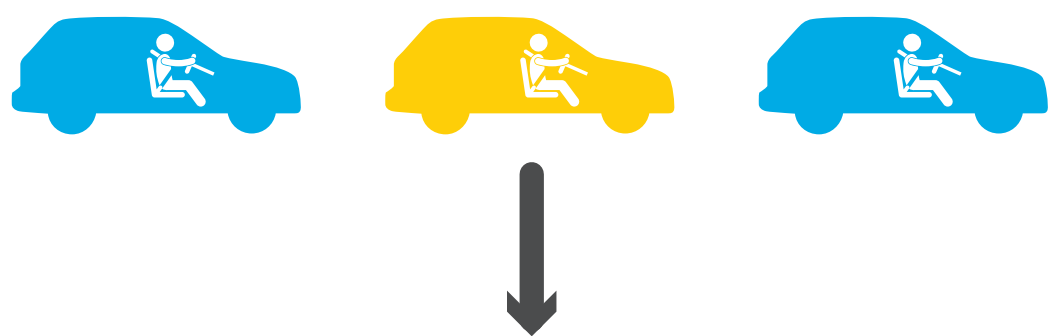

Mobility as a Service (MaaS)

Total mobility solution based on individual travel needs

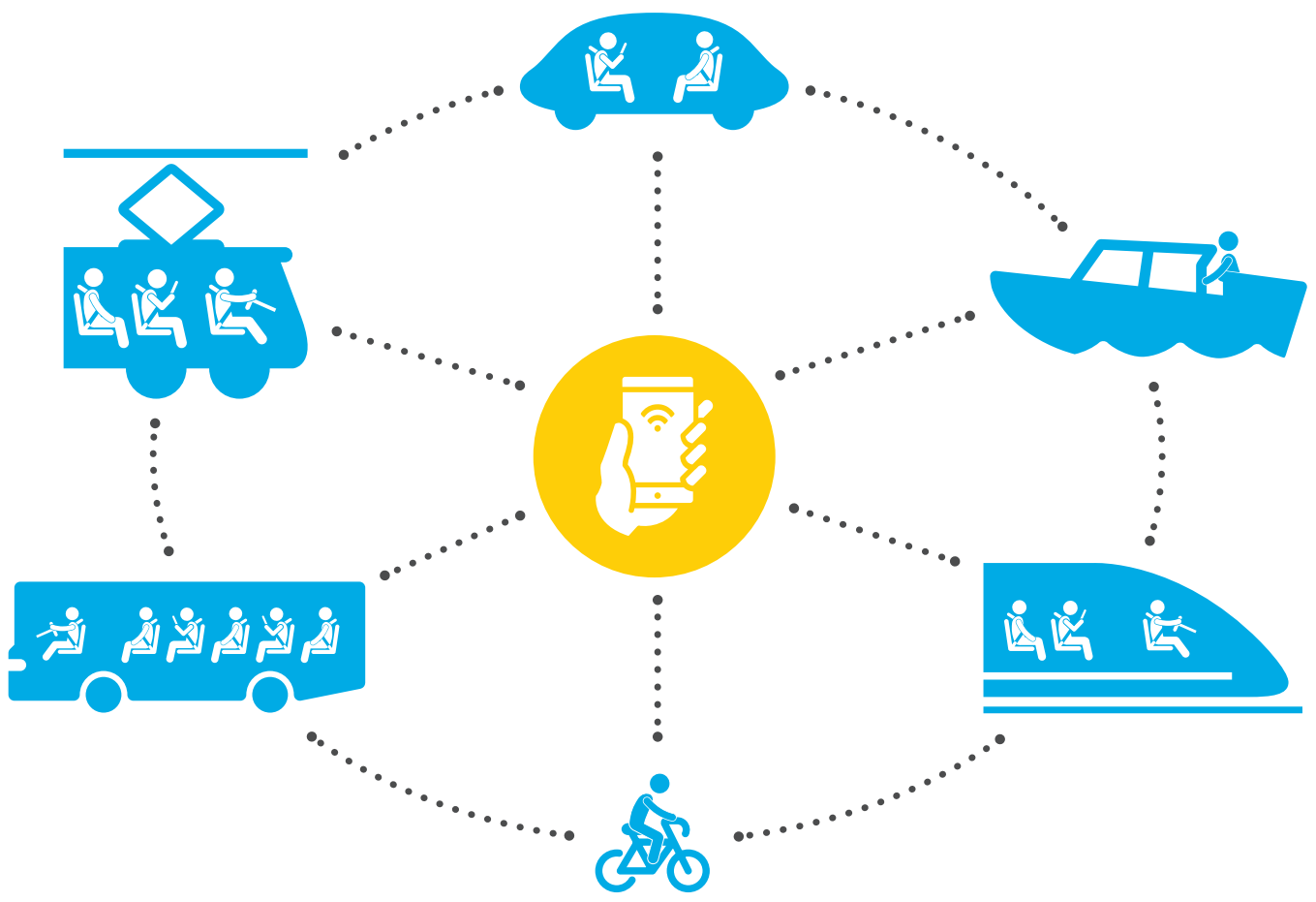


Mobility-as-a-Service (MaaS), also known as 'Transportas-a-Service' or 'Combined Mobility Services,' is the concept that an individual will have multiple mobility options tailored to their needs and wants (a door-todoor service with the capability to incorporate several modes of transport to optimise the travel experience). Some have described MaaS as the Netflix approach to cars. ${ }^{19}$ MaaS is not necessarily likely to see a reduction in the use of cars as a mobility option; rather, it seeks to use cars as an on-demand service that can be used in seamless conjunction with other transport modes.

Intermodality is the concept that a trip can be taken through multiple modes of transport. A complete MaaS system with intermodality in a city setting could include cycling, buses, trains, trams, light rail and car use.

There are a number of ways in which MaaS could be offered. One could be an all-encompassing mobile application offered by the municipality which creates an end-to-end journey that can be booked and paid for up front.

Already a number of cities have experimented with versions of an end-to-end mobility booking system. Two such examples are Whim, which operates in Helsinki, Finland, and Qixxit, which operates in a number of locations across Germany. Transport for Newcastle is the first important step for an Australian city on this journey.

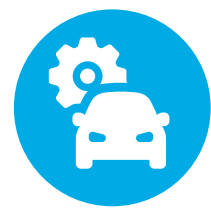

$$
\begin{aligned}
& \text { With technology } \\
& \text { companies like Apple } \\
& \text { and Google pursuing } \\
& \text { automation and } \\
& \text { mobility solutions, } \\
& \text { manufacturers may } \\
& \text { change in the future }
\end{aligned}
$$

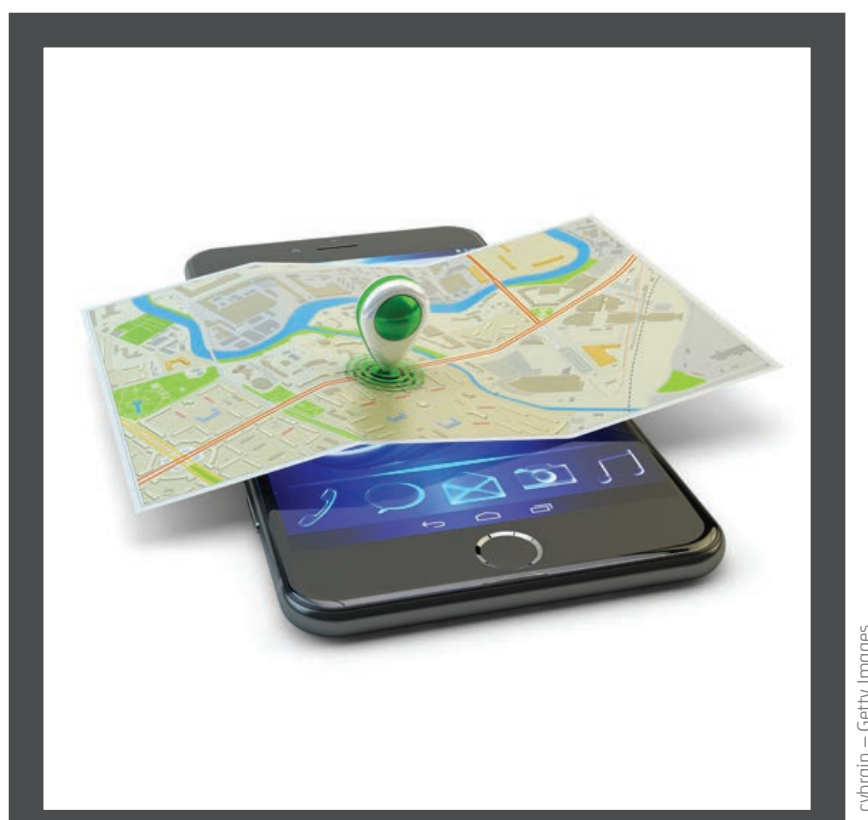

\section{Case Study: Whim}

MaaS Global, a company based in Finland, has recently launched an app called Whim, which has the express aim of ending car ownership in Helsinki. It plans to expand to Birmingham, United Kindom in 2017.

Whim works like a traditional route planner, such as the planner facility on Google Maps, or the various trip planner apps available from Transport for NSW; however, once you book a trip, it is paid for in advance. There are two payment options: on a per trip basis, or a monthly subscription basis.

The monthly subscription option allows three different price structures, depending on usage. To encourage consumers to use the service, a number of innovative mobility options have been developed, including a tram that functions as a pub. ${ }^{20}$ 


\section{The Silicon Valley effect}

As noted, the revolution in mobile technology is influencing the customer service expectations of millennials, and how environmental impacts are affecting their views on cars and driving.

Two companies, Google and Apple, are currently placing pressure on OEMs by entering the world of autonomous vehicles and developing their own mobility products.

Google (now under the Alphabet subsidiary called Waymo) is testing a self-driving car that is not relying on driver-assist to help progress the development of the technology. Essentially, they want to skip Conditional Automation - also known as Level 3 Automation because it ultimately relies on a human being to undertake the driving task. Google have yet to reveal whether they view the future as shared autonomous mobility or whether they will offer their cars in a form of personal ownership.

Apple have also entered the race to produce an autonomous vehicle. In April 2017, they were granted a trial permit from the Californian Department of Motor Vehicles to test their autonomous vehicles on public roads using a hybrid Lexus.

Consumers are also very interested in a car produced by the two tech giants. A consumer survey in the United States suggested that 59 per cent of respondents would be interested in a Google car, while 52 per cent would be interested in an Apple car. ${ }^{21}$

It's not just in Silicon Valley, however, where tech companies are getting involved in developing cars. A good example of how end-to-end consumer services are interested in autonomous vehicles is the news that Chinese online sales giant Alibaba has recently entered into a partnership with the Shanghai Automotive Industry Corporation to develop an internet-enabled car that has predictive capabilities in what is thought to be a precursor to autonomous vehicle development. ${ }^{22}$

Another poignant illustration of how vehicle technology is merging with other modern developments in society is the entry of NVIDIA, who supply a growing number of OEMs with natural language processing, gesture control and deep learning programs for their cars. NVIDIA started as a graphics chip maker in the video game industry.
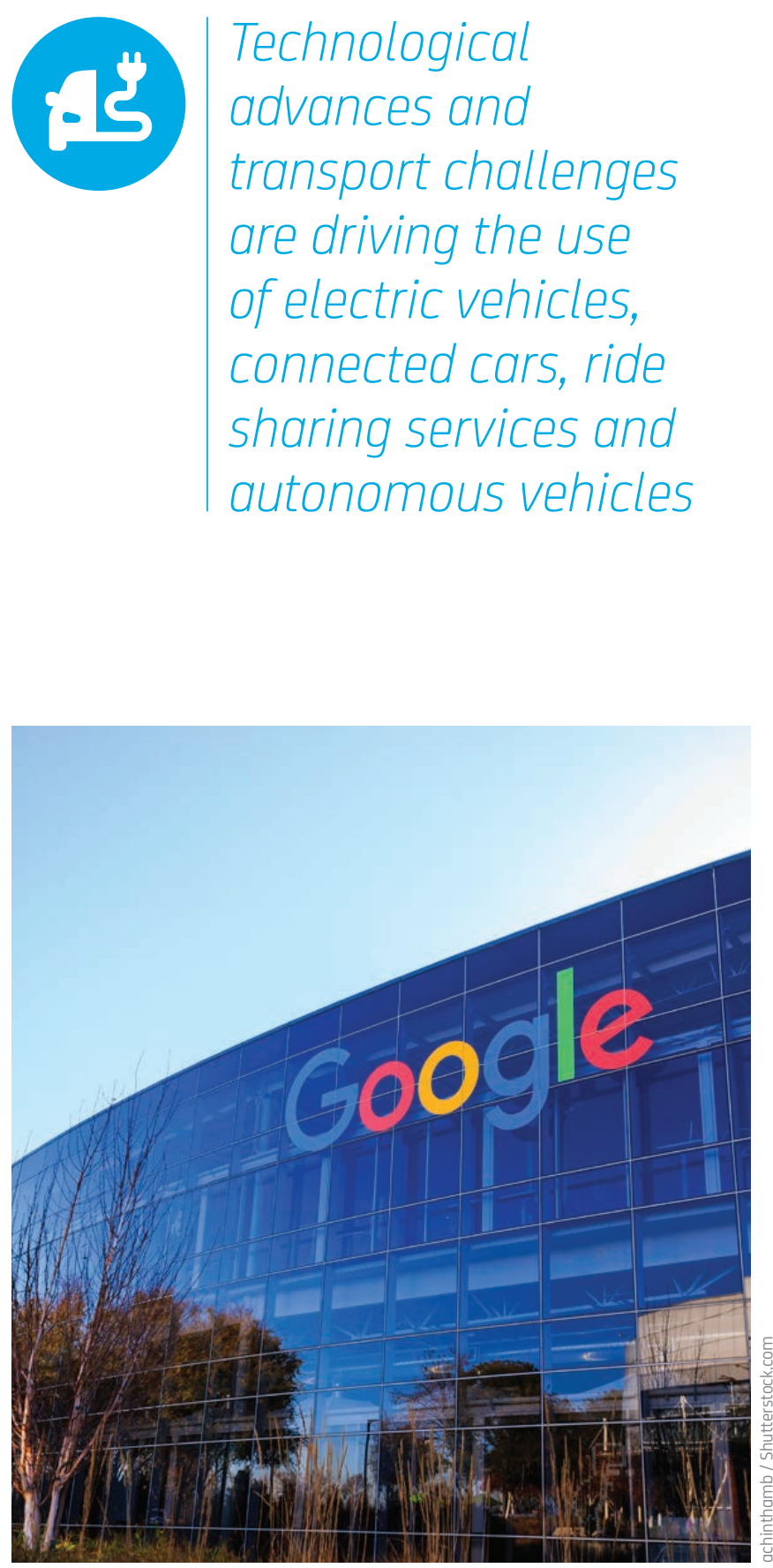
The cars of

the future 


\section{Alternative drive train technology}

The environmental benefits of alternative fuelled vehicles are immense. Transport emissions currently account for 14 per cent of Australian greenhouse gas emissions.

The cars of the future are unlikely to be powered by petrol and diesel as most cars are today. Environmental and societal pressures are being used by regulators to put pressure on OEMs to develop cleaner, more efficient vehicles.

An autonomous vehicle-led future will also depend on greater uptake of alternative fuel vehicles. Indeed, World Economic Forum research suggests that citizens expect that autonomous vehicles are to be powered by hybrid and electric technology. ${ }^{23}$

OEMs over the past decade have pursued hybrid technology, which can be thought of as a cleaner version of a conventional car, as they use petroleum or diesel combustion to power an electric motor. However, these should probably be thought of as the vehicles that will extend the life of internal combustion as we transition to cleaner vehicles such as electric or fuel cell powered vehicles.
While at present it is inconceivable in Australia that petroleum powered vehicles would be banned in the future, some jurisdictions around the world have flirted with the idea. In early 2016, the lower house of the Dutch Parliament mooted banning petroleum and diesel cars by 2025. ${ }^{24}$ Even the German Bundesrat, in a nation that is one of the world's largest producers of automobiles, passed a resolution last year calling on the European Union to ban petrol vehicles by 2030. ${ }^{25}$

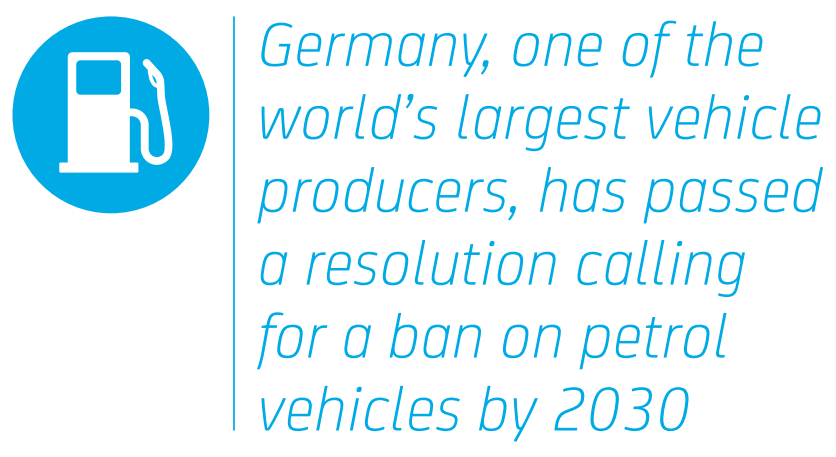

\section{Pre-modern transportation}

(Rudimentary vehicles)

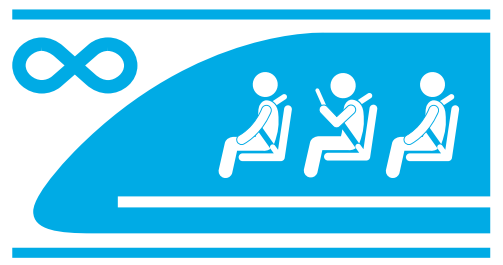

Future transportation

(Flying cars, Hyperloop etc.)
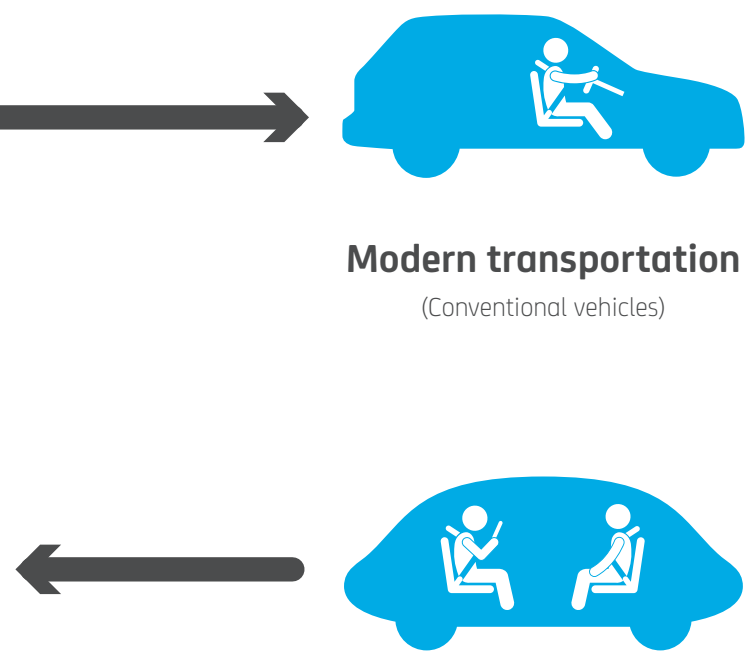

Modern transportation

(Conventional vehicles)

\section{Automated transportation}

(Automated vehicles) 


\section{Electric vehicles}

Electric vehicles actually existed in the late 1800s, but their popularity declined rapidly in the 20th century with advances in internal combustion engines. Due to more recent technological improvements, particularly around battery storage and management, electric vehicles have once again surfaced.

Despite growing electric vehicle sales around the world (electric vehicles experienced a 37 per cent rise in the United States in 2016), ${ }^{26}$ electric vehicles have yet to gain enough traction to threaten internal combustion engines as the most popular propulsion system.

However, this may be changing. In July 2017, Volvo announced plans to produce only electric or hybrid vehicles from 2019, putting an end to the pure internal combustion engine.

While worldwide sales have increased, electric vehicle uptake has been slow in Australia. The CEO of BMW Group Australia, Marc-Heinrich Werner, recently encouraged the Australian Government to do more to promote electric vehicles by voicing concerns pertaining to the lack of consumer uptake. ${ }^{27}$

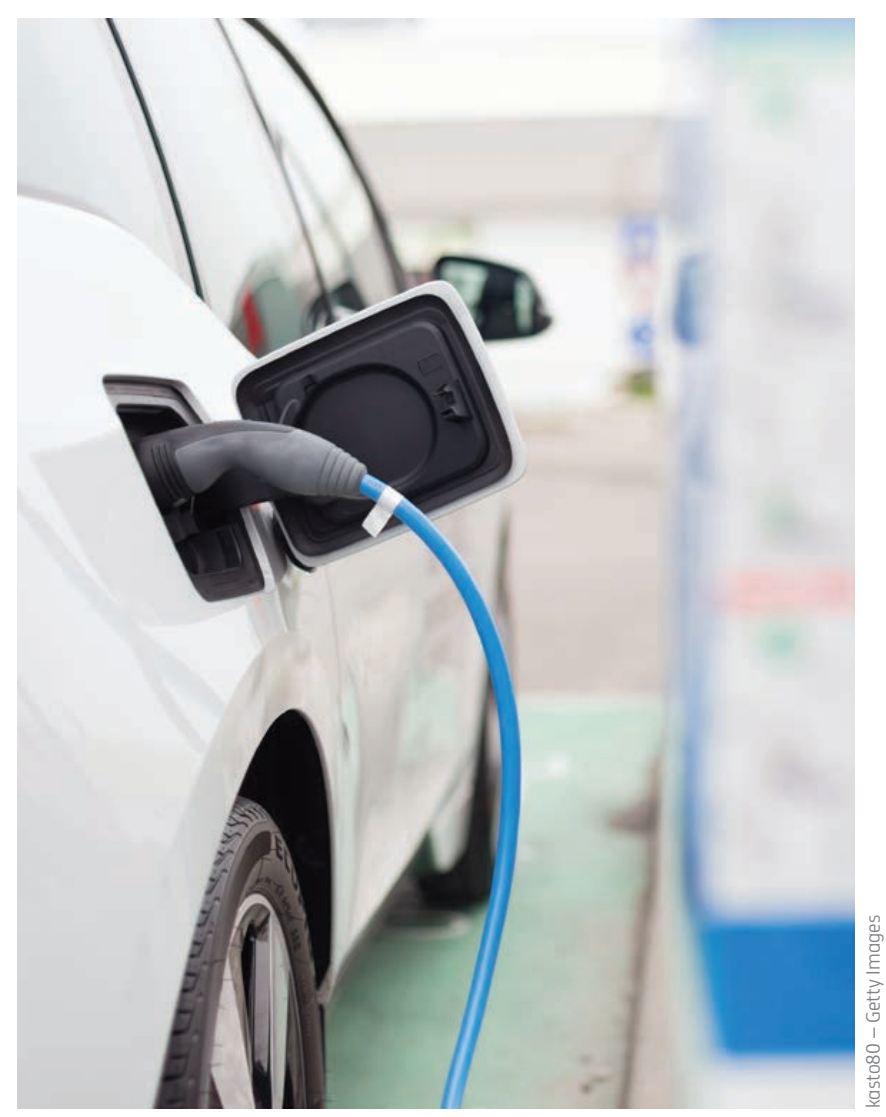

\section{FIGURE 8: CONSUMER SURVEY, Q3 2015: WORLD ECONOMIC FORUM - BCG ANALYSIS}

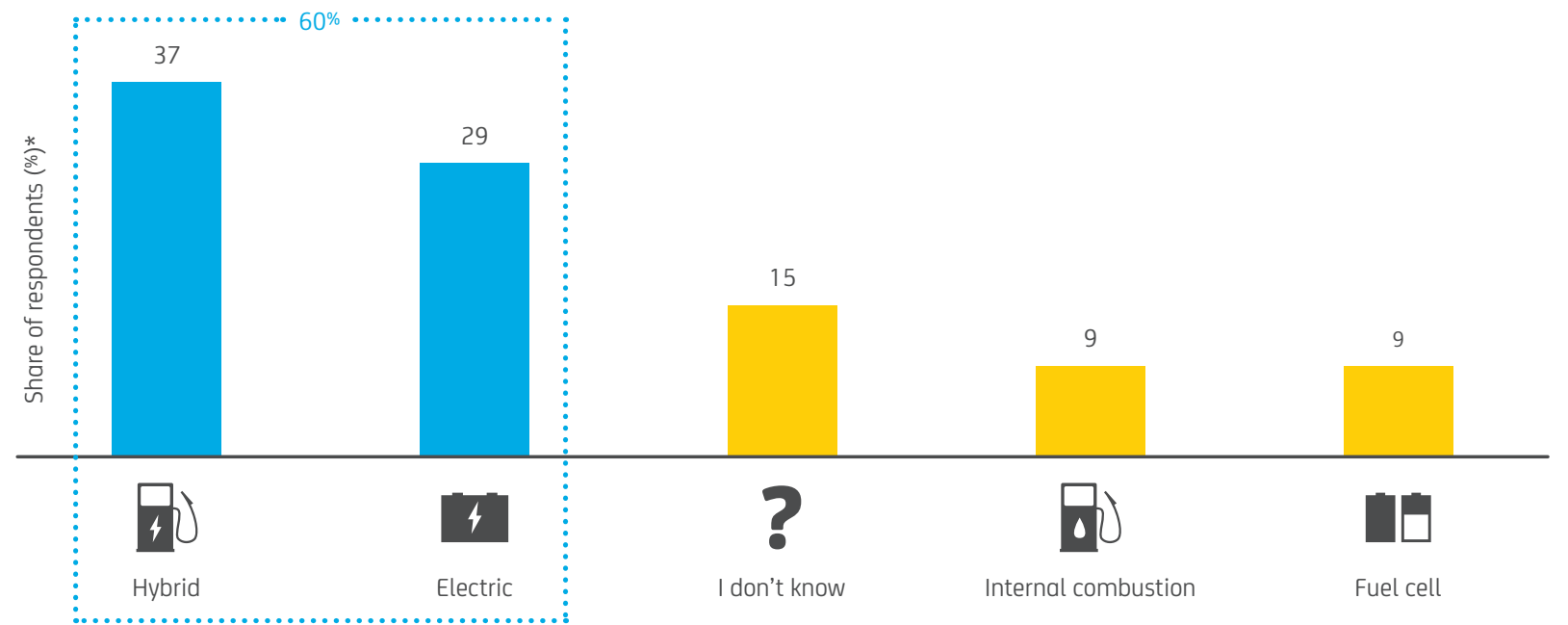

Source: The Boston Consulting Group 


\section{Fuel cell}

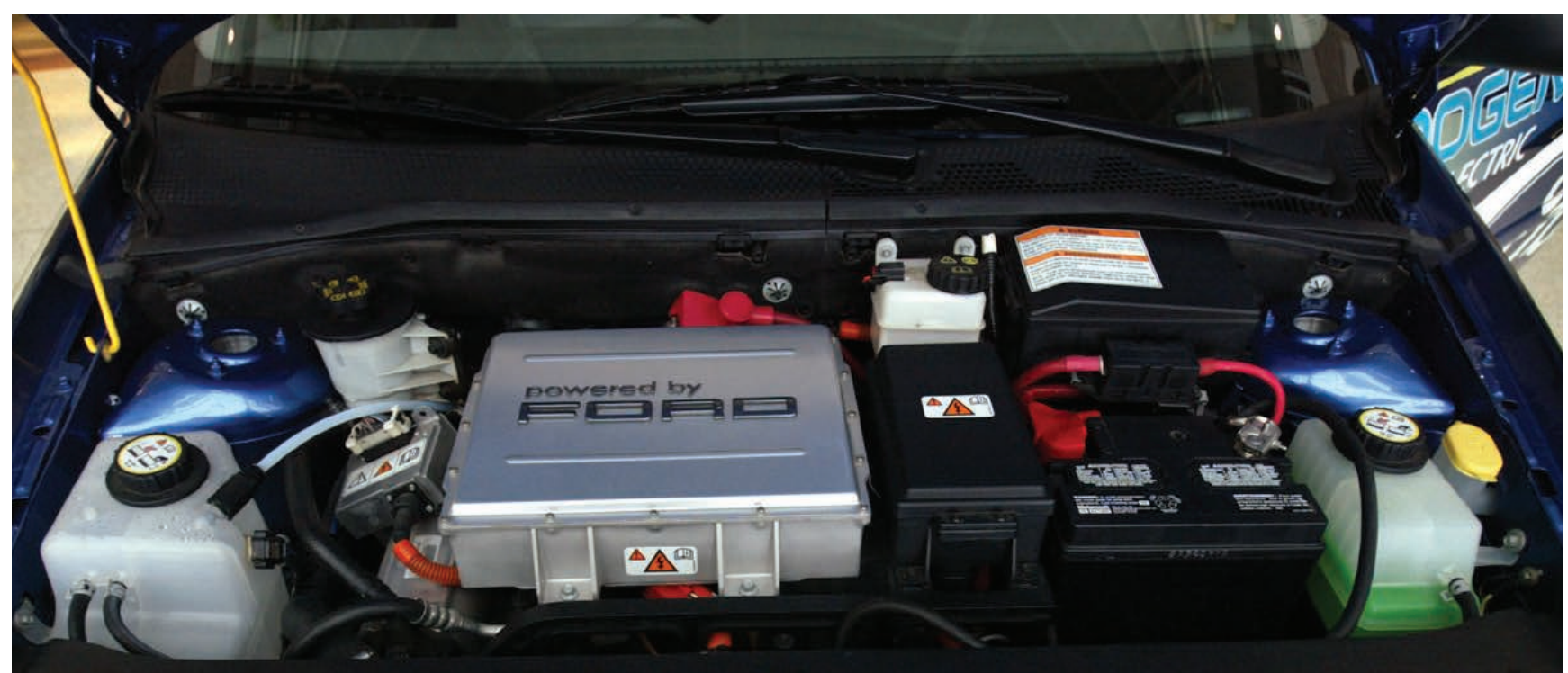

\section{HYDROGEN FUEL CELL ELECTRIC}

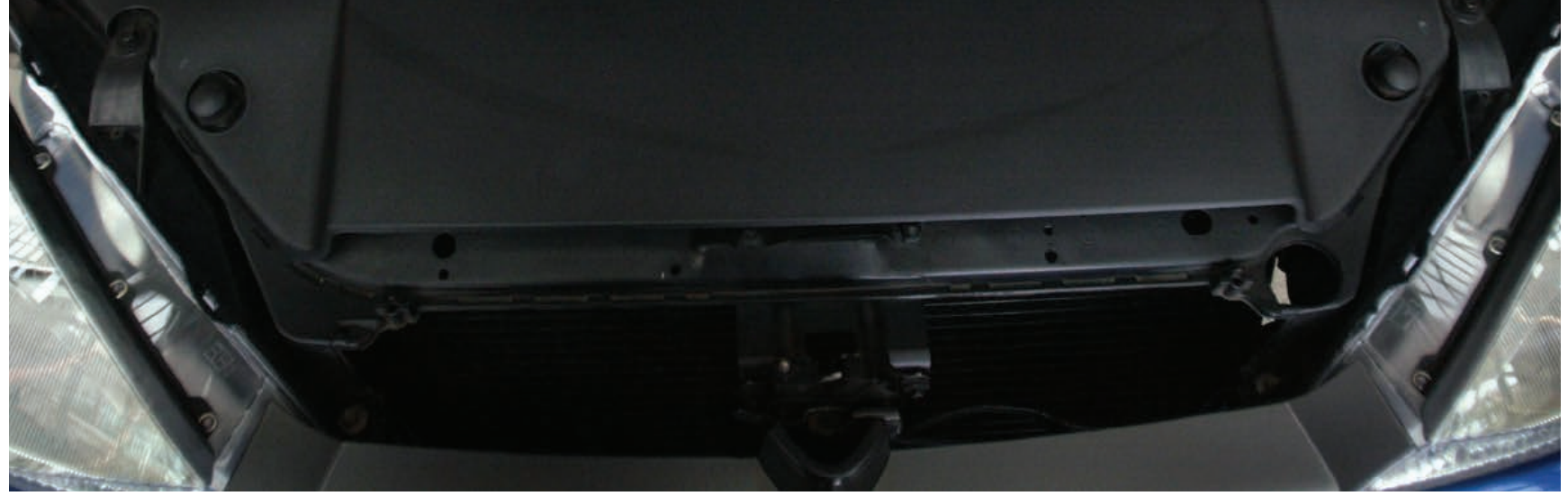

A fuel cell vehicle is an electric vehicle which uses a fuel cell (an electrochemical cell that converts chemical energy into electricity) to drive its motor as opposed to a battery. It does this primarily by creating a chemical reaction using compressed hydrogen and an oxidizing agent such as oxygen. The major benefit of this approach is very low to zero emissions; fuel cell vehicles generally output only water and heat.

The caveat to very low or zero emissions is that hydrogen comes from methane, which presently outputs carbon dioxide. It's worth noting, though, that electric vehicles face a similar issue, so fuel cells and electric vehicles are about on par with each other from an emissions point of view. ${ }^{28}$

Toyota, Hyundai and Honda are currently pursuing hydrogen technology. In 2015, Toyota released the Mirai, one of the first commercially available cars powered by hydrogen. In Norway, the government has plans to deploy a hydrogen refuelling network.

Despite this, the consensus is that the future of very low to zero emissions vehicles more than likely rests with electric vehicles as they have the potential to be the cleanest of all cars with the right technological advances. 


\section{Autonomous vehicle}

\section{What is an autonomous vehicle?}

There are many developmental points on the road to fully autonomous vehicles. SAE International developed six levels describing the road from a normal vehicle to a fully autonomous Level 5 vehicle. This SAE index is now globally accepted as the standard for autonomous vehicle development:29

\section{- Level 1 and 2 (Driver Assistance and Partial}

Automation) technologies such as automatic brake assist have been fitted to vehicles since the mid-2000s.
- Level 3 (Conditional Automation), which the NRMA expects to debut in 2018, is capable of overseeing the driving task in limited situations with a driver present behind the wheel.

- Level 4 (High Automation) removes the need for a driver; however, the technology cannot fully operate under all road conditions.

- Level 5 (Full Automation) negates the need for pedals and a steering wheel, completely removing the driver from the driving task under all conditions.

\section{FIGURE 9: AUTONOMY LEVELS OF VEHICLES}

\begin{tabular}{|c|c|c|c|c|c|c|}
\hline $\begin{array}{l}\text { SAE } \\
\text { level }\end{array}$ & Name & Narrative definition & $\begin{array}{l}\text { Execution of } \\
\text { Steering and } \\
\text { Acceleration/ } \\
\text { Deceleration }\end{array}$ & $\begin{array}{l}\text { Monitoring } \\
\text { of Driving } \\
\text { Equipment }\end{array}$ & $\begin{array}{l}\text { Fallback } \\
\text { Performance } \\
\text { of Dynamic } \\
\text { Driving Task }\end{array}$ & $\begin{array}{l}\text { System } \\
\text { Capability } \\
\text { (Driving } \\
\text { Modes) }\end{array}$ \\
\hline \multicolumn{7}{|c|}{ Human driver monitors the driving equipment } \\
\hline & $\begin{array}{l}\text { No } \\
\text { Automation }\end{array}$ & $\begin{array}{l}\text { The full-time performance by the human driver of all } \\
\text { aspects of the dynamic driving task, even when enhanced } \\
\text { by warning or intervention systems. }\end{array}$ & Human driver & Human driver & Human driver & $\mathrm{n} / \mathrm{a}$ \\
\hline & $\begin{array}{l}\text { Driver } \\
\text { Assistance }\end{array}$ & $\begin{array}{l}\text { The driving mode-specific execution by a driver assistance } \\
\text { system of either steering or acceleration/deceleration } \\
\text { using information about the driving environment and } \\
\text { with the expectation that the human driver perform all } \\
\text { remaining aspects of the dynamic driving task. }\end{array}$ & $\begin{array}{l}\text { Human driver } \\
\text { and system }\end{array}$ & Human driver & Human driver & $\begin{array}{l}\text { Some driving } \\
\text { modes }\end{array}$ \\
\hline & $\begin{array}{l}\text { Partial } \\
\text { Automation }\end{array}$ & $\begin{array}{l}\text { The driving mode-specific execution by one or more driver } \\
\text { assistance systems of both steering and acceleration/ } \\
\text { deceleration using information about the driving } \\
\text { environment and with the expectation that the human } \\
\text { driver perform all remaining aspects of the dynamic } \\
\text { driving task. }\end{array}$ & System & Human driver & Human driver & $\begin{array}{l}\text { Some driving } \\
\text { modes }\end{array}$ \\
\hline \multicolumn{7}{|c|}{ Automated driving system monitors the driving environment } \\
\hline 3 & $\begin{array}{l}\text { Conditional } \\
\text { Automation }\end{array}$ & $\begin{array}{l}\text { The driving mode-specific performance by an automated } \\
\text { driving system of all aspects of the dynamic driving task } \\
\text { with the expectation that the human driver will respond } \\
\text { appropriately to a request to intervene. }\end{array}$ & System & System & Human driver & $\begin{array}{l}\text { Some driving } \\
\text { modes }\end{array}$ \\
\hline 4 & $\begin{array}{l}\text { High } \\
\text { Automation }\end{array}$ & $\begin{array}{l}\text { The driving mode-specific performance by an automated } \\
\text { driving system of all aspects of the dynamic driving task, } \\
\text { even if a human driver does not respond appropriately to } \\
\text { a request to intervene. }\end{array}$ & System & System & System & $\begin{array}{l}\text { Some driving } \\
\text { modes }\end{array}$ \\
\hline 5 & $\begin{array}{l}\text { Full } \\
\text { Automation }\end{array}$ & $\begin{array}{l}\text { The full-time performance by an automated driving } \\
\text { system of all aspects of the dynamic driving task under } \\
\text { all roadway and environmental conditions that can be } \\
\text { managed by a human driver. }\end{array}$ & System & System & System & $\begin{array}{l}\text { All driving } \\
\text { modes }\end{array}$ \\
\hline
\end{tabular}

Source: SAE International 
Several autonomous vehicle trials are happening around the world at present, mostly at the Level 3 stage with the leader so far being Waymo, Google's self-driving vehicle arm, recently announcing the completion of three million miles of testing. They are also getting quicker at completing miles, with the last million taking seven months to complete, while the first two million took seven years. ${ }^{30}$

Private companies working on technological advancements to assist autonomous vehicles are commanding record levels of investment and funding. In addition to start-ups and small tech companies, large companies are also focusing on the future by advancing their thinking and knowledge.
Companies like Apple, Bosch, Intel, Volvo, Tesla, Ford and Huawei are all working on technology to support a future of autonomous vehicles. It is clear from this small list that the future mobility companies may be quite different to that of mainstream car manufacturers we know today.

\section{When will autonomous vehicles be here?}

The NRMA predicts that a vehicle containing Level 3 technology will be available to buy very soon. The new 2018 Audi A8 is expected to be capable of Level 3 automation, a world first, but it will not be possible to use it on Australian roads due to prohibitive regulations. ${ }^{31}$

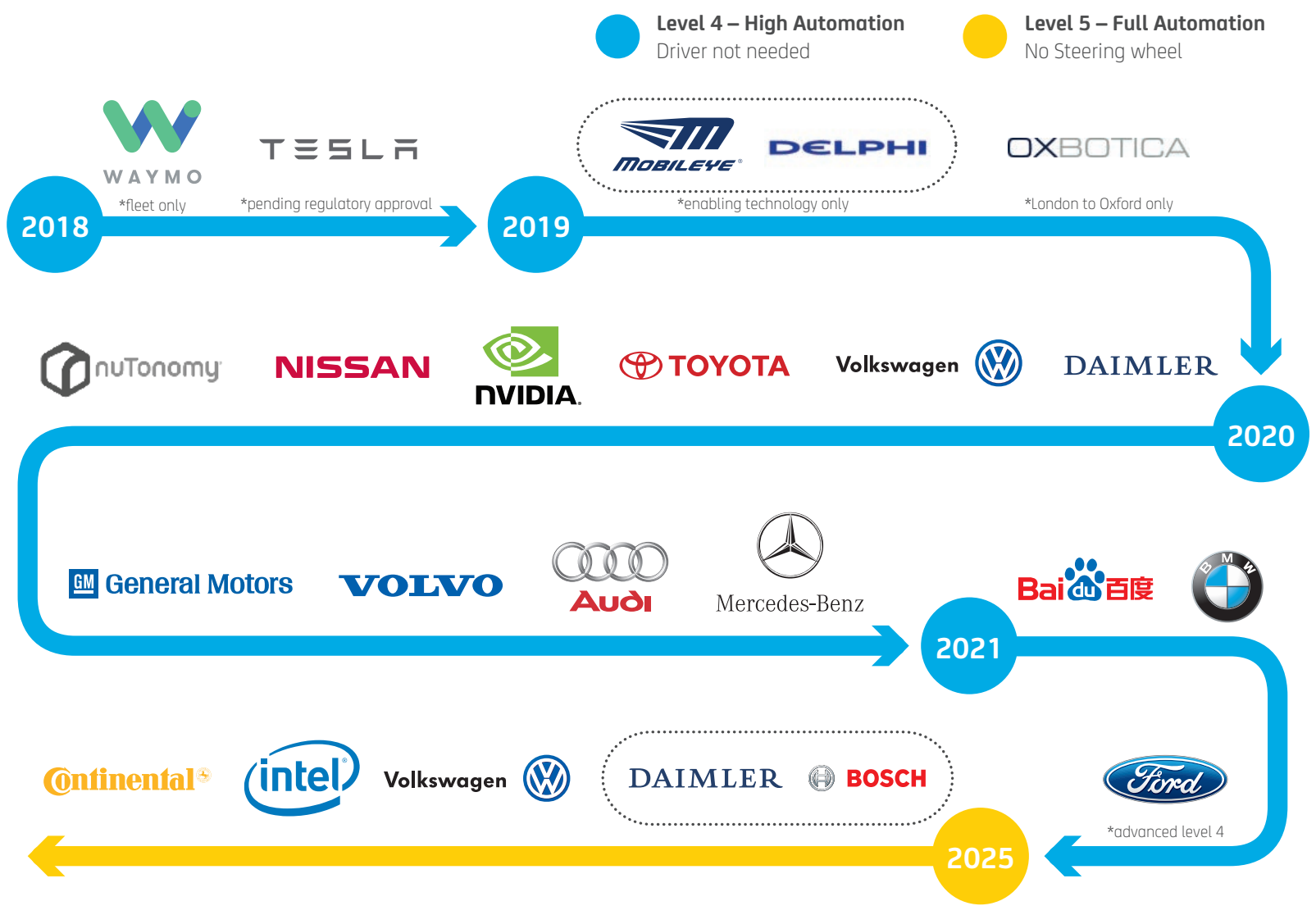


NVIDIA, who are developing artificial intelligence for autonomous vehicles recently announced that they will introduce a Level 4 enabling system by $2018 .^{32}$ They expect highly automated Level 4 vehicles to be operational by 2020. ${ }^{33}$ NVIDIA's predictions are particularly important because they partner with several major OEMs.

Fully autonomous vehicle capability - where no human is needed and cars do not even have a steering wheel or accelerator - could be here as early as 2025 .

OEMs, start-ups, dedicated technology companies, academics and automobile organisations around the world have entered the debate around when autonomous vehicles will actually be on our roads. Despite some similarities existing, it is clear that no definitive timeline is broadly accepted at this point.

The most aggressive predictions come from Waymo (Google), Mobileye (Intel), Delphi and Oxbotica, who see Level 4 technology a reality by as early as 2018 or 2019. However most OEMs believe Level 4 technology will become available around 2020. Daimler, Volkswagen, Toyota, Nissan, GM and Volvo all agree that Level 4 systems and cars will arrive in 2020.
Level 5 predictions are harder to come by, and most timelines are vague on the roll-out of this technology. However, Daimler, Volkswagen, Continental and Intel have all hinted that Level 5 vehicles will be here by 2025 .

Ford has announced plans to roll out a vehicle in 2021 with no steering wheel, gas pedal or brake pedal. The vehicle, however, will only operate will operate within a defined fenced area as part of a ride sharing experience and is therefore classified as Level $4 .{ }^{34}$

The Australian Driverless Vehicle Initiative (ADVI) has also developed timelines as to when the various levels of autonomous technology will be available in Australia. ADVI suggests that we will see Level 3 technology prior to 2020, Level 4 technology between 2020 and 2025, and Level 5 technology between 2026 and $2030 .{ }^{35}$ This view aligns with the timeframes identified by the NRMA.

While challenging to predict the future, the NRMA believes the following guide to autonomous vehicle introduction in Australia is representative of the best information currently available from all sources, including OEMs, start-ups, technology focused companies, academics and automotive industry bodies.

\section{AUTONOMOUS VEHICLE INTRODUCTION IN AUSTRALIA}

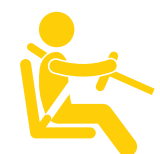

The Present

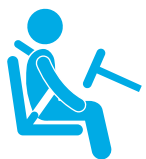

The Future

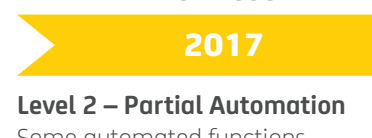

Some automated functions

\section{$2018-2019$}

Level 3 - Conditional Automation Level 4-High Automation Hands off the wheel

$2020-2024$

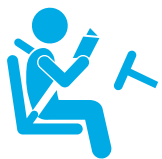
Driver no longer needed

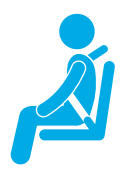

2025 onwards

Level 5 - Full Automation

Steering wheel gone

It is worth noting that even if the technology is ready for our roads by these indicative times, our road infrastructure and legislation may not be. If our legislation is not ready, this could result in Australians being deprived of the benefits compared to citizens of other nations that have been proactive in preparing for an autonomous vehicle future. 


\section{Connected car}

If autonomous vehicles and smart infrastructure are the building blocks of a mobility future, the technology that makes the car 'connected' is the glue that binds them together.

Vehicles are not immune from the internet of things (IOT) revolution and the further progression of this concept as described by Cisco Systems as the internet of everything (IOE). ${ }^{36}$

A 'connected car' is a vehicle which is IP-enabled and is able to interact through the internet with other vehicles and infrastructure around it. Infrastructure is not limited to roads and traffic lights, it can include other civil infrastructure such as buildings.

Some elements that make up the connected car are not new. Nearly all cars rolling off production lines today have various computers that run self-diagnosis or have the ability to collect data about its performance and the way it is driven.

Connected car packages are currently offered to customers of high end manufacturers such as Tesla, BMW and Audi. The NRMA is developing consumer connected car products for aftermarket vehicles. These products are currently available to fleet customers. In a fully autonomous vehicle future, connected car technology will have to be rolled out across all vehicles on the road in order for the network to be fully utilised.

\section{What are the benefits of a connected car future?}

A future connected car with autonomous capability offers a series of interesting benefits.

A connected car will be able to talk to other cars, which will allow vehicles to group together (platoon) on a journey like a school of fish. This will allow vehicles to travel closer together at higher speeds, reducing journey times and congestion. In a distant future, a centralised traffic management system could optimise routes for every vehicle in a city network ensuring smooth traffic flow. This would allow greater and more efficient use of the road network as cars become a platoon of vehicles on their way to common destinations. Platooning also allows vehicles to travel at constant speed, reducing energy consumption.

Platooning trials are already underway on roads with semi-autonomous connected trucks. The 2016 European Truck Platooning Challenge saw trucks from a number of companies platoon across Europe from various starting points, making their way to Rotterdam in the Netherlands. A Volvo platoon of three trucks drove from Gothenburg to Rotterdam via Denmark, Germany and Belgium.

A connected and automated vehicle (CAV) will have the ability to book and take itself for a service; the on-board computer diagnostics will communicate that something needs tweaking. It will also be able to forecast future wear and tear to determine the optimal time for repair or replacement. An IP-enabled vehicle will allow information to be relayed to the servicer who may or may not be human. The issue that requires attention will be known prior to the arrival of the vehicle at the service centre.

Connected vehicle technology will also have benefits in regards to safety. Some of these are being demonstrated currently. For example, the European Union has developed a system called eCall, which automatically calls emergency services in the advent of a serious accident. The European Union has passed a law that makes it compulsory for the technology to be installed in all new cars from April 2018. ${ }^{37}$

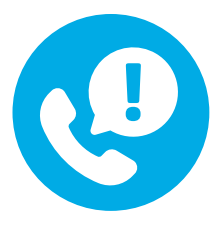

Utilising connected car technology, eCall will improve emergency response times by $50 \%$ 


\section{Service investments}

Investment in other services by OEMs offers perhaps the greatest indicator of where various technological developments are converging. In the race to stay relevant, OEMs are beginning to invest in a wide range of technology services in order to gain a competitive advantage over their rivals and experiment in future service offerings:

- Earlier this year, Intel announced it would pay $\$ 15.3$ billion to acquire Mobileye, an Israeli chip and camera company with experience applicable to self-driving technologies.

- In 2016, Toyota invested in Uber, and also announced a strategic partnership to provide leasing arrangements to Uber drivers in the United States.

- Volkswagen have invested in Israeli ride share company Gett and have started their own mobility company called Moia. Moia is specifically city focused and hopes to run on-demand shuttle services with electric drivetrains.

- General Motors has invested a reported US\$500 million in Lyft, Uber's main rival in the United States, taking around 9 per cent equity. They also bought defunct ride share provider SideCar's intellectual property and other assets, turning it into their own car share application Maven. In mid2016, Maven and Uber trialled a car sharing service allowing Uber drivers to hire vehicles through the Maven platform.

- Tesla have foreshadowed that in 2017 they will launch Tesla Network, their own car and ride share network which will allow Tesla owners to hire out their vehicles if unused. Tesla have also stated that the hiring out of an autonomous Tesla for commercial purposes in the future will only be allowed through the Tesla network.
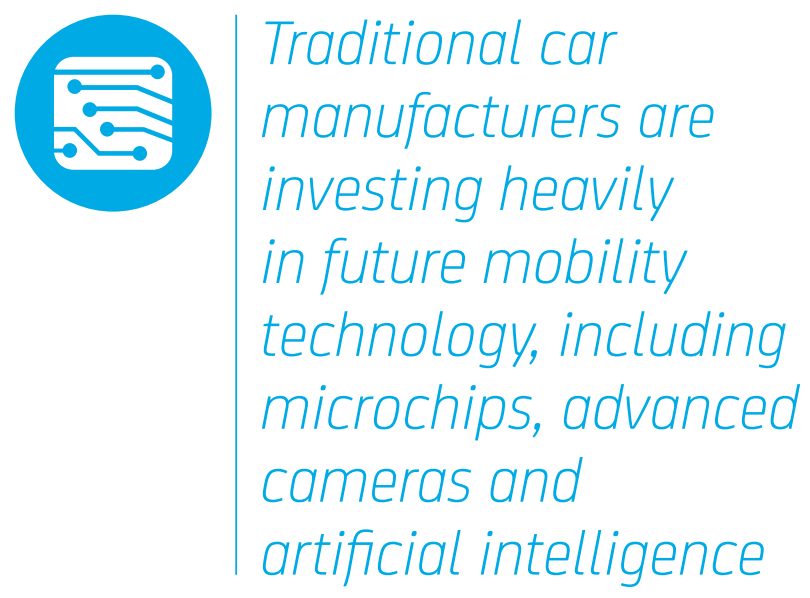

- Ford Motor Company recently started Ford Smart Mobility, an innovation company which is designed to experiment in connectivity, mobility, autonomous vehicles, the customer experience and big data. They have also invested in:

» Velodyne - a company that develops LIDAR (Light Detection and Ranging) technology.

» SAIPS - a company which develops algorithms for machine learning and computer vision.

» Nirenberg Neuroscience - machine vision technology.

» Civil Maps - a mapping firm which is working to crowd-source dynamic 3D maps for safe driving by autonomous vehicles.

»Argo $\mathrm{Al}-\mathrm{a} \$ 1$ billion investment, which produces artificial intelligence software for autonomous cars. 


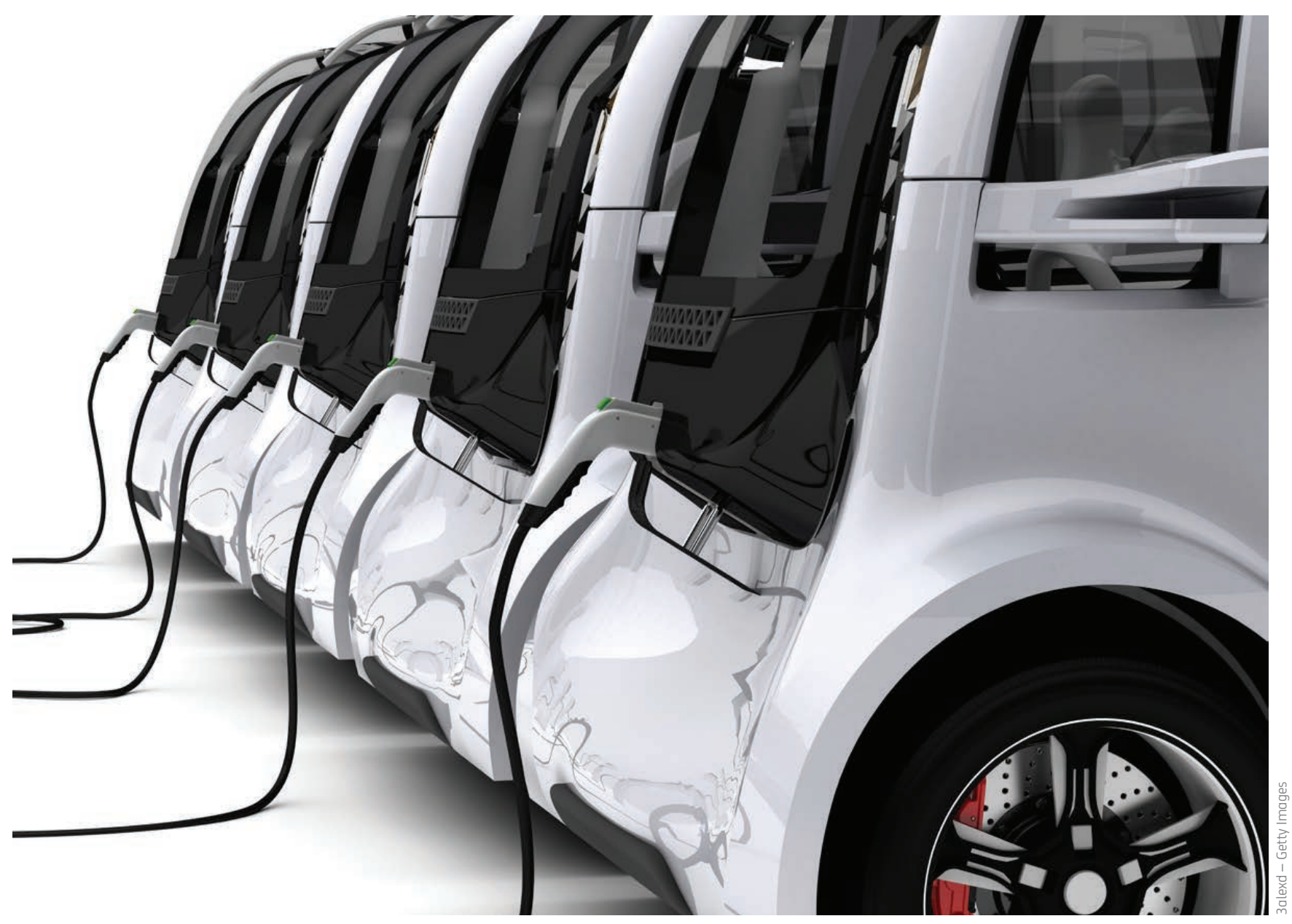

- Ford Smart Mobility has undertaken a number of car sharing trials around the world, all with varying parameters:

» City Driving on Demand (London, UK) - an ondemand focused car sharing service. In this trial a network of Ford-owned electric Focuses and eco-boost Fiestas were positioned around London. Usage of the assets were on a per-minute charge, which included the price of insurance, fuel and the London Congestion Charge.

» Car Swap (Dearborn, MI, USA) - an app that allows Ford employees to share vehicles. Intended to be an experiment which will give Ford insights into how they can help make car sharing easier.
» Share-Car (Bangalore) - Ford is working with Zoomcar to test sharing vehicles between a number of small groups such as co-workers and apartment dwellers.

» Ford Carsharing (Germany) - a nationwide car sharing program in 55 cities in partnership with Flinkster, a German car sharing organisation.

- Audi, BMW and Daimler bought HERE, a mapping data firm from Nokia which also counts Intel as an investor.

This is not an exhaustive list. New announcements from OEMs in technology partnerships are increasing in velocity as they make strategic moves to increase their stake in a smart mobility future. 
What do these converging trends mean for the future of car ownership?

Firstly - a note of caution. Prediction is difficult. Whatever the future brings will be whatever countless people around the globe decide on to enhance their lives and mobility needs.

If we consider the public policy process - which is crucial for some of the regulatory changes that need to be made in order to allow a fully autonomous vehicle on the road, we can see the complexity of the process. Local desires and events will influence factors within communities, which in turn will influence local public policy.

What this means is that there could be a great deal of difference in acceptance between municipalities, regional governments and nations themselves. The same can be said for products and services, and how they are viewed and perceived between consumers because of environmental, geographical and historical factors.

Assuming that autonomous vehicle incidents and misfortunes do not increase compared to current statistics, it seems the world is gravitating to a future where we won't have a need to own a vehicle. While safety is seen as a major benefit of autonomous vehicles, it is perhaps unreasonable to assume that incidents will immediately cease altogether; rather, we can expect incidents to lessen over time as autonomous technology continues to advance.

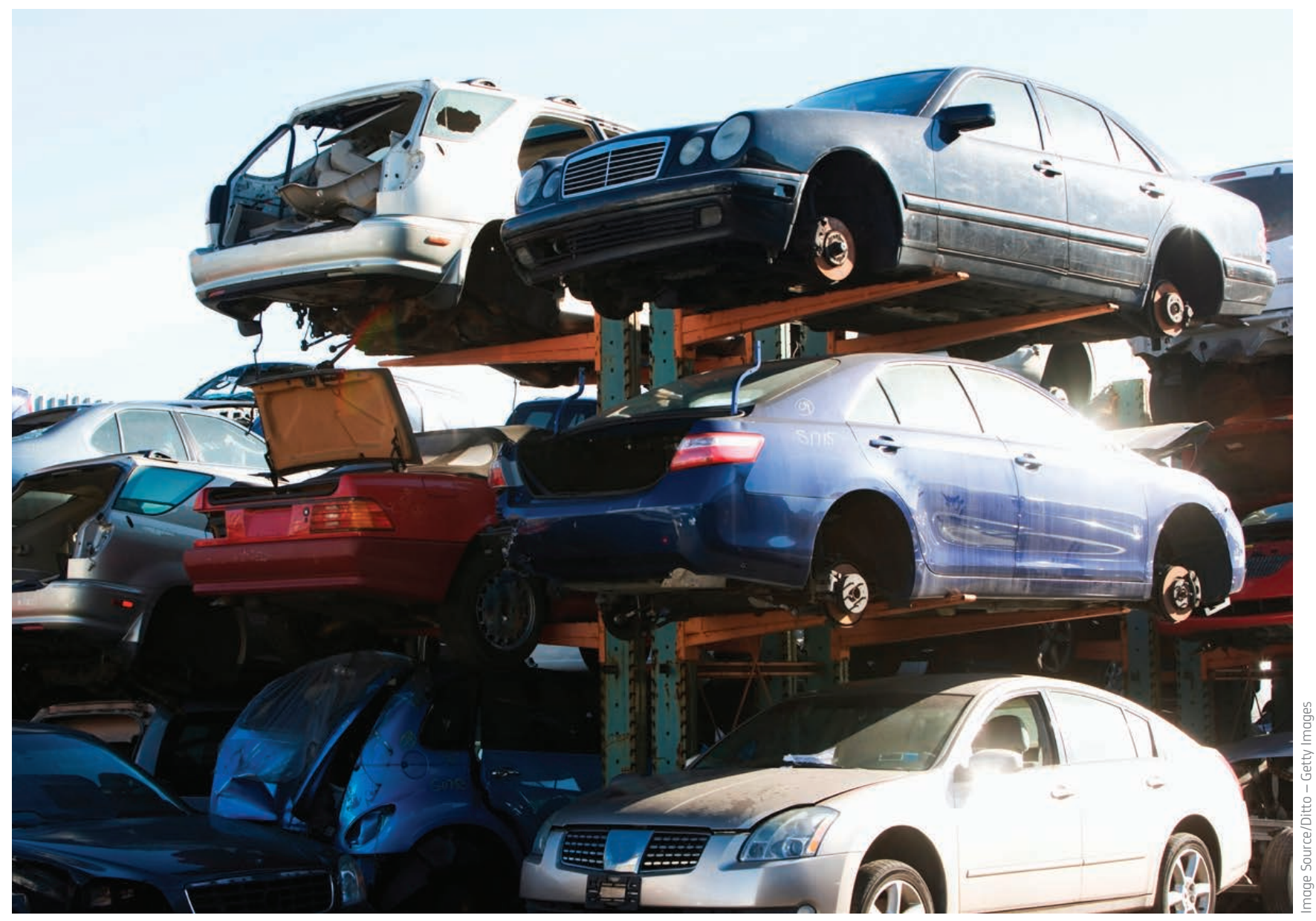




\section{Issues with estimating declines in ownership}

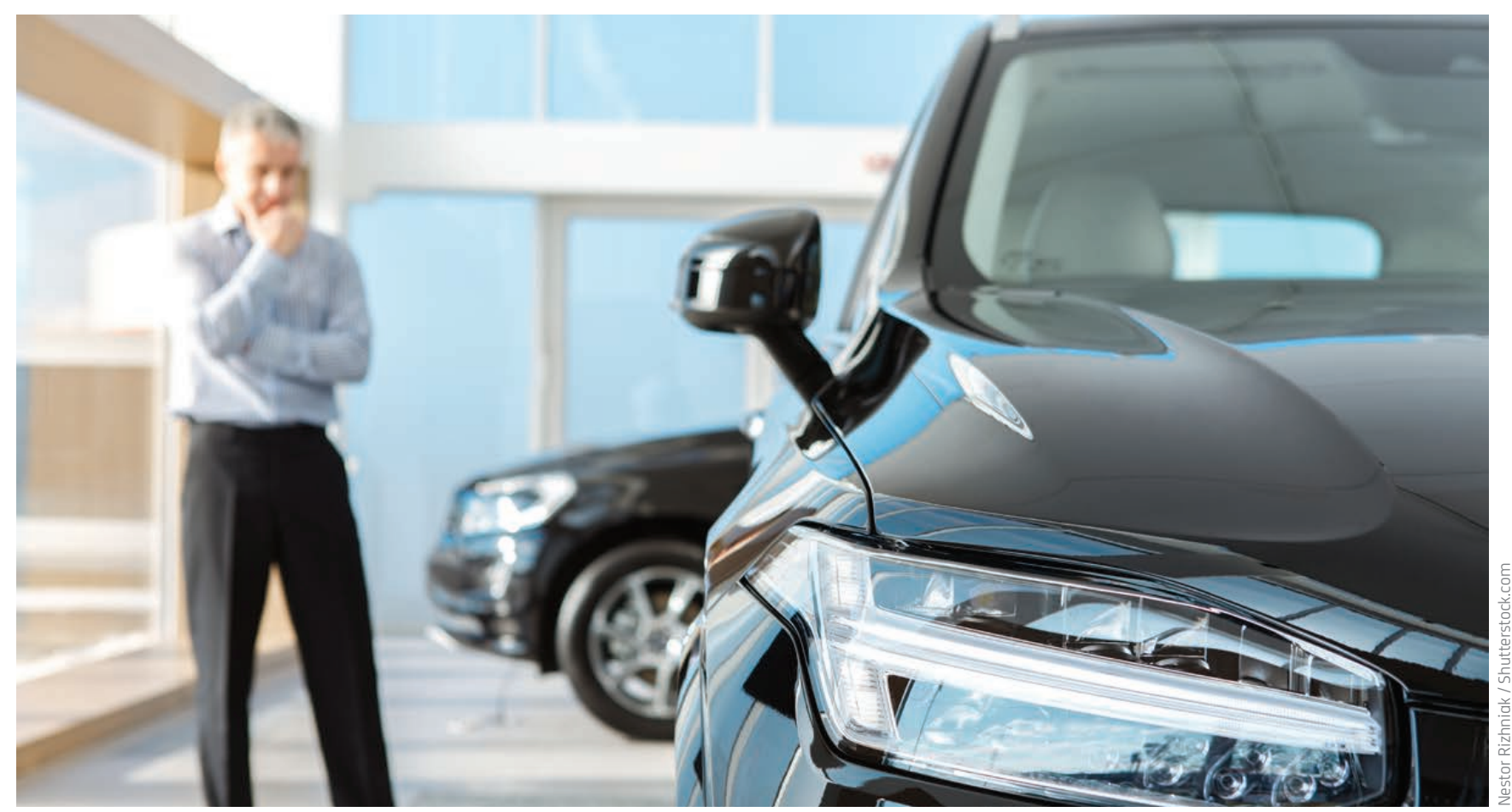

It is necessarily speculative to estimate the impact autonomous vehicles will have on car ownership. CitiGroup have modelled a scenario assuming autonomous vehicle led take up rates by fleet providers in four US states: Illinois, New York, Florida and California.

Citi's model estimates that in those four states, the implementation of driverless vehicles will mean the likely shedding of 17 million vehicles from the road net of population growth by 2030. ${ }^{38}$ This reduction, though, does not take into account ownership levels.

RethinkX, an independent transportation think tank based in the United States, recently issued a paper entitled Rethinking Transportation 2020-2030. They believe that car ownership could be obsolete in the United States by 2030 after autonomous vehicles have effectively been on the road for ten years.

While they make various assumptions, they suggest that take up would be a lot more radical than current estimates suggest, however their model is based primarily on the United States.
As already noted, different geographical and societal environments will mean a different mix of policy solutions, differences in the way technology is developed, and ultimately different solutions to the mobility conundrum.

The United Kingdom for example is a prime target for a move to full MaaS with diminishing car ownership. John Leech, Head of Automotive for KPMG recently said that green belt policies that restrict development in outlying areas have caused greater densification compared to North America and Europe. ${ }^{39}$

Australia is a rather vast country with the ability to still unlock large amounts of land supply on the fringes of its suburbs, and therefore may be less enthusiastic, or perhaps less primed, than the United Kingdom for a shift to MaaS.

However, in a nation where 76 per cent of population growth occurs in just four cities, we may transform into a nation that is ripe to embrace this technology once it is fully available. 


\section{Solving the hassle-premium: car or no car?}

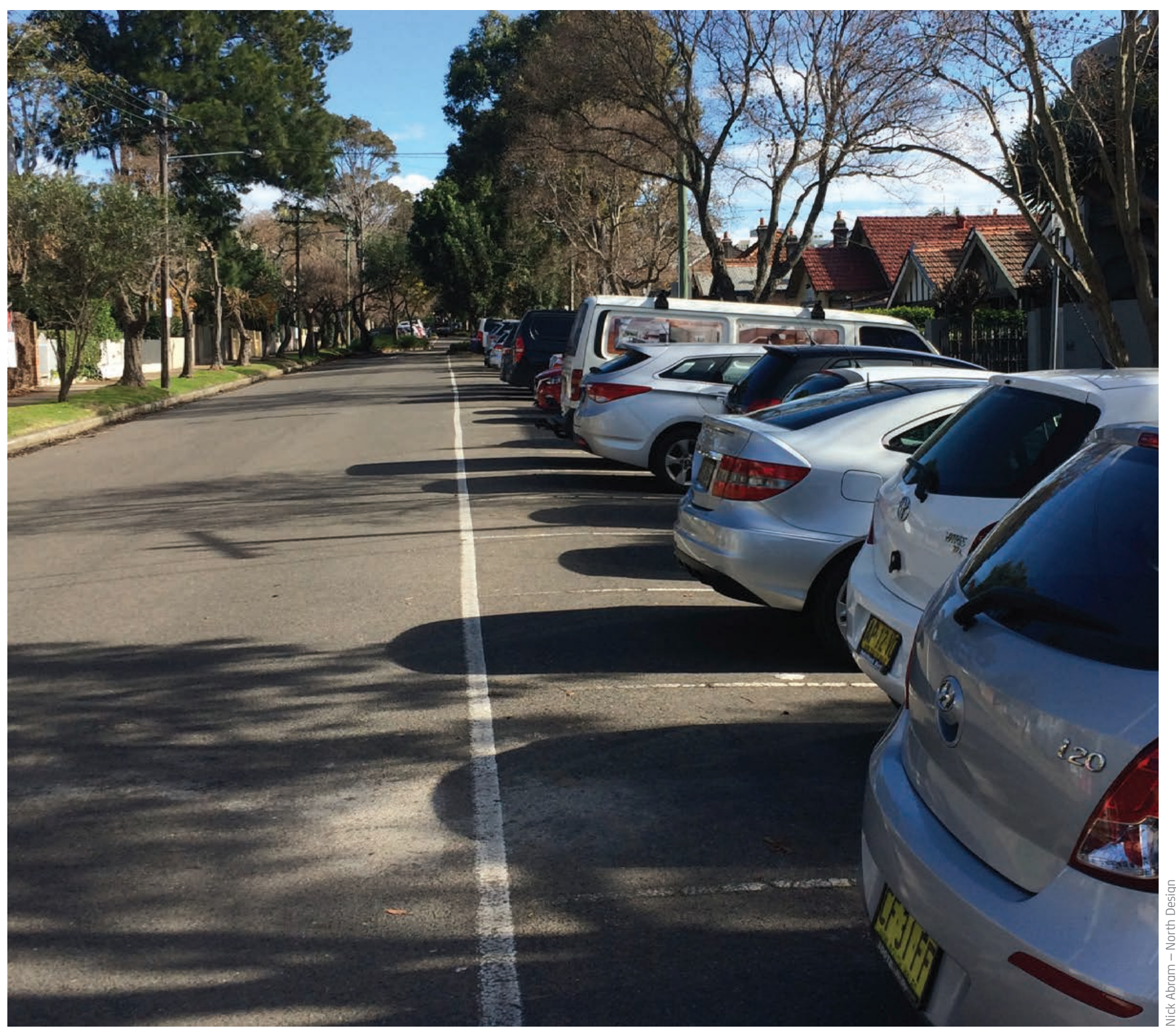

In The Personal MBA, Business Author Josh Kaufmann describes the Hassle Premium, in his chapter on the opportunities for value creation: "People are almost always willing to pay for things that they believe are too much of a pain to take care of themselves. Where there's a hassle, there's a business opportunity." ${ }^{40}$

Owning a car is quite a hassle in many ways, as companies like Tesla, Uber and Lyft have realised.
Cars demand numerous payments and fees; you have to fill them with petrol; they vastly depreciate as soon as they are driven out of the showroom; and they can break down. And once you add in things like loan repayments and servicing, the costs soon begin to climb.

Not only are they expensive, they sit idle for 95 per cent of the time. It's hard to believe that an asset that traditionally is the second highest priced purchase after a house is so inefficient. 


\section{Consumer surplus}

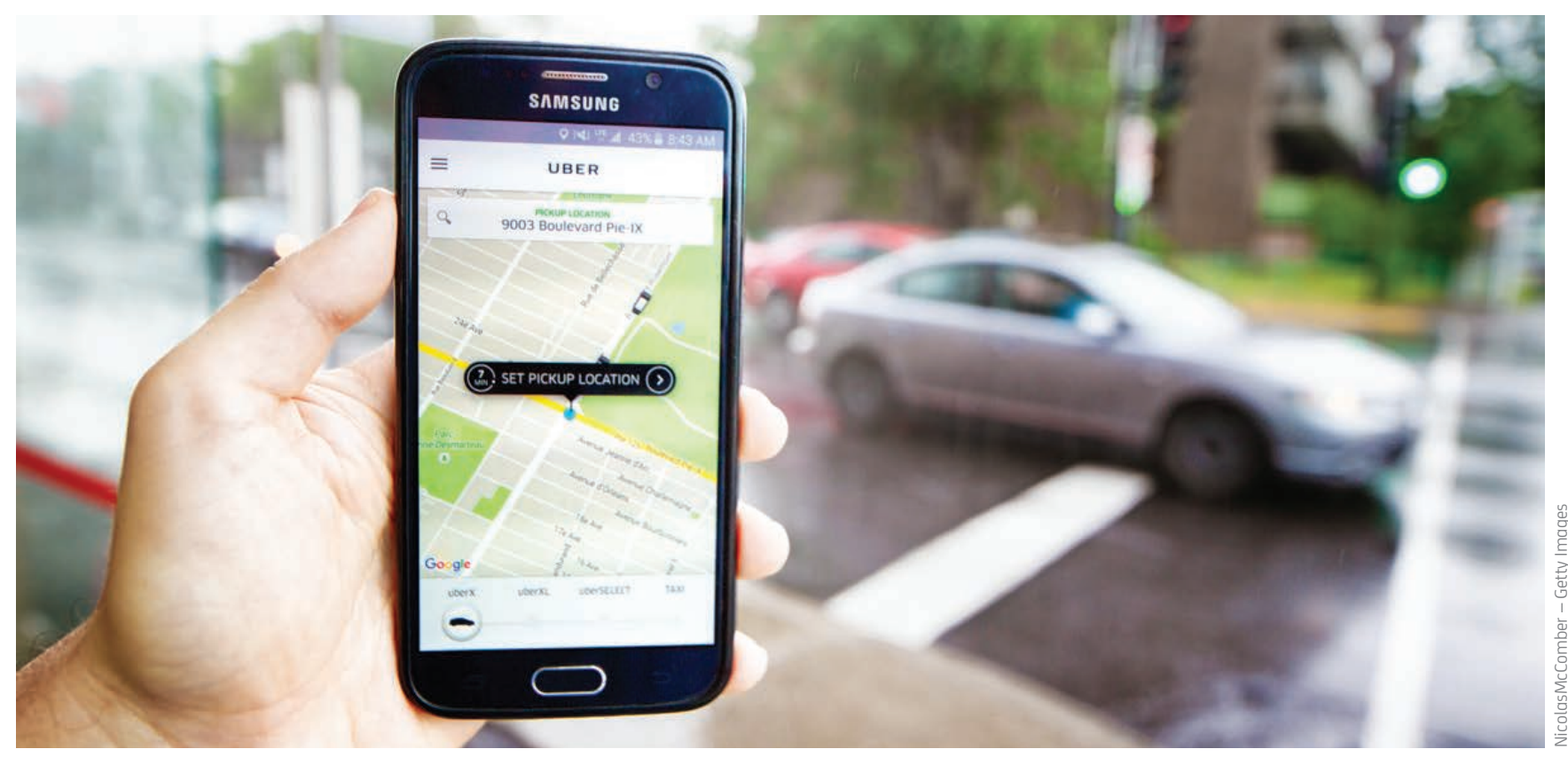

Once fully autonomous (Level 5) vehicles are on our roads, you will not have to own a car because hailing one from an app as an on-demand service will likely be cheaper than owning one.

Presently, it costs Australians a significant amount for mobility. The Australian Automobile Association, on behalf of the NRMA, estimated that it costs the average Australian family $\$ 22,000$ for transportation every year. ${ }^{41}$

In 2016, 17 per cent of household income went towards owning a private car. ${ }^{42}$ By comparison, gas and electricity have been shown to demand around 2.3 per cent. ${ }^{43}$

Sydney is the costliest city in Australia in terms of transportation costs, with a two-car family on average paying around $\$ 428$ a week compared to $\$ 313$ in Canberra. ${ }^{44}$

There have been many movement cost estimates pertaining to autonomous vehicles. Deloitte has estimated that trips could plummet to US $\$ 0.46$ per mile, ${ }^{45}$ which is approximately AUD $\$ 0.38$ per kilometre (at an exchange rate of 1.32 AUD).
This suggests it may be much cheaper to catch an autonomous robo-taxi for day-to-day mobility, and hire a more suitable vehicle for certain specialised activities. There is certainly a consumer surplus opportunity between what we are willing to pay for auto mobility at present, and what it will cost in the future.

However, governments and organisations need to be careful in looking at just the true financial cost to a car share user, or indeed a car share owner. While it may seem irrational for people to hold on to a depreciating asset which is little used, it betrays the fact that some may get a certain utility out of maintaining and owning a vehicle over and above financial considerations.

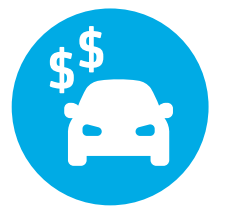
$17 \%$ of household income goes towards owning a car 


\section{Convenience and better choice}

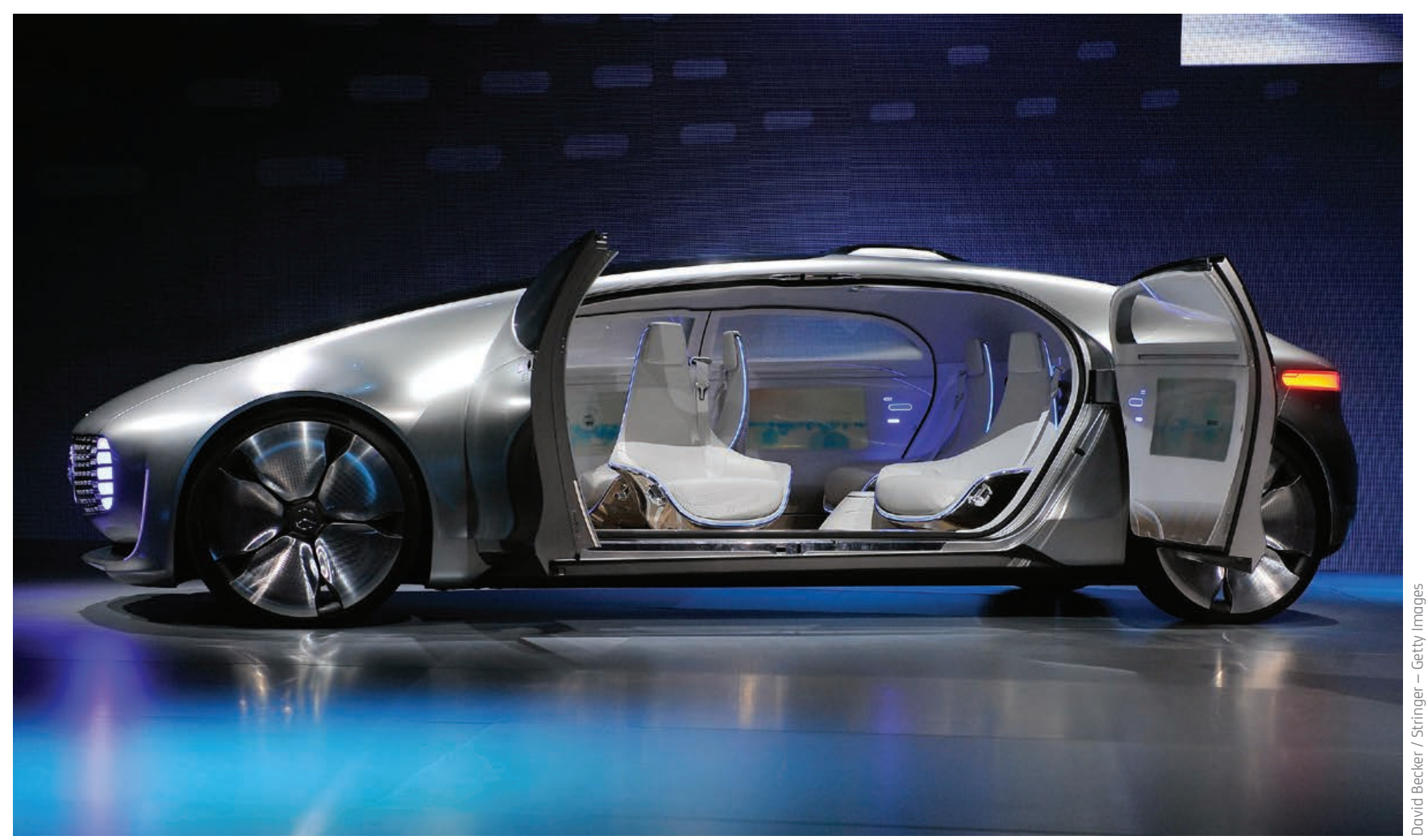

Presently, consumers have to weigh up a number of choices when they purchase a vehicle. Often vehicles need to suit, first and foremost, their day-to-day use, whether it is commuting, or simply dropping children at school or sport. Geographical factors also must be taken into account. Small city cars are popular in Europe because they are easier to park in extremely dense cities. The SUV's growing popularity in Australia could be attributed to our suburbanisation.

But when making the decision, compromises have to be made. You may have to sacrifice the performance you wanted because of practicality. Or you may not have been able to purchase the interior options you wanted because it was cost prohibitive.

Barclays Investment Bank have suggested that these are the four types of vehicles that may exist in 2040:

- Traditional Automobiles - performance and utility vehicles intended for personal or work use.
- Family autonomous vehicles (FAVs) autonomous vehicles owned or shared by families.

- Shared autonomous vehicles (SAVs) on-demand chauffeur, minus the human driver.

- Pooled shared autonomous vehicles (PSAVs) SAVs that service multiple people simultaneously. ${ }^{46}$

In an autonomous vehicle future you may have the option of choosing which vehicle you feel like using on any given day and it will arrive at your home to pick you up. It may know how you like your seat reclined, what news items you are interested in and your favourite music. Instead of having an idle family vehicle, families will be able to hire any car which suits their needs at any time of the day, whether it is a robo-taxi to get to work or drop children off at school, or an SUV to fit the entire family and the dog in for a visit to the beach. 


\section{Who will still own a car?}

It is unlikely that all privately-owned vehicles will disappear from the roads altogether.

Regardless of technology or advances in mobility, some people may still wish to own and drive a car. There will always be individuals opposed to sharing, as well as those that view the car as a recreational tool as opposed to a mobility device.

Niche manufacturers like Porsche, Ferrari, Lamborghini and others are lifestyle brands offering sensory driving experiences to users as opposed to mobility companies. It is highly likely that some people will seek to retain individual ownership for pleasure - and it seems these companies know that.

Ferrari announced in 2016 that it would not build a self-driving car. The company sees a future in hybrids and smaller engines but emphasises that the experience of driving is what compels people to purchase a Ferrari.

Owning a vehicle in the future will also depend on where autonomous services will be available. Certainly inner cities will benefit at first from the introduction of robo-taxis, but the difficulties in mapping the entirety of Australia in a suitable form for fully autonomous vehicles may be difficult and could take some time. However, this will only impact vehicles utilising some types of technology.

This could mean a delay in the uptake of autonomous vehicles in some rural areas due to 'last mile' capabilities (autonomous technology may not be available or suitable for some road or surface conditions for several years). WiFi connectivity in regional areas also presents as a good example of a barrier that could hinder mass adoption.

The technical barriers to autonomous vehicle adoption in rural areas is particularly important as the deployment of autonomous vehicles on arterial roads may be only a simple step forward from adaptive cruise control. On-demand, autonomous vehicles may also be the first ever real alternative to car ownership in these locations.

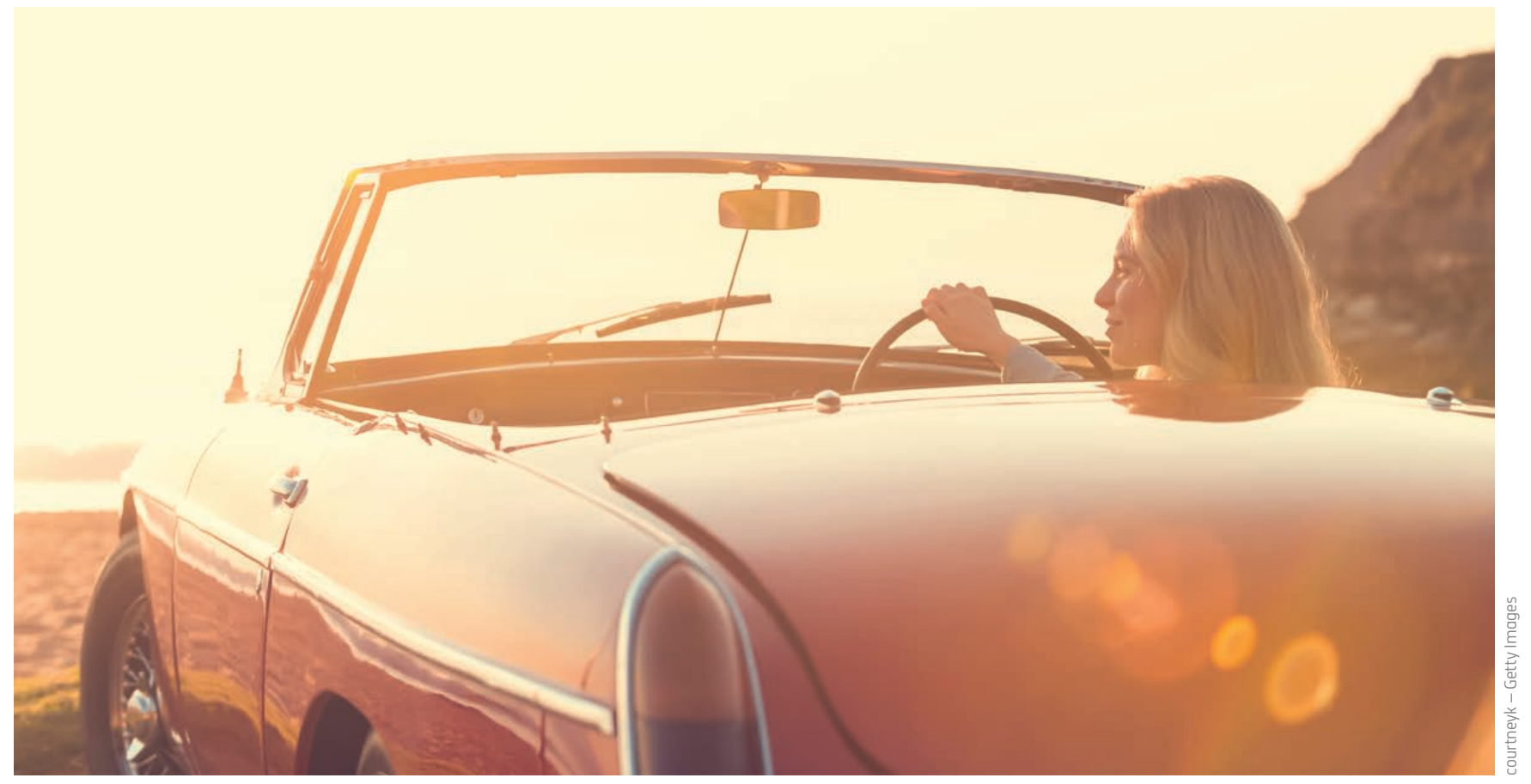




\section{What type of car-use services can we expect?}

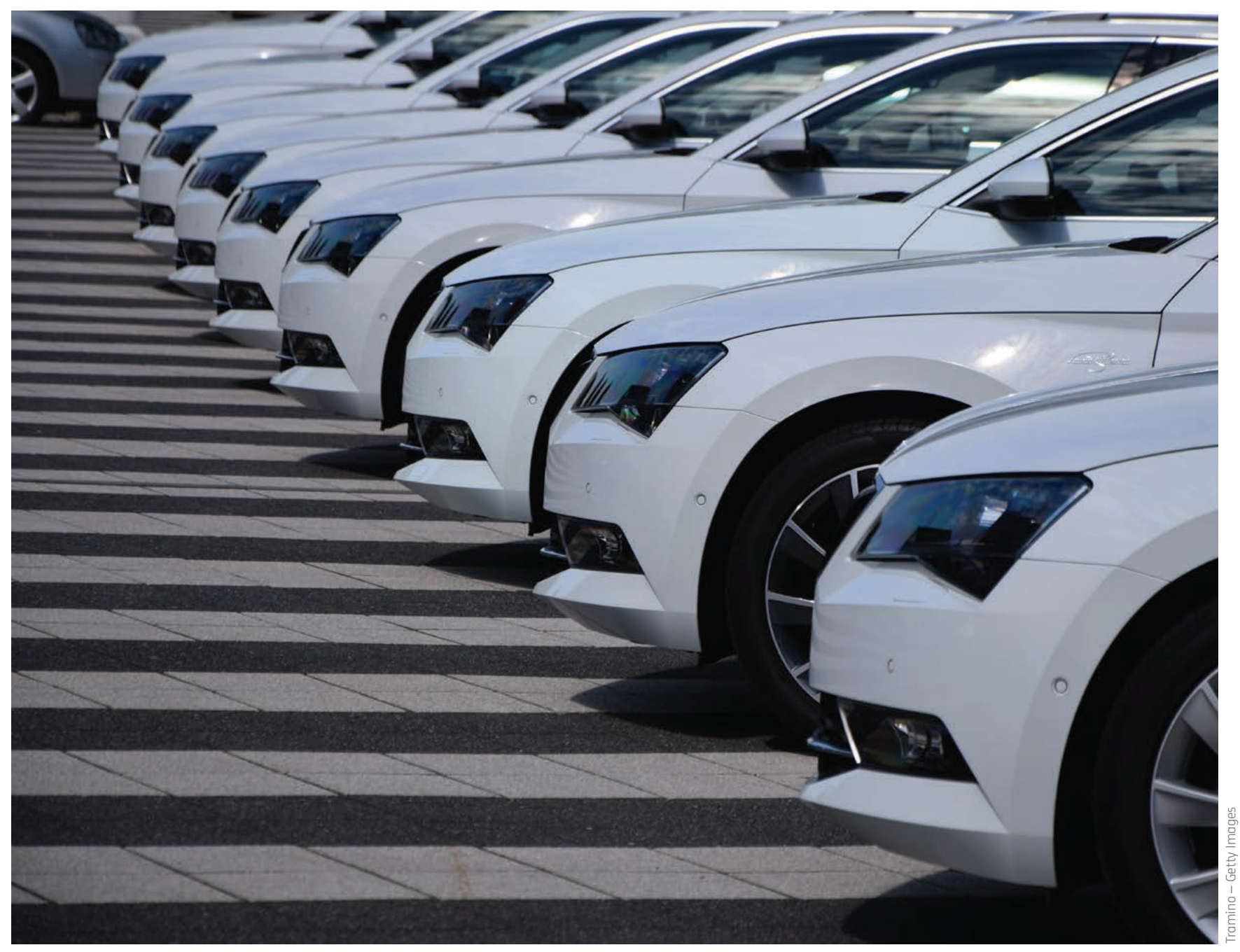

If only a select group of people will own vehicles, where will we lease our vehicles from?

Mobility could be offered through a range of subscription or club-based services once there is no need to own a private car. Some of the models that may be available include:

Captives - A captive will be an OEM subsidiary that will offer a range of vehicles to consumers as a subscription service within the OEM's product range (Tesla have signalled their preference for this model).

Specialists - A specialist will be a mobility company that provides a certain type of product, such as a long distance vehicle, a holiday vehicle, or a luxury vehicle from a variety of different brands (similar to the model of holiday and campervan rental today).

Leasers - A leaser will focus on fleet subscriptions to companies (such as Invers which was established in Germany in 1993).

Generalists - A robo-taxi town and city operator multiple vehicles as a hail-and-ride service (this seems a potential option for Uber).

Co-operatives - A small user-owned car sharing club, which may be popular in regional communities, outlying suburbs and small towns (similar to the Car Next Door car share model). 


\section{How autonomous vehicles interact with wider transport policies}

While the previous section looked primarily at how auto mobility will be affected by the move to an autonomous and connected vehicle future, we should now turn to how this will be part of the wider mobility network of a city, town or broader geographic region. In other words - how autonomous car based mobility will form another mode of intermodality.

A number of groups have attempted to describe future transport and mobility scenarios. Following is a précis on how other organisations have begun to think about how mobility in our cities could eventually work and how autonomous vehicles are integrated.

\section{The Boston Consulting Group}

The Boston Consulting Group have framed their future of mobility on the city, based on how a city may develop depending on what mobility policies a municipal government will implement.
In the first scenario, an autonomous vehicle is used much like cars today. Primarily, they would be owned by most citizens, with multiple vehicles within one household. This could be described as a "business as usual' approach with limited involvement from policy makers. As we have seen, however, this is not the progressive future the OEMs are envisioning. What this perhaps describes, though, is the very beginning of the introduction of autonomous vehicles in 2025 .

The second scenario is that self-drive vehicles rule the streets but are still owned primarily by individual users, and autonomous vehicle use is encouraged by regulators.

The third and fourth scenarios are similar and present scenarios where privately-owned vehicles are actively discouraged and fleets of self-driving vehicles are the primary mobility choice.

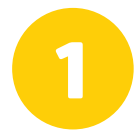

The premium car that drives itself

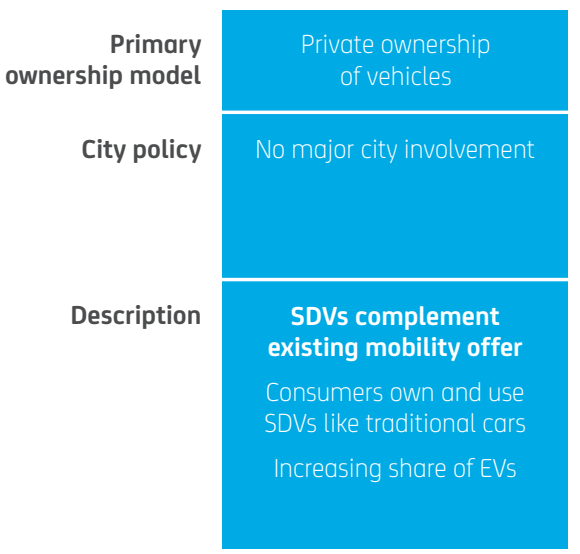

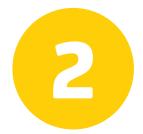

SDVs rule the streets

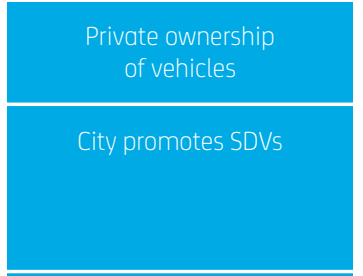

SDVs replace most cars Private SDVs replace most traditional cars and some public-transportation options Increasing share of EVs

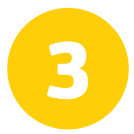

Robo-taxis
take over

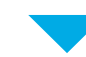

Fleet ownership by a mobility provider

City imposes disincentives to discourage private-car ownership and promote EVS and SDVS

Electric-SDV taxis are the primary mobility option Private cars become rarities within the city; citizens use shared, electric taxis; SDVs replace some buses

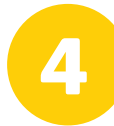

The ride sharing revolution

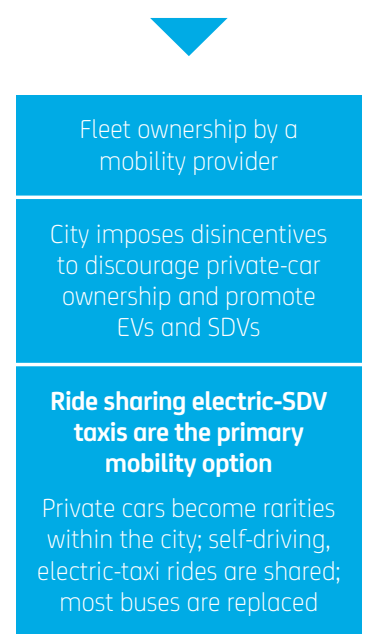




\section{Deloitte}

Deloitte envisages four future scenarios that could happen based on current trends:

1. Incremental change - This vision of the future sees private ownership remaining the norm as consumers opt for the privacy, flexibility, security and convenience that comes with owning a vehicle. While incorporating driver-assist technologies, this future state assumes that fully autonomous drive doesn't completely displace human-controlled vehicles any time soon.

2. Shared driver-driven - The second future state anticipates continued growth of shared access to vehicles through ride sharing and car sharing. Economic scale and increased competition drive the expansion of shared vehicle services into new geographic territories and more specialised customer segments. As shared mobility serves a greater proportion of local transportation needs, multivehicle households can begin reducing the number of cars they own, while others may eventually abandon ownership altogether.

3. Personally owned autonomy - The third state is one in which autonomous drive technology proves viable, safe, convenient and economical, yet private ownership continues to prevail. Drivers still prefer owning their own vehicles but seek autonomous functionality for safety and convenience. This future will see a proliferation of highly-customised, personalised vehicles catering to families or individuals with specific needs.

4. Shared autonomy - The fourth future state anticipates a convergence of both the autonomous and vehicle sharing trends. Mobility management companies and fleet operators offer a range of passenger experiences to meet varied needs at differentiated price points. Taking off first in urban areas but spreading to the suburbs, this future state provides seamless mobility.

\section{NSW Government Future of Transport}

The NSW Government's anticipated Future of Transport report is due to be released in 2017. In anticipation of the report, their Future Transport Roadmap was released in which four different scenarios for the future of mobility have been developed:

1. The (autonomous) car is still king and citizens make individual point-to-point trips in personally owned units.

2. Customers access a broad range of automated, ondemand and mass transport modes with dynamic demand management and integrated payments.

3. Customers use an extended public transport active and flexible shared-service network where autonomous vehicles are for specific highproductivity use only.

4. Customers choose where they wish to work, shop, learn, socialise and be entertained. Technology enables them to minimise the time spent on these activities as services are 'delivered' in or near the home.

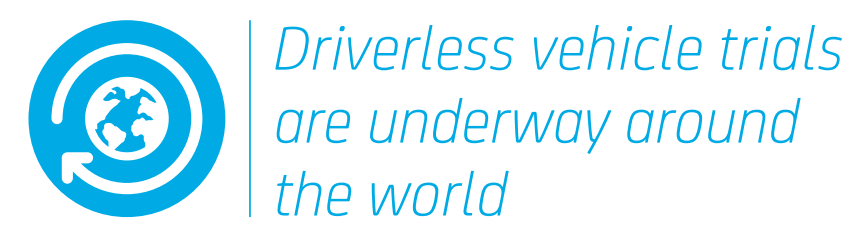




\section{Challenges and opportunities}




\section{The impact of door-to-door public transport (Mobility-as-a-Service or MaaS)}

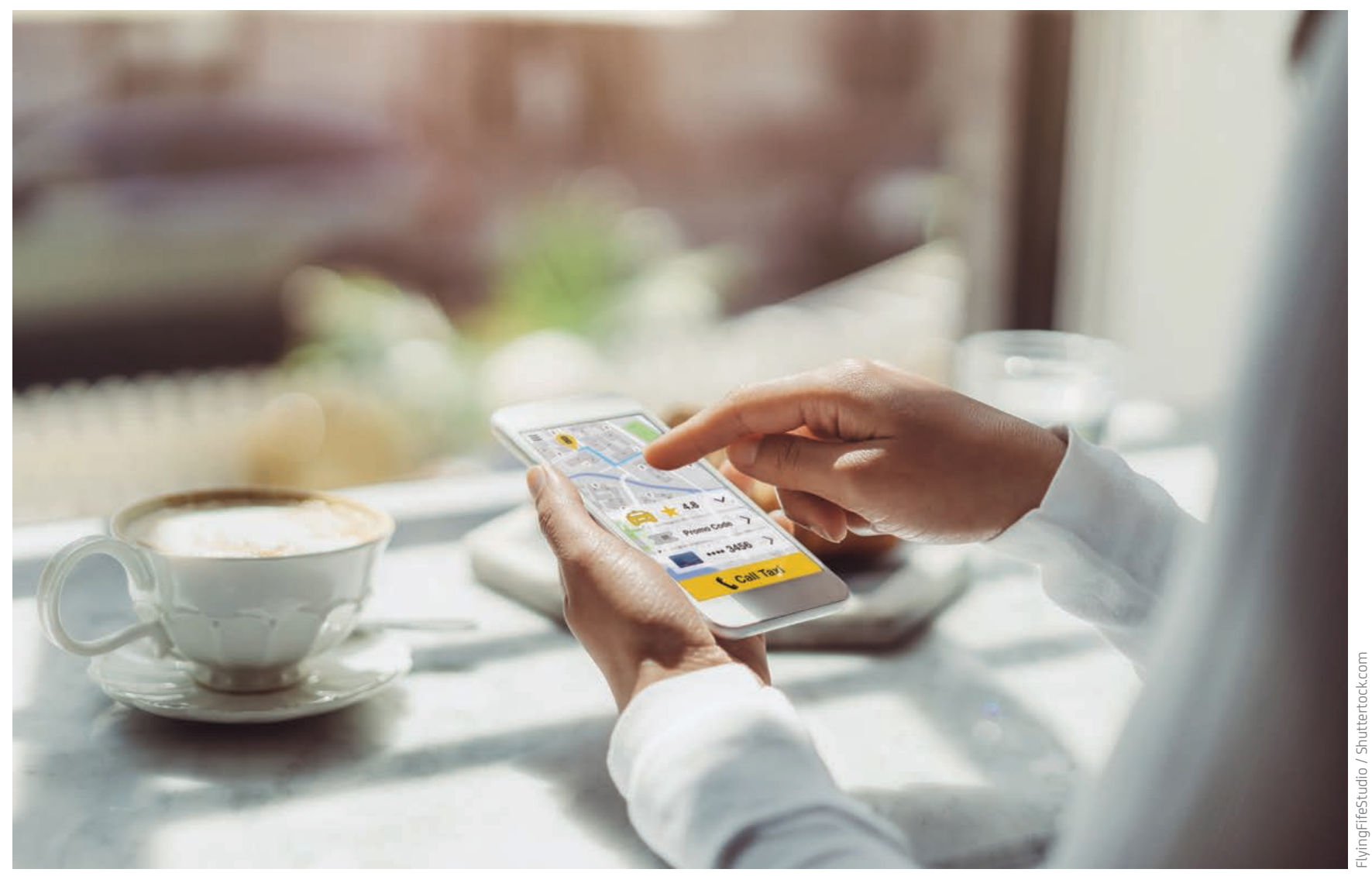

For OEMs, MaaS (or door-to-door public transport) represents both a challenge and an opportunity. Since the global financial crisis in 2008, OEMs have had to re-think their business models in order to compete with challenges posed by a contraction in purchasing power and consumer credit. Now that global sales growth seems to be back on track, they are challenged by something that is not just a mere trough in the business cycle - the challenge is now a change that impacts the very existence of their business model.

The need to compete is also a significant commercial opportunity: the global car market is worth US\$2.3 trillion per year, but the transport services market is worth more than double that at US $\$ 5.4$ trillion per year. ${ }^{47}$ Ford has estimated that in the future, the sale price of a vehicle will represent only 10 per cent of whole-of-life vehicle value.
PwC has estimated that there will be $\$ 120$ billion worth of value up for grabs in this market by 2030. OEMs will have to watch out, lest being overtaken by new entrants with more agile and flexible approaches to product development. ${ }^{48}$

But why is this the case? Why has such threatening disruption come to an industry that has fought off major challenges in the past?

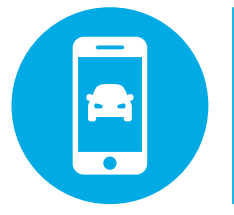
The transport services market is worth US\$5.4 trillion per year 


\section{Competition from the outside}

Investment by OEMs in new technology is a response to what is being developed outside the traditional vehicle industry. In other words, this is not intra-industry competition for market share, it is instead a fight for the survival of the vehicle industry as they know it against highly innovative technology start-ups and some of the world's largest other established companies such as Google and Apple.

The disruption mentality is something that OEMs struggle with compared to new entrants in car mobility. The challenges to OEMs is significant - new high tech entrants simply scale faster and are not worried about the historical way of doing things.

The disruption is based around the utility function a consumer derives from their choice of mobility. New technology and services are only useful if they improve the lives of consumers. That improvement could be financial, material, lifestyle-based or otherwise. But it has to be an improvement. For nearly 75 years, the car has been seen as the pinnacle of mobility.

The rapid rise of companies like Uber and Lyft demonstrate the enormity of the challenge. Five years ago, many of the companies banging down the gates of the vehicle industry were unheard of, but now some command estimated values above the market capitalisations of OEMs that have been around for nearly 100 years. Factor in the transition into this space of Alphabet (Google) and Apple, and it is clear that OEMs have a real fight on their hands.

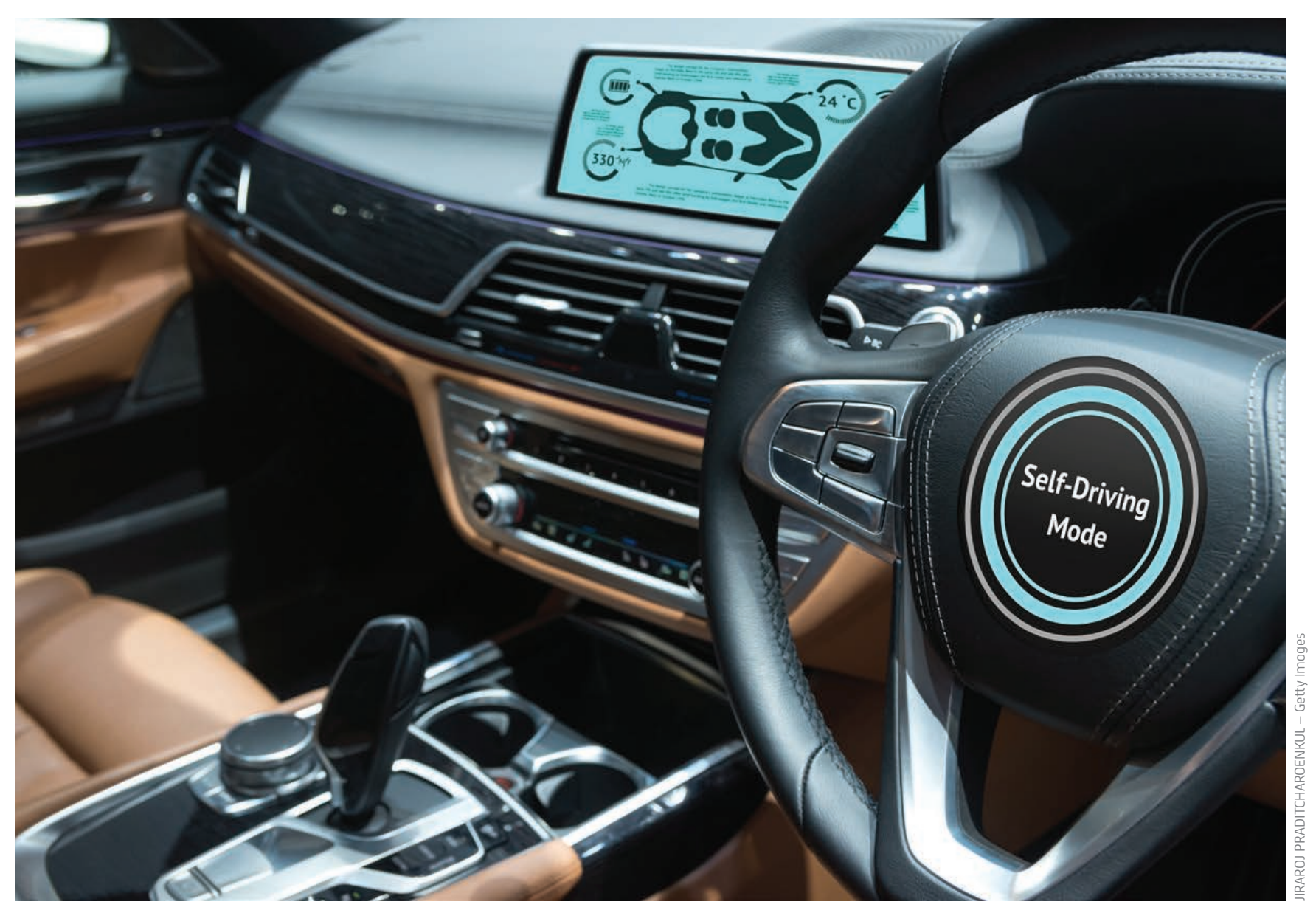




\section{New preferences}

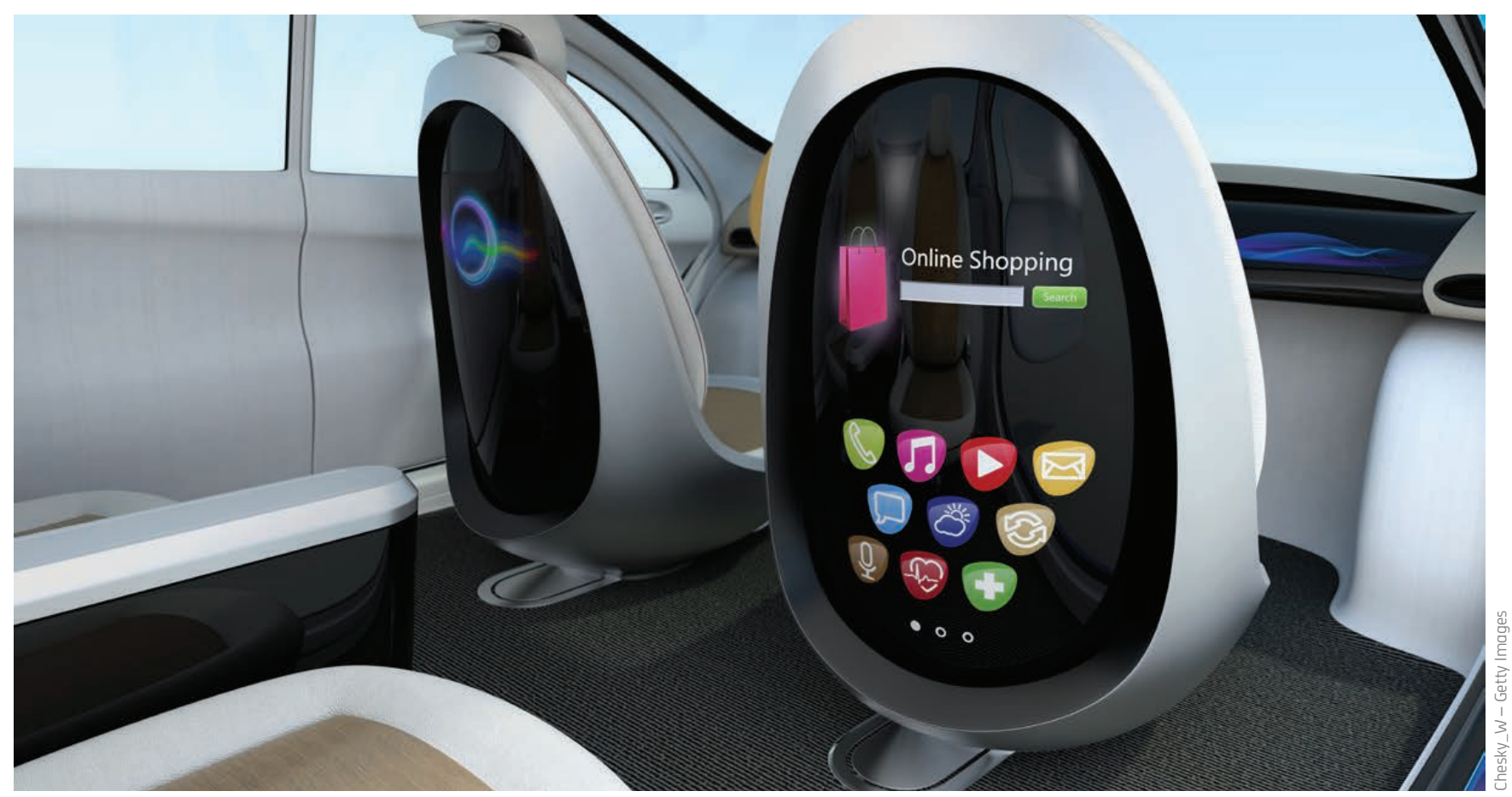

As noted previously, urban customers are increasingly turning away from the traditional motor vehicle. It is hard for OEMs to compete when lifestyles no longer require a car. Further densification of suburbs and the maturing of millennials will only exacerbate this trend.

In the City of Sydney LGA, around 35 per cent of households do not own a vehicle - whereas for greater Sydney the figure is 12 per cent. ${ }^{49}$ This could explain the growth of car sharing in the City of Sydney - but as urbanised environments offer important agglomeration benefits and people move towards them, it is easy to understand why OEMs are a little nervous.

OEMs currently have to deal with a large number of regulatory and policy constraints when putting their vehicles on the road. For Google and Apple, an autonomous future could potentially see lessened compliance requirements. With fewer moving parts, low to zero emissions, and the absence of a human driver, autonomous vehicles may not be subject to some of the regulatory constraints placed on today's internal combustion automobiles.
Perhaps, though, new start-ups and entrants simply do not care much for regulatory barriers. Uber for example has an explicit goal: to end the need for car ownership. Uber realised that this could be done by tapping into the availability of an incalculable amount of consumer surplus around the world that was there for the taking. This is because the highly regulated taxi market with strong barriers to entry had become complacent due to a lack of competition. Markets were often regulated with price floors, ceilings, or in some cases, both.

In some regulatory environments, Uber drivers and users that were technically breaking the law had regulators turning a blind eye because it was a way to overcome a powerfully entrenched industry that was incapable of reform, and one which offered poor services to customers.

These issues demonstrate that OEMs will have to fundamentally shift their mentalities if they wish to eventually compete and survive. As PwC has put it: we are in for a battle of the business models between incumbent OEMs and the new players in the next 15 years. ${ }^{50}$ 

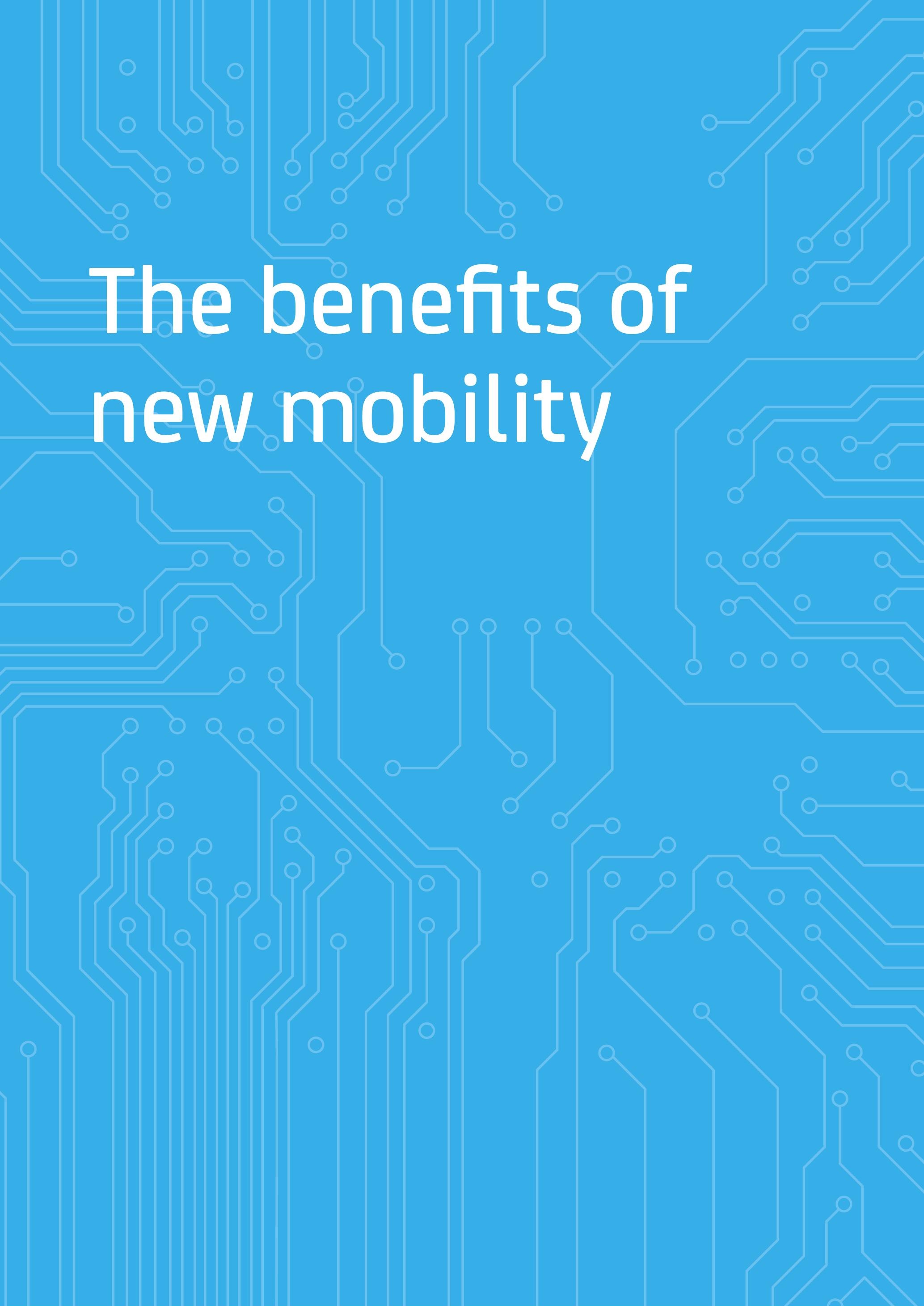
The growth of connected and autonomous vehicles and the move towards a new form of mobility will usher in enormous benefits that are likely to be broadly spread throughout the community.

Increased choice and convenience will allow consumers to transition away from owning their own vehicles if they feel the traditional model of ownership does not offer value for money or peace of mind.

Yet some of the biggest beneficiaries of an autonomous vehicle future will be those who cannot access a car presently because they are unable to drive.

People with limited mobility such as the elderly or people with disability will perhaps be the greatest beneficiaries from the advent of autonomous vehicles. Provided that transport hubs are accessible, people with epilepsy, narcolepsy, sensory disability, as well as the elderly and the young who are unable to hold a traditional driver licence will be able to use point-topoint transport that meets their needs.

Remote Australia, where the majority of residents are indigenous, has a number of challenges that exacerbate social isolation and service delivery. Over 70 per cent of indigenous Australians living in remote locations have no access to public transport and one in ten indigenous adults in Australia have mobility issues in getting where they need to be.

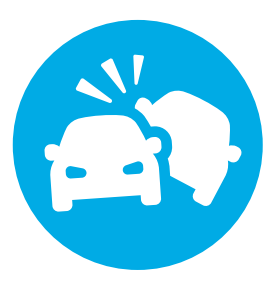

Greatly improved safety

$94 \%$ of accidents are caused by human error

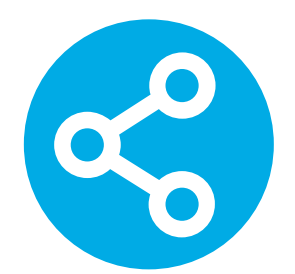

\section{Improved transport interconnectivity}

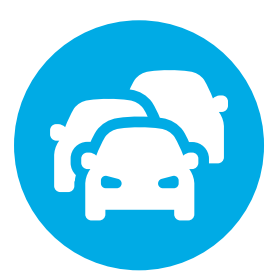

Reduced congestion

Congestion will cost NSW $\$ 6.9$ billion in 2017

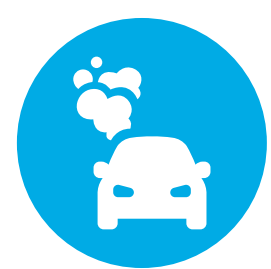

Reduced pollution and emissions

Reducing transport energy consumption by up to $90 \%$

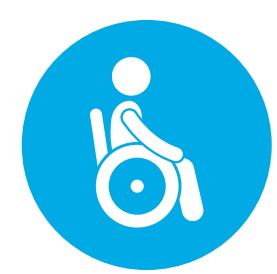

Greater mobility options

For elderly, young and disabled users

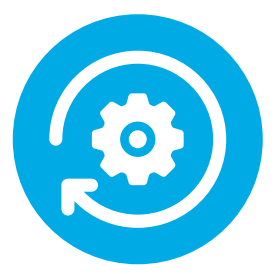

Greater convenience, efficiency and reliability

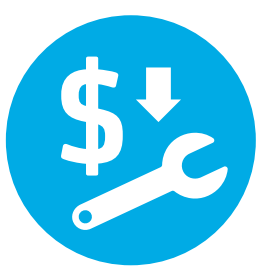

Reduced costs and maintenance requirements 


\section{Improved safety}

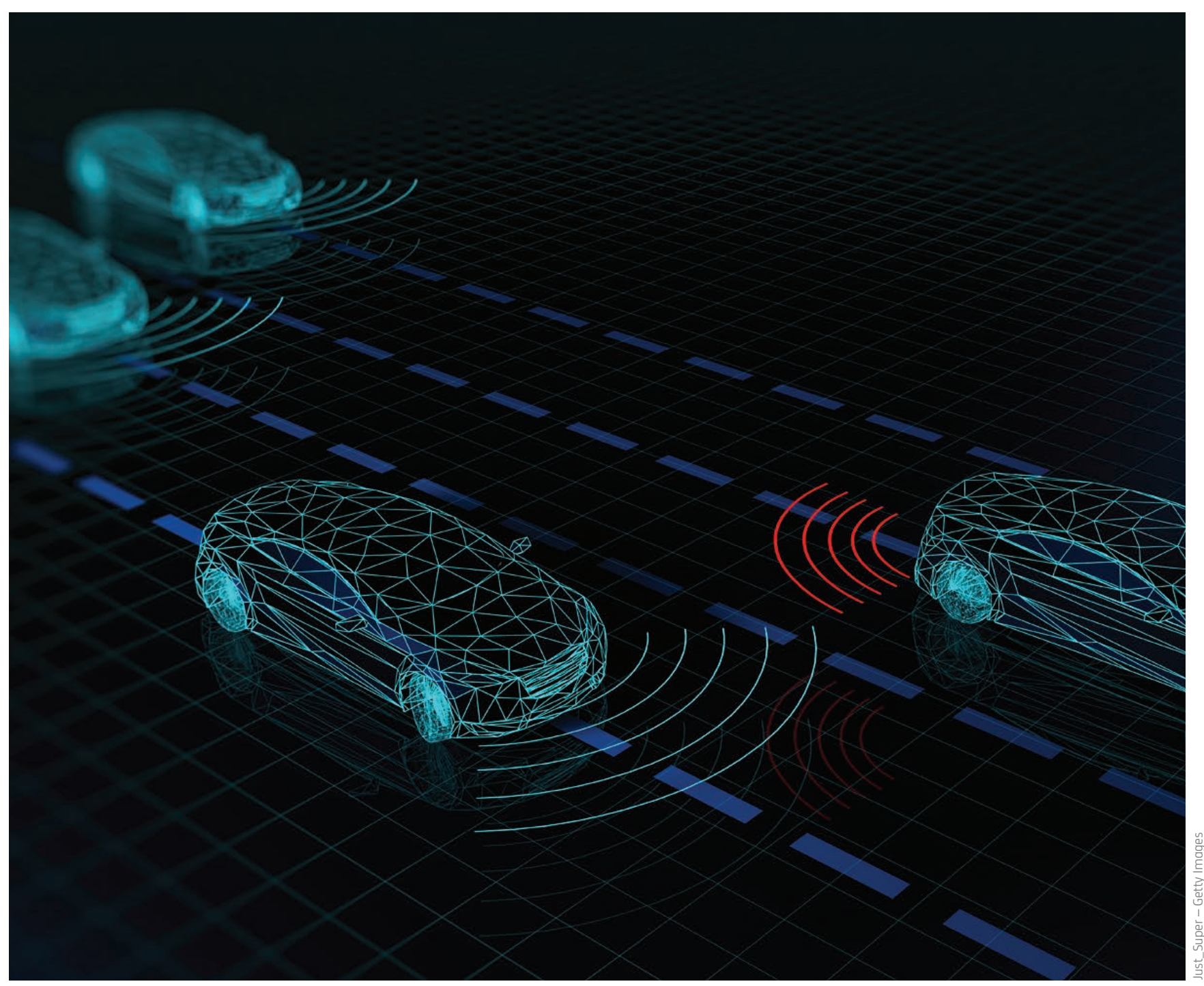

Community safety will be a big winner in an autonomous mobility future. At present, 94 per cent of accidents are caused by human error. ${ }^{51}$ When we reach Level 4 and Level 5 autonomy in the future, this statistic will significantly diminish or disappear altogether.

A study by the Eno Centre for Transportation estimates that if 90 per cent of cars on American roads were autonomous, the number of accidents would fall from 5.5 million per year to 1.3 million per year, and that road deaths would fall from 32,400 per year to 11,300 per year.
This is a significant reduction that will only further improve as autonomous technology and safety develop. This will result in changes in the structure of the medical industry and health sector as the rate of trauma reduces.

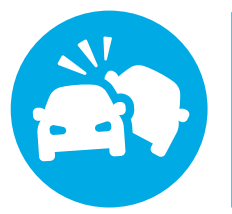
$94 \%$ of road accidents are caused by human error 


\section{Environment}

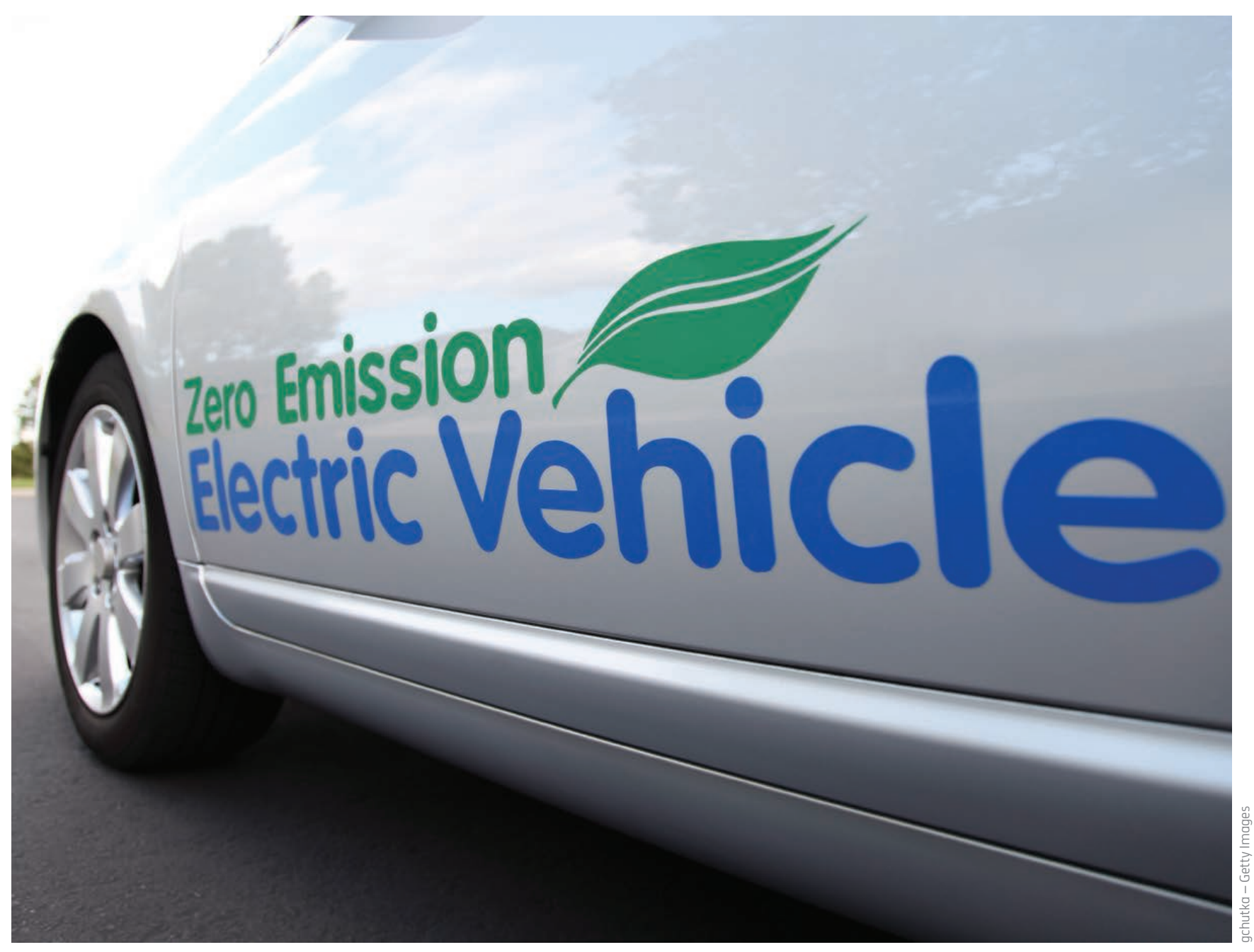

The environment also has the potential to benefit greatly from an autonomous future, given we expect lower fuel usage and lower emissions, reducing the amount of pollution expended. Due to the arrival of autonomous vehicles, some estimates contend that transport energy consumption could be reduced by up to 90 per cent compared with current levels. ${ }^{52}$
With significant reductions possible, our urban places of work and play will become cleaner and healthier, and lead to better lifestyle outcomes and improved productivity. 


\section{Congestion}

In 2017, congestion will cost NSW \$6.9 billion - and this is expected to increase to $\$ 12.6$ billion by 2030 . Despite recent significant investment in infrastructure, NSW still possesses an infrastructure backlog of at least $\$ 100$ billion.

Our increasing population will continue to place pressure on our urban areas, which continue to develop and expand.

Autonomous vehicles have the potential to greatly improve congestion by taking private cars off the road and increasing our mobility options. With smart technology in place, many efficiencies can be implemented.

Fleets of autonomous vehicles could replace or complement other modes of transport, and undertake trips more effectively by optimising acceleration and braking, and rerouting when necessary to avoid converging traffic and congestion hotspots.

A study by the University of Texas estimates that 90 per cent penetration of self-driving cars in America would be equivalent to a doubling of road capacity and would cut delays by 60 per cent on motorways and 15 per cent on suburban roads. ${ }^{53}$

Research by Dan Fagnant of the University of Utah, drawing on traffic data for Austin, Texas, found that an autonomous taxi with dynamic ride sharing capabilities could replace ten private vehicles. This is consistent with findings that suggest one share car typically removes 9 to 13 private cars from the road..$^{54}$

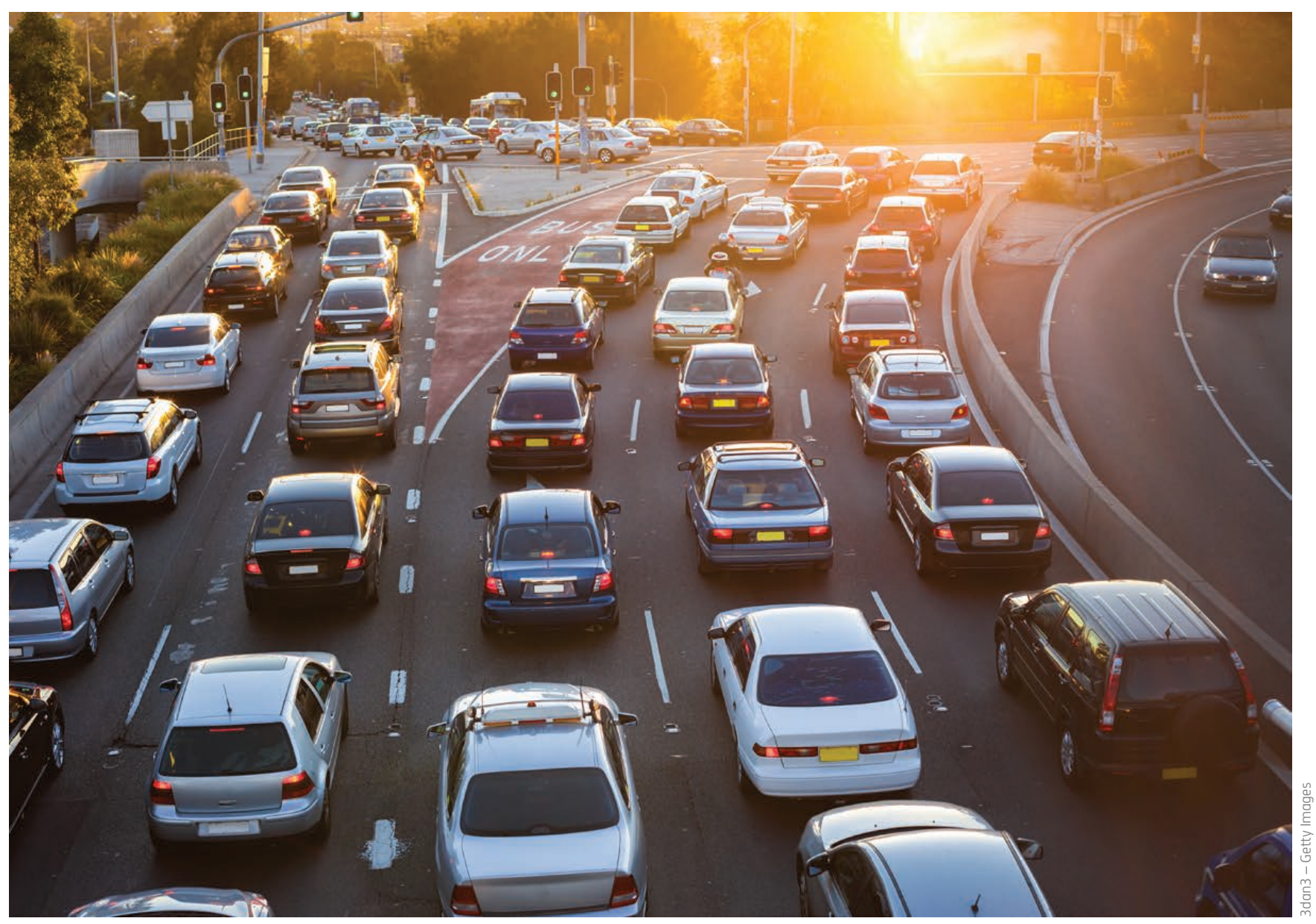

53. http://worldifeconomist.com/article/12123/horseless-driverless

54. http://www.newgeography.com/content/005024-preparing-impact-driverless-cars 


\section{Productivity}

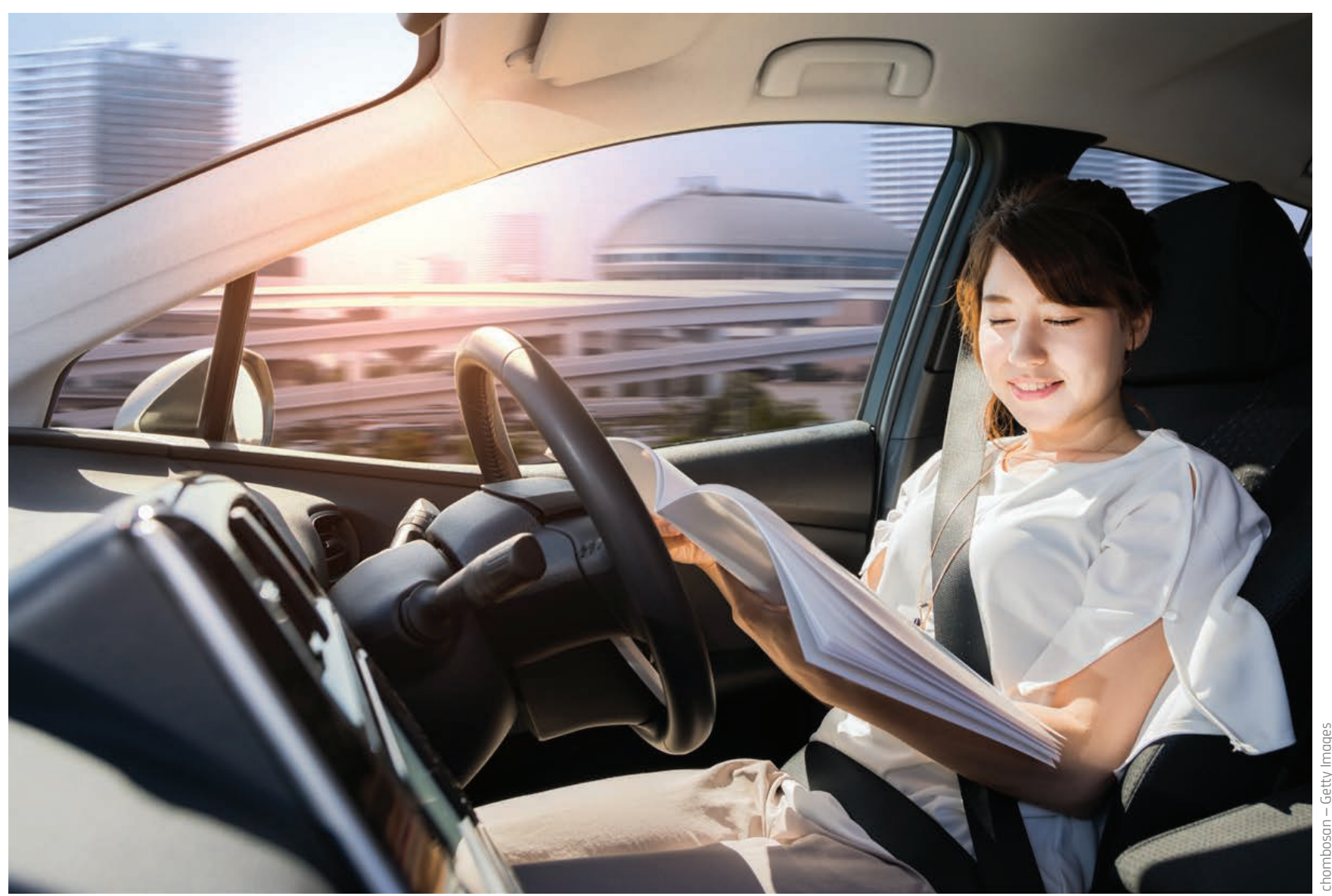

We currently spend a significant amount of time in our cars, especially in congested urban areas. While autonomous vehicles will ultimately reduce travel times, we will still be required to move from $A$ to $B$.

Presently, we can't do too much in the car if driving. Listening to music or participating in a hands-free call is about the limit of what can be achieved.

In a Level 4 or Level 5 autonomous vehicle, however, drivers will become passengers, and it is reasonable to expect that access to technology will improve as autonomous vehicles enter the market.

Imagine trading the driving task with grocery shopping via the internet, or getting a jump start on the working day. Perhaps an extra 30 minutes sleep or the opportunity to catch up on the latest news?
If commute time could be freed up for more productive work, we could start charging our employers and clients for the time it takes to transit to the office, or perhaps even take the time to learn a new skill or language.

We can get back to reading books, catching up on the phone with friends, getting ahead of deadlines and improving ourselves as people..$^{55}$

Whatever it is individuals like to do, there will be opportunities in autonomous vehicles to increase personal productivity.

The myriad of benefits that come together due to an autonomous vehicle future will significantly enhance the liveability of our cities. 


\section{What change is required?}


A future where car ownership is reduced would have substantial mobility access benefits and put downward pressure on the cost of mobility and transport for people and businesses.

Delivered optimally with behavioural incentives, including an efficient road access pricing regime, future shared mobility could provide significant wellbeing and liveability benefits.

But the path to this future is not easy and is fraught with political and institutional barriers.

This section seeks to lay out a number of the already identifiable barriers to a future where car ownership is reduced. Many of these barriers are actually impediments to the introduction of autonomous vehicles. But there are a number of barriers that are currently inhibiting the growth of technology including electric vehicles and car sharing which could make our cities much better today, and allow us to get ready for the future.

Governments need to set an overarching but flexible mobility policy framework. That way policy design and solutions are nimble and can be adapted over time as new challenges emerge and old ones are overcome. The three tiers of government around Australia will need to work together and integrate a number of their policy settings in order to capitalise on what the future has to offer for its citizens.

Experience suggests this is easier said than done. However, it is crucial in order to capitalise on the benefits that MaaS offers. Governments have a lot of decisions to make, but the time to start making those decisions is now.

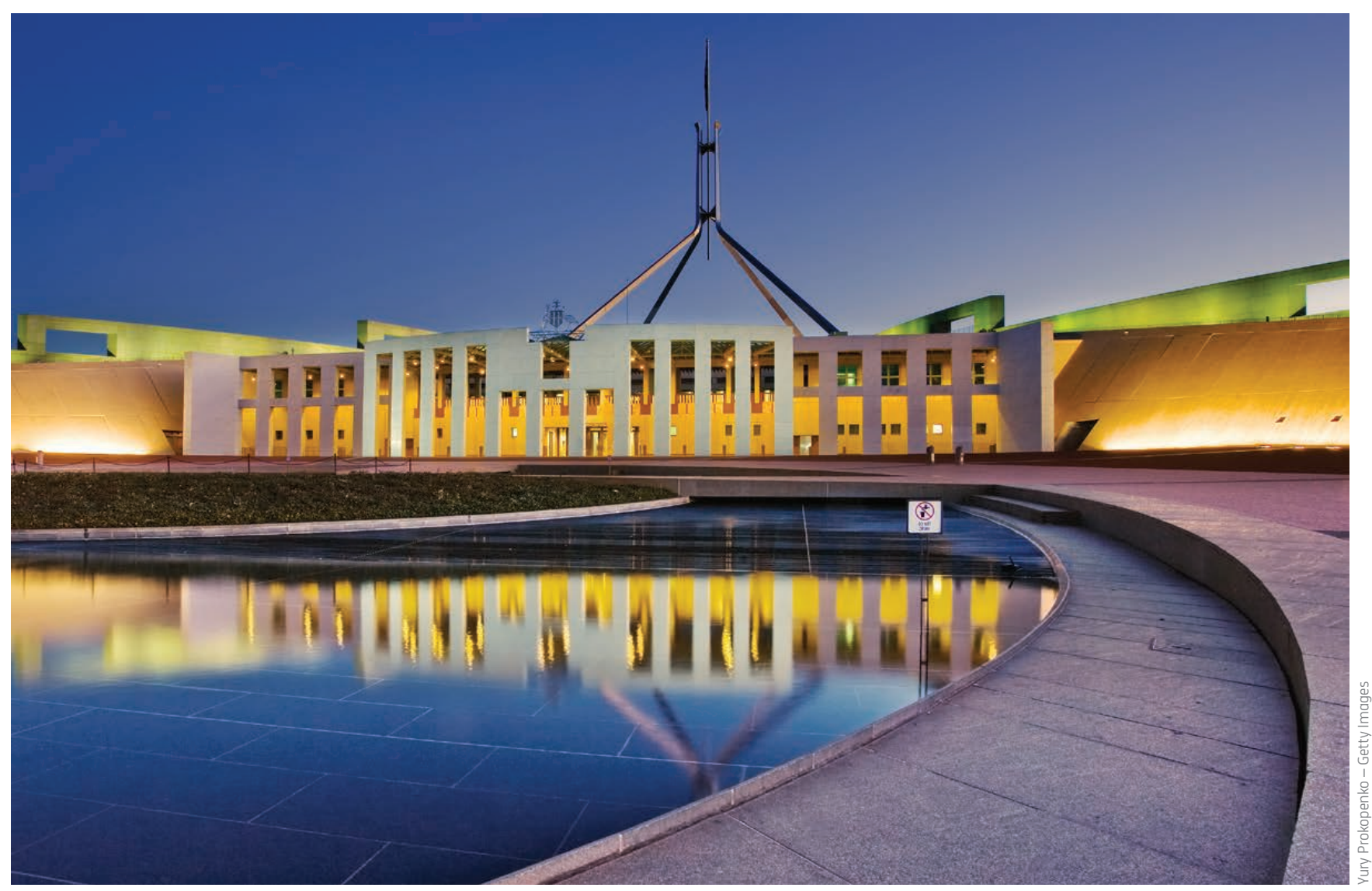




\section{What questions need to be asked?}

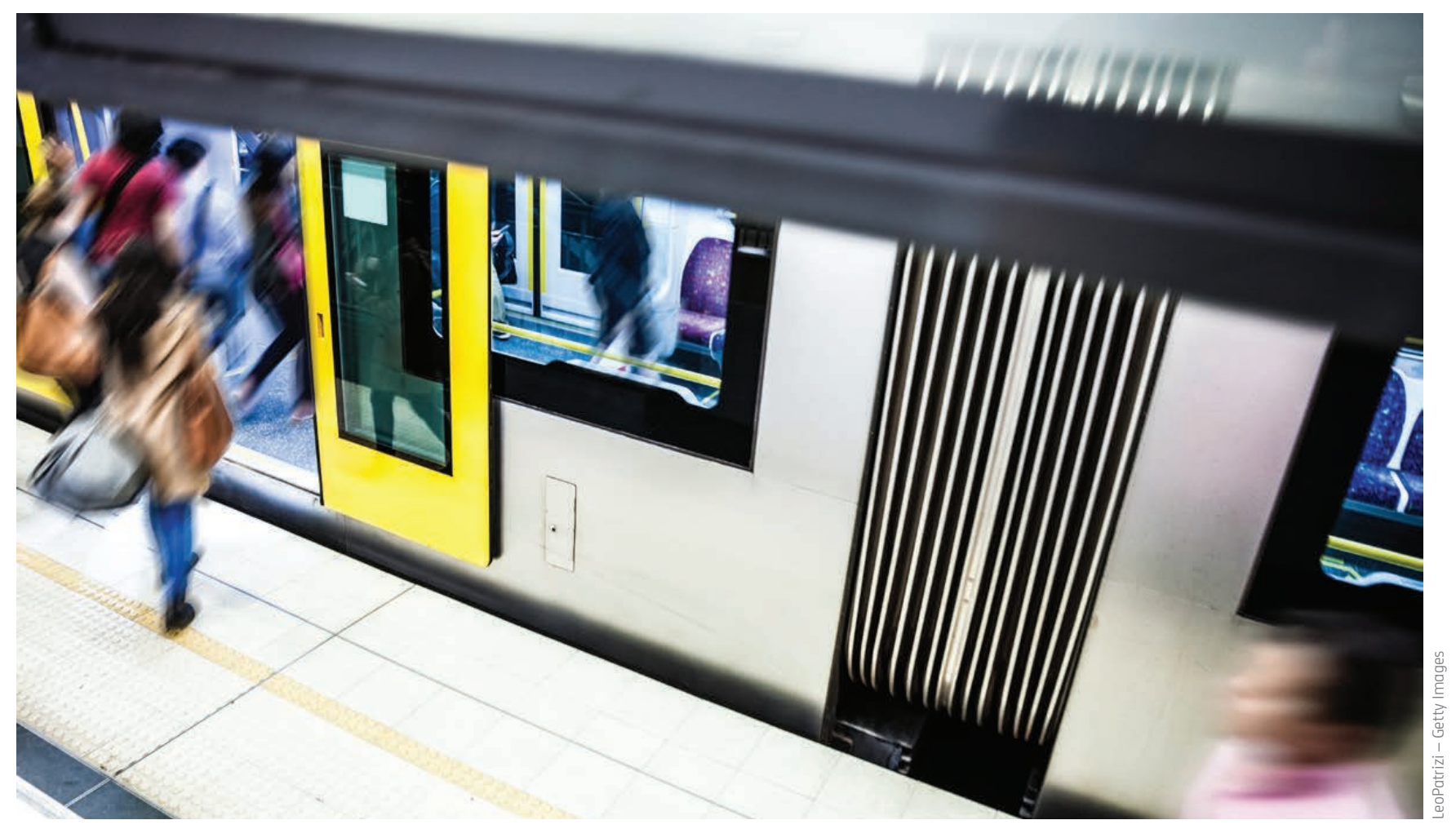

Governments must begin to respond to industry and societal trends and set comprehensive mobility policies for the future. These policies need to promote an overall mix of mobility options and choices that can be connected through mobile technology and book and pay systems.

Key questions for policy makers include:

1. Whether or not to promote or incentivise the take up of connected, electric or autonomous vehicles separately or combined.

2. Whether or not to set an active goal of no human driven vehicles.

3. Whether to prioritise new public transport infrastructure over road infrastructure.

4. How to price a new road network for access, use and finance repayments.

Governments over many years have maintained separate approaches to mobility options such as rail policies, freight policies and road policies, and divided them into separate portfolios. Even if they are still part of the same government ministry, there has rarely been an effective level of coordination across portfolios. Autonomous and connected vehicles, however, present new capabilities which will challenge conventional thinking around separate road, rail, transport and infrastructure portfolios. Policy makers and regulators should not prioritise one form of mobility over another as the future transport challenge will require the efficient provision of all mobility modes to optimise the consumer experience.

As mobility becomes more interconnected, distinctions will begin to disappear. One simple change could make all the difference - doing away with separate roads and transport portfolios and instead having one mobility portfolio. Governments need to take a holistic view of mobility, where public transport and car use are complementary mobility options rather than mutually exclusive ones. 


\section{Public and consumer acceptance}

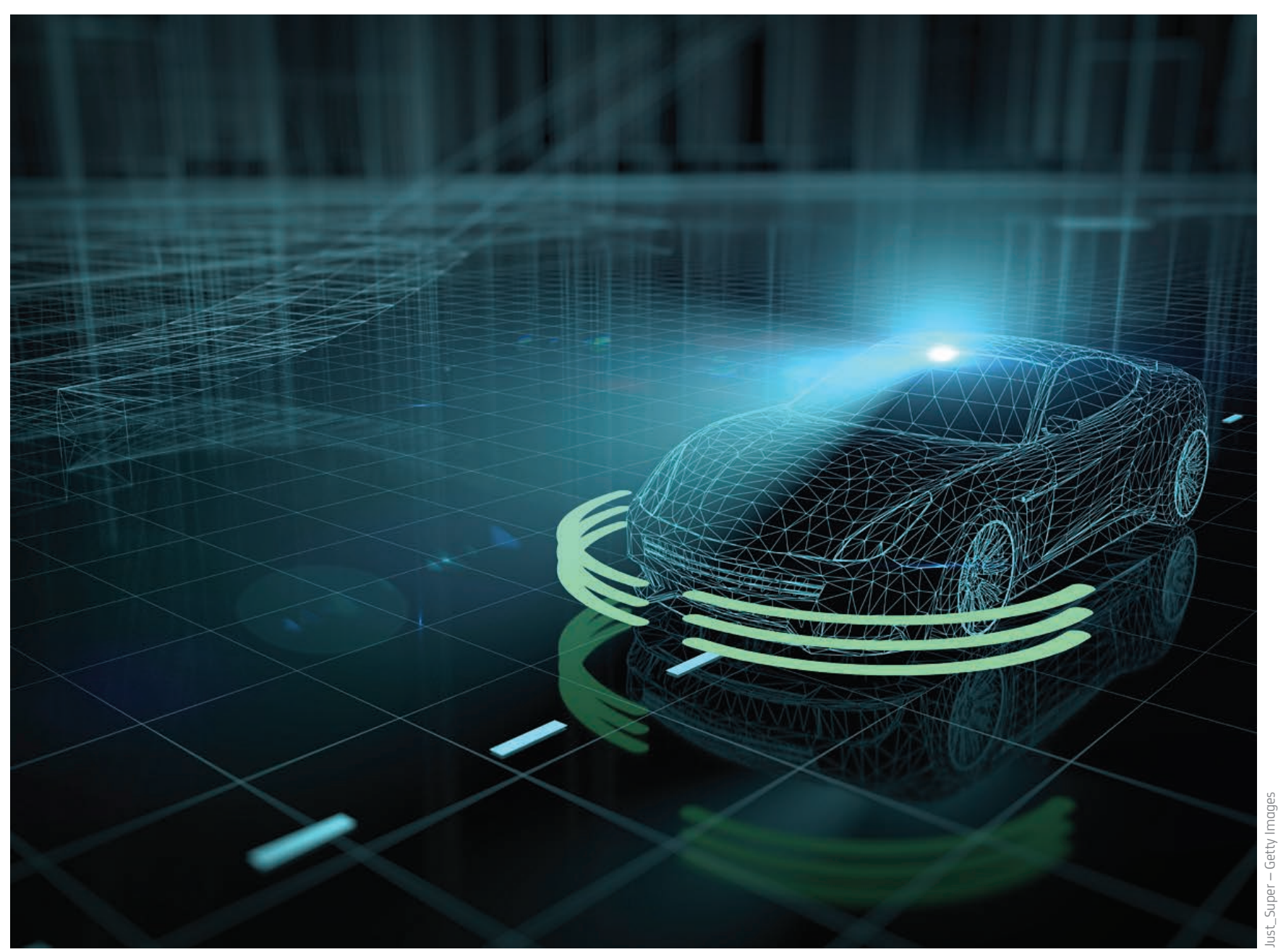

Will the public accept an autonomous vehicle future? Autonomous vehicles could make mobility much cheaper, but will consumers decide that this suits their desires, and will the public trust the technology given they would have no control?

Social attitudes and consumer preference are central to this report. As we have stated, auto mobility is a key part of Australian culture, and overcoming this will not be easy.

Ultimately, consumers need to be in charge of their own destiny when it comes to the future of car ownership. Consumers will weigh up many considerations as to what benefits them and their family the most when deciding to continue or dispense with private car ownership. It would be naive to suggest that this decision will be purely financial. Some may value owning and maintaining their own autonomous vehicle beyond the financial savings resulting from on-demand services. This is about personal choice and preference rather than financials. In many instances, the utility of private vehicle ownership is well entrenched in Australia. ${ }^{56}$

A similar theme emerges with the move to autonomous vehicles from driver-based vehicles. Some people may enjoy driving and be reluctant to switch to a more autonomous future. These views must be respected by governments and planners as we move forward. 


\section{Road rules and regulations}

In 2015, the Council of Australian Governments' Transport and Infrastructure Council tasked the National Transport Commission (NTC) to undertake a review of regulatory barriers to the introduction of autonomous vehicles and automated rail. This became the Regulatory Reforms for Automated Road Vehicles report which was released in 2016.57

That report found that there are no legislative barriers to automated rail in Australia. Indeed, the NSW Government plans to introduce automated rolling stock on the Sydney Metro North West (previously known as the North West Rail Link) and Sydney Metro West projects. However, astonishingly the report found that more than 700 laws and regulations are likely to need to be amended in order to allow autonomous vehicles on Australian roads. The good news is that Australian transport ministers have agreed to a reform program that should see fully autonomous vehicles able to operate on Australian roads from 2020.

Already, we have seen South Australia introduce legislation in 2016 to allow autonomous vehicle trials, while the NSW Government recently confirmed they would expect to legislate for autonomous vehicle trials in 2017, which the NRMA subsequently supported in its submission to the $2017 / 18$ State Budget.

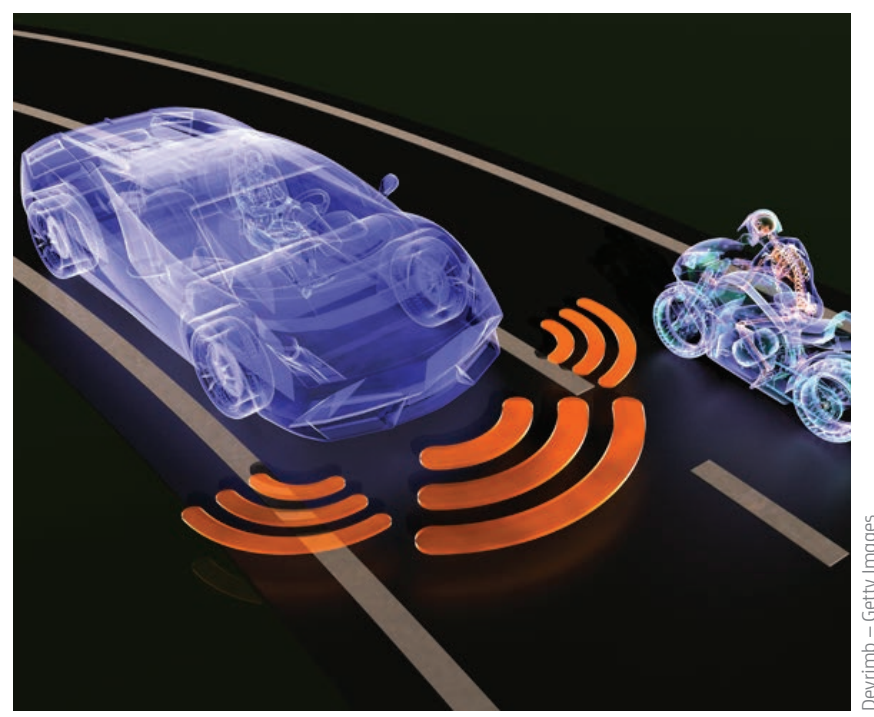

The NTC released a discussion paper in November 2016 entitled National guidelines for automated vehicle trials which considered issues pertaining to the introduction of nationally consistent autonomous vehicle trial guidelines. ${ }^{58}$ We should not underestimate the legislative process that will need to be managed to allow for a holistic national reform that will allow autonomous vehicles on our public roads.

Regulators have been caught on the back foot in Australia by autonomous vehicles. The recent NSW Parliament Joint Standing Committee on Road Safety (StaySafe) report on autonomous vehicles highlighted this basic issue, noting:

"When we began our inquiry we might have expected to learn about embryonic trials and anticipated changes to which we could respond in good time. Instead, we learned that automated vehicles are already available and technological advances are occurring almost daily'. ${ }^{59}$

However, much work has already been carried out to identify legislative barriers, and departments, representative bodies and other regulators have designed a large program of works to address some of these issues.

Sometimes regulatory decisions that have been made in the past act as a barrier to the uptake or implementation of new technologies. It is often the case that these regulatory barriers are hard to repeal or change due to political impediments. These types of impediments can often be in the form of 'transitional gains traps' where cancelling or amending a regulation may remove economic rent that the instrument provides to a particular set of stakeholders.

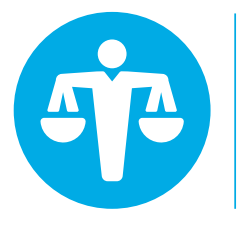
More than 700 laws
and regulations need
amending 
There are multiple examples of this around the world on the subject of ride share regulation. In general, governments have been slow to adapt to ride sharing and in some cases have been outright hostile. This is despite ride sharing having the potential to help achieve government targets in congestion reduction, meeting environmental standards, and offering greater mobility.

The importance of having flexible regulation in Australia was recently highlighted by the KPMG auto industry executive survey for 2016 where Australia was ranked sixth in the world for desirability to launch and trial new products. This was despite only two Australian based executives being part of the survey sample. ${ }^{60}$ If Australian regulations are not reformed to allow autonomous vehicle trials then this desirability could decrease and have a delaying effect on the introduction of fully autonomous vehicles in Australia.

Delivering the best regulatory framework for mobility innovation is reliant on knowledgeable legislators and regulators making purposeful decisions that allow for the best future operating environment. A recent parliamentary inquiry in New Zealand highlighted this issue when the representatives of the committee failed to understand the operating nature of ride share company Uber, ${ }^{61}$ despite it having a significant media profile and being operational in the country since 2014 .

Another example are the innovation-destroying rules that do not allow the Renault Twizy - a compact electric car with zero emissions - to be driven on Australian roads, despite it being able to travel up to $100 \mathrm{~km}$ on full charge.

While classified as a quadricycle in Europe, there is no similar category in Australia. It is, therefore, required to conform to local passenger vehicle standards despite performing the job of an electric scooter, hence placing a significant roadblock in the way of its introduction. ${ }^{62}$

A potential future of reduced car ownership will only deliver successful mobility outcomes if there is a widespread move to support autonomous vehicles.
Presently, especially in Australia, there are barriers to unleashing fully autonomous vehicles on roads. Australia is behind Europe and the US when it comes to the adoption of specific policies to introduce electric vehicles into the market.

In some respects, the replacement of a largely privately-owned, petroleum powered fleet with an electric and autonomous fleet will allow for a clean slate for certain regulatory regimes.

The Australian Government has responsibility for design rules for new vehicles, but state and territory governments have jurisdiction over in-service vehicle standards, road rules, enforcement, registration and licensing. There is a risk that this complex regulatory framework will result in inconsistent regulation of automated vehicles across states and territories (similar to the mixed rail gauges of the eastern Australian states during the 1800s) if a nationally consistent approach is not adopted.

Regulators should develop a regulatory environment that allows Australian consumers the ability to try and buy whatever safe automobile manufacturers have to offer. The recent relaxation of import laws is a welcome addition that will be beneficial to consumers in the future.

However, it is not just in the regulation of how autonomous vehicles operate on the road, the regulation of services itself needs to be as light handed as possible to encourage innovation and consumer choice in any potential ride share, car share or subscription services that may eventuate as an alternative to vehicle ownership.

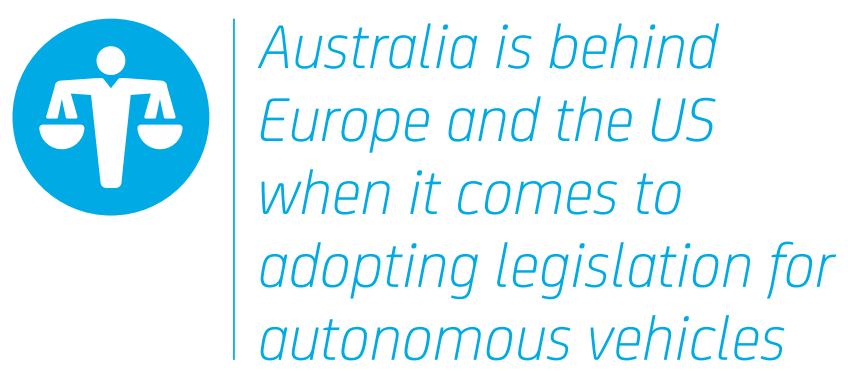




\section{National Policy Framework for Land Transport Technology - Policy Principles ${ }^{63}$}

1. Government decision-making on transport technologies will be based on capacity to improve transport safety, efficiency, sustainability and accessibility outcomes.

2. New technologies should be implemented in a way that is consumer centric (i.e. designed to meet the needs of those using the service). This includes consideration of:

a. options to deliver transport information and services in a way that is consistent and familiar,

b. the diverse needs of travellers, in particular travellers with a disability, vulnerable road users such as cyclists and pedestrians, and users of multiple modes of transport.

3. Where government investment is required to support the deployment of new technologies, that investment will be evidence based, consistent with long-term strategic planning and will deliver value for money.

4. Where feasible, government agencies will avoid favouring particular technologies or applications, in order to encourage competition and innovation. New applications should support interoperability, backwards compatibility and data sharing, and should account for possible future transitions to other technology platforms.

5. Planning for transport technologies will build on existing infrastructure networks (including public transport) and seek to leverage existing consumer devices (such as smart phones) where appropriate.
6. When considering regulatory action, governments will consider low cost approaches such as collaborative agreements or self-regulation before pursuing formal regulation.

7. If required, best practice regulatory approaches will be adopted to ensure regulation is cost efficient, transparent, proportionate to the risk, fit for purpose and done in consultation with affected stakeholders. This includes adopting relevant international or regional standards, unless there is a compelling reason for a unique Australian requirement.

\section{Proposed Amendments}

The NRMA proposes the following amendments to the National Policy Framework for Land Transport Technology - Policy Principles to improve choice, convenience, accessibility and productivity:

2a. options that support informed choice for transport consumers to optimise their journey;

2b. the diverse needs of travellers, in particular travellers with disability, non-English speakers, vulnerable road users such as cyclists and pedestrians, and users of multiple modes of transport; and

2c. access to, travel of and storage of autonomous vehicles and associated technology. 


\section{Infrastructure}

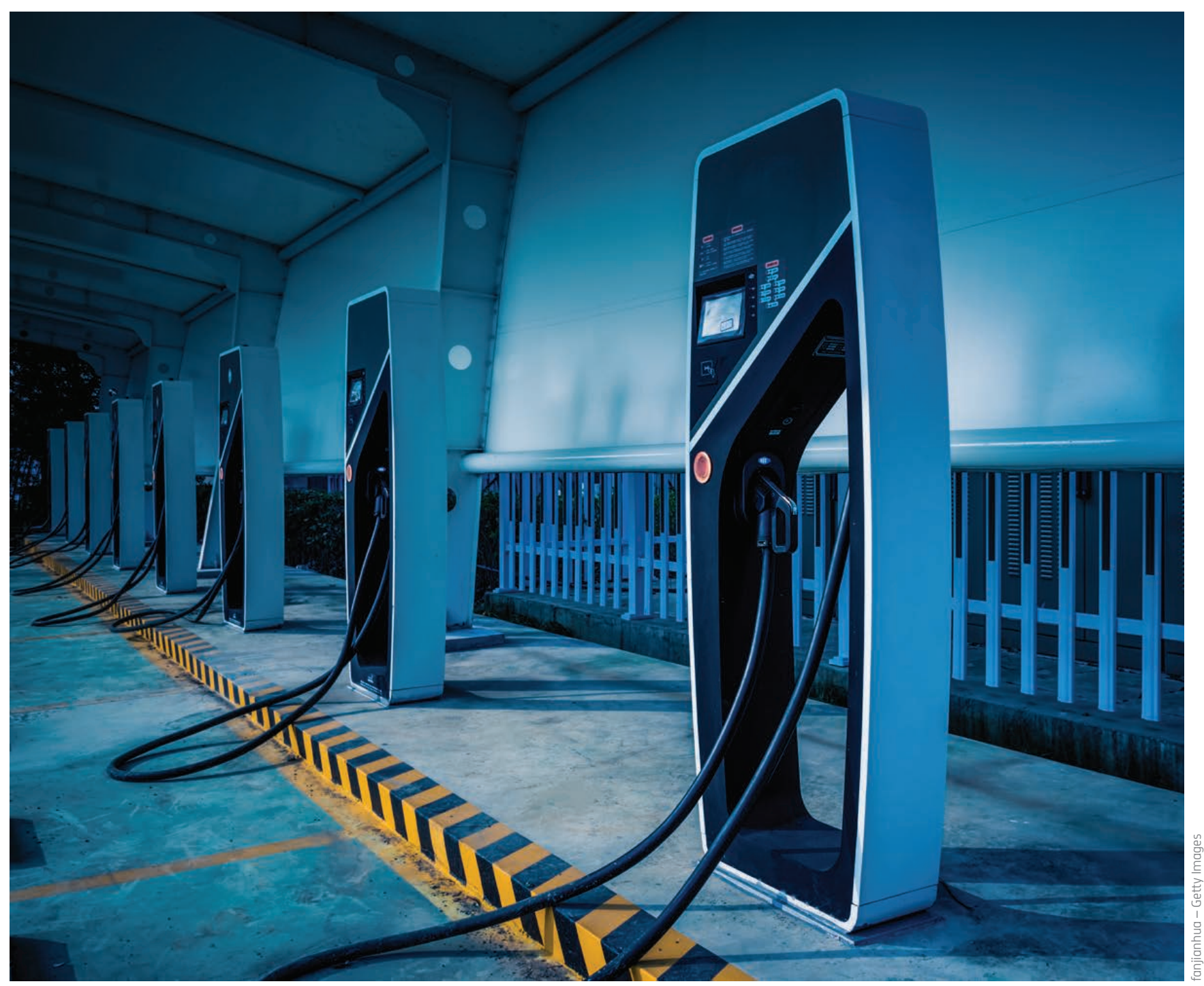

As autonomous vehicles progress through greater levels of automation, there may be a requirement for infrastructure modification to support their operation. Autonomous vehicles will eventually need to communicate with each other as well as other infrastructure like bridges, highways, tunnels and buildings.

As more and more autonomous vehicles become reality, petrol stations may be replaced with charging stations, highways may require sensors or wireless technological additions, and car parking stations may act as mixed-use spaces.
Depending on the technology that is rolled out over the coming years, mobile and wireless networks may need to be upgraded, particularly in rural and regional areas that presently don't have access to fast wireless technology.

These potential barriers and challenges will need to be addressed. Current trials around the world will teach us more about the implications for infrastructure and whether or not major upgrades or additions may be necessary for the proper operation of autonomous vehicles. 


\section{Taxation and funding}

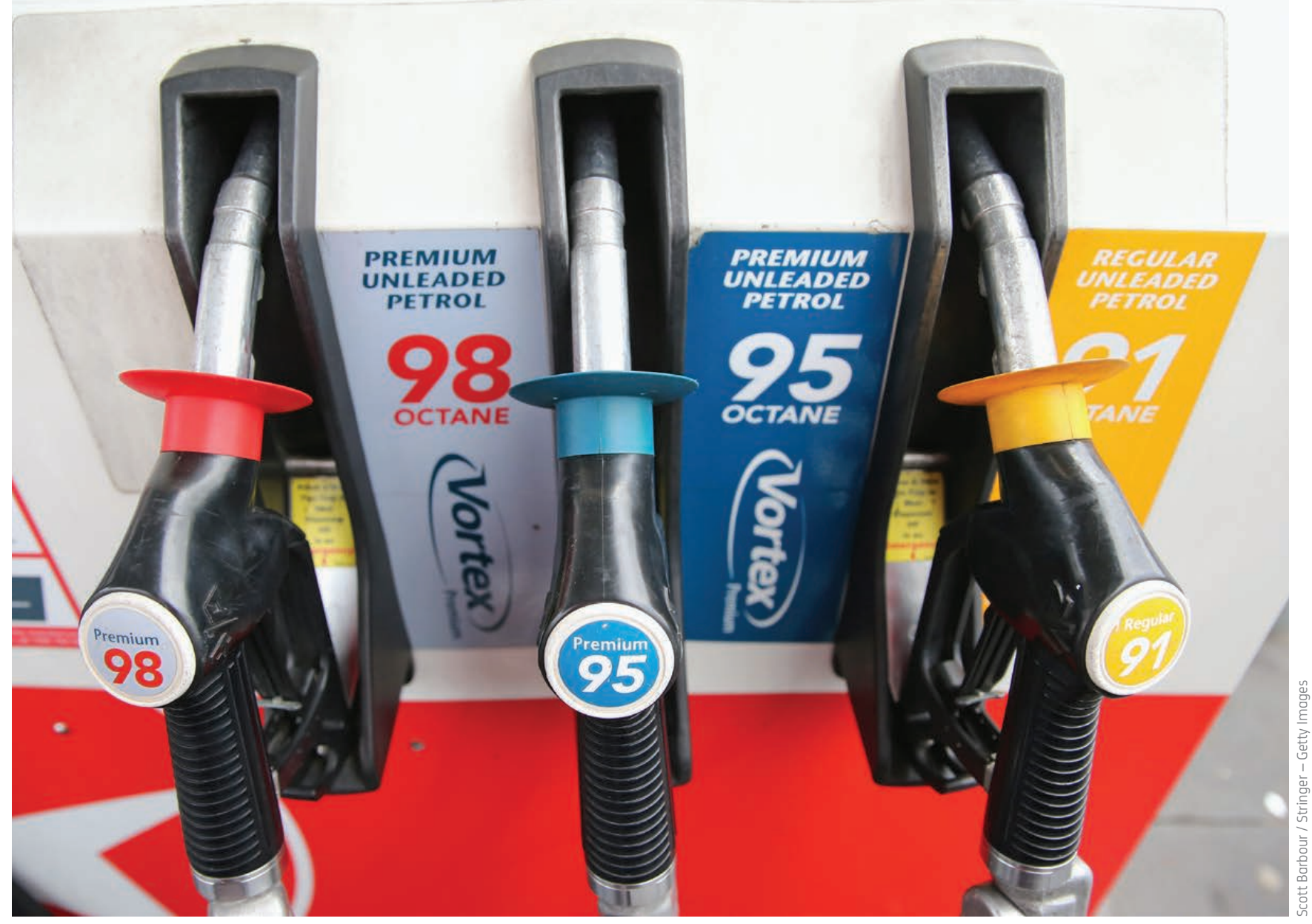

How we fund infrastructure has been a major public policy issue in Australia since the first settlement and the 'Rum Hospital.'

Fuel excise collection will significantly decline with the rise of fully electric vehicles. Presently, fuel excise is material to the budget, and the amount that is returned to consolidated revenue outnumbers the amount returned to road budgets, which is a significant structural budgetary concern.

Our future infrastructure will have to be fit for purpose if we are to reap the rewards of connected, electric and autonomous vehicles, MaaS and on-demand public transport. However, the declining revenue base to address an already existing infrastructure and maintenance deficit will be further exacerbated by an autonomous future.

We will still need roads and public transport, even if they look different to what we see today.

Major roads that require public financing and/ or community pays funding from now on should demonstrate the ability to be a hybrid road capable of carrying autonomous and conventionally driven vehicles in the future.

Similarly, transport built with public money should have as part of its business case a way of looking at the material risks to taxpayers of the investment against changes in the way mobility is delivered. 


\section{Road access pricing}

While there is conjecture relating to the congestion benefits that may arise as a result of autonomous vehicles hitting the road, at the very least, the shift towards autonomy should expedite our need to establish an equitable road access pricing solution.

With declining fuel excise and decreases in vehicle registration and driver licence fees due to electric vehicles and autonomous vehicles, a new mechanism for road and infrastructure delivery will be required to service our future needs.

\section{Congestion charging}

Congestion charging is a system of surcharging road users based on road congestion at a given point in time. Pricing is generally dynamic so that road demand can be manipulated via the lowering or raising of pricing.

Two examples of cities that currently have a congestion charge in place are London and Stockholm:

1. The London Congestion Charge took effect in 2003. It was introduced to curb congestion in Central London and raise funds for London's transport system. The charge is in place from 7am to $6 \mathrm{pm}$ Monday to Friday. The introduction of the congestion charge had an immediate impact, reducing the amount of traffic in the heart of the capital by about 15 per cent. Additionally, annual revenue collected from the charge is approximately £250 million (AUD $\$ 420$ million). ${ }^{64}$

2. Stockholm's Congestion Charge took effect in 2007 after a referendum found the majority of residents supported it post a seven-month trial during 2006. The charge, which is primarily aimed at reducing congestion and improving environmental conditions, is imposed on motorists when they pass through unmanned control points situated around Stockholm. While the charge took effect in Stockholm post the referendum, 14 surrounding municipalities opposed the implementation of a congestion charge.

While congestion charging can be effective in manipulating road demand at a given time, it does not generally take into account other factors affecting road users such as origin, destination, commute time, speed of travel, distance travelled, and alternative mobility options.

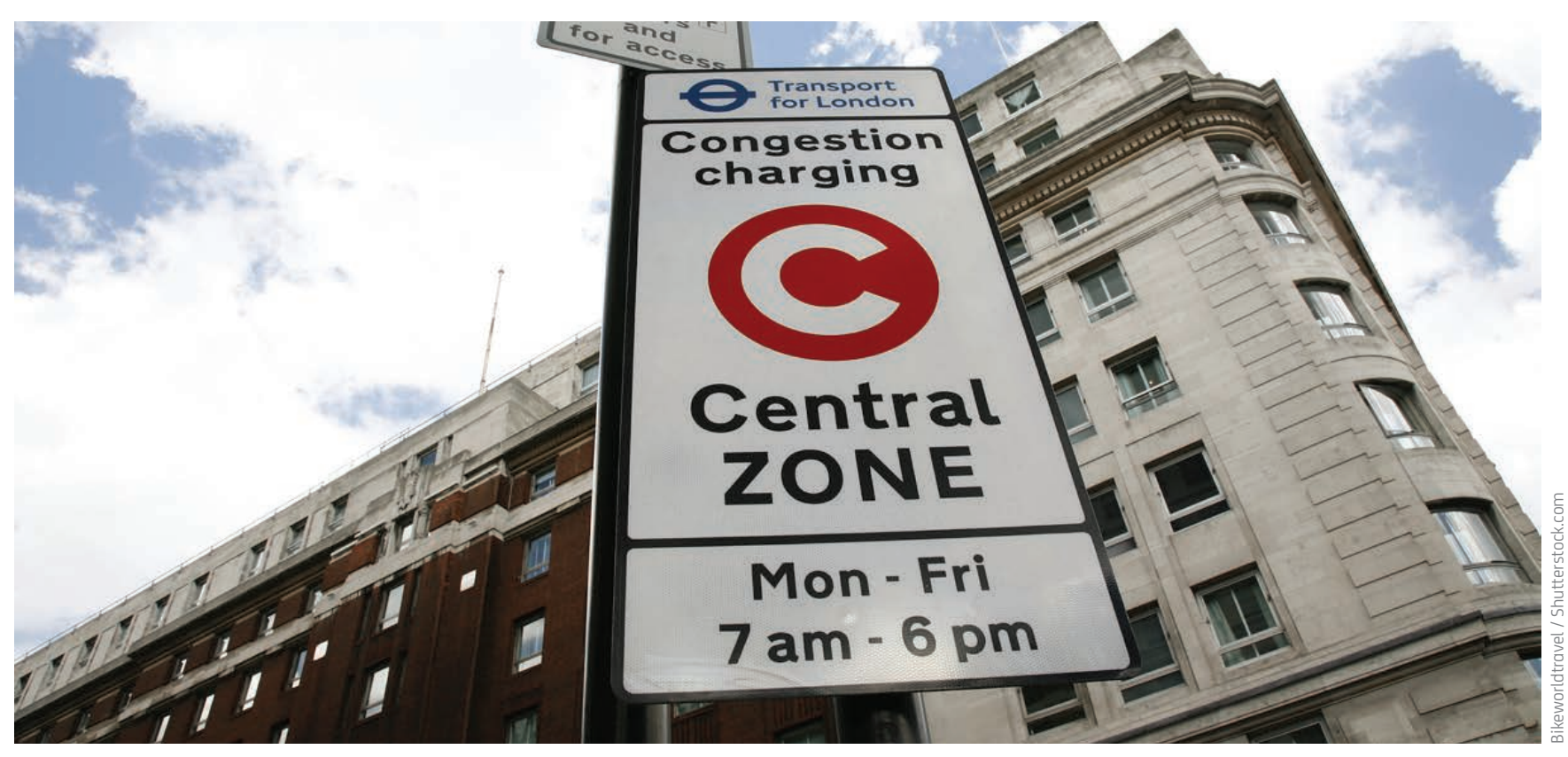




\section{Road user charging}

Road user charging is a whole-of-system pricing scheme that surcharges road users based on a number of relevant factors, including congestion. If implemented correctly, road user charging has the capacity to optimise road usage within an integrated transport system. Given its flexibility, it presents states and municipalities with a potentially equitable road access pricing mechanism which can be used to address transport infrastructure needs.

In addition to recognising congestion, a road user charging scheme can give consideration to many other factors, including distance, frequency of use, alternative mobility options, journey commencement time and place, vehicle type and mass, engine type, alternative road access options and commute time.

Many variations of road user charging schemes exist around the world, and many governments and organisations view holistic user charging as the best future model for addressing road and transport pricing issues.
While the structure of a road user charging model requires careful consideration and development, at a conceptual level, it offers opportunities to make systems fairer, more sustainable and more efficient. ${ }^{65}$ As a component of a change to MaaS, road user charging also has the capability to deliver more transparent and equitable transport costs to consumers.

Given our mix of rural, regional and urban areas and our need for significant infrastructure delivery to keep pace with our increasing population, road user charging currently presents the best future pricing model for our needs, offering equity, efficiency and seamless transport system integration in a potentially costeffective manner.

A properly considered road user charge in Australia should replace existing charges, such as the collection of fuel excise, vehicle registration fees and driver licence fees, which will no longer be required in a fully autonomous future.

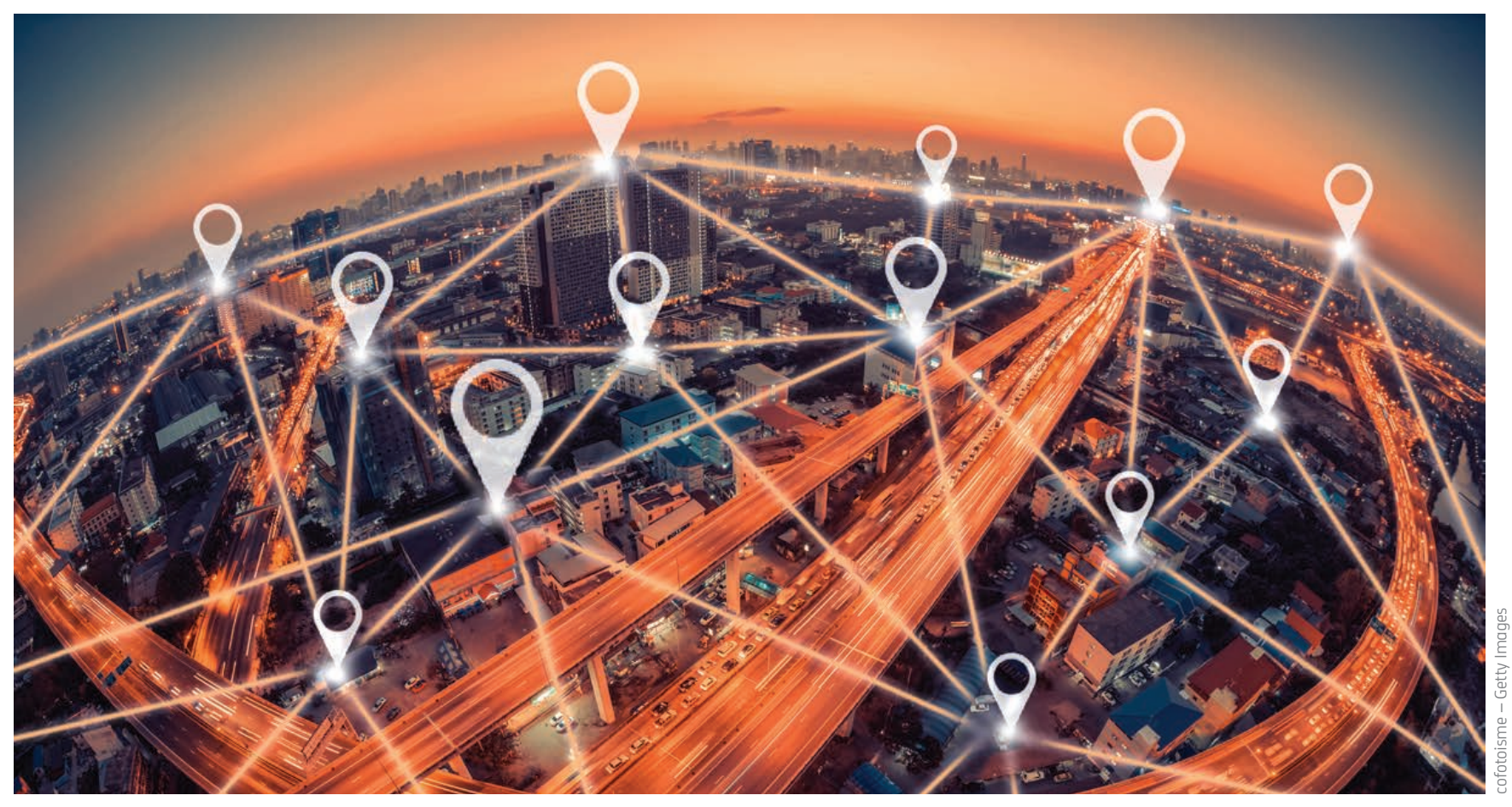




\section{Case study: Singapore}

Singapore is an innovative city-state with significant international relevance. While somewhat unique in terms of its population density and geography, its mobility policies and experiences can act as valuable lessons in how governments can drive transportation policy.

For some time, Singapore has experimented with pricing policies aimed at easing peak congestion and disincentivising private vehicle ownership. Initiatives such as access charging, limits on parking spaces, driving certificate requirements and other government fees have all limited the growth of congestion - a key public policy focus for the government.

While these initiatives have provided relief with varying degrees of success, a growing population and constantly increasing demand required a complete rethink of how people would move around in the future.

With a view to moving away from private vehicle ownership, Singapore has placed public transport at the heart of its mobility system. By 2025, 75 per cent of all peak journeys will be reliant on the public transport system.

To complement its transport vision and provide endto-end mobility options for residents and visitors, the Committee on Autonomous Road Transport for Singapore was established in 2014. Tasked with guiding the development of autonomous vehicles, the Committee set out four priority areas:

1. Fixed Routes, aimed at moving mass on schedule

2. Point-to-Point, aimed at satisfying first and last mile needs

3. Freight, aimed at truck platooning

4. Utility, aimed at cleaning and servicing roads
The Singaporean government has decided to support the development of autonomous vehicle technology and integration to improve traffic flow and reduce congestion. In addition, safer roads, mobility for the elderly and disabled, parking space optimisation and on-demand services were all viewed as positive potential additions to the transport system.

Since the Committee's establishment, several trials have been conducted to increase Singapore's understanding of how autonomous technology can benefit mobility and complement existing transport systems. Future trials are set to test vehicle-tovehicle and vehicle-to-infrastructure communication systems to ascertain what requirements may be necessary for these vehicles to interact properly with existing infrastructure like buildings, signals and other artificial devices.

Like Singapore, cities around the world will need to develop and test mobility solutions to suit their unique needs and circumstances.

Singapore's overarching transport vision - based on better services, more connections and enhanced liveability - will transform the way people move. By viewing transport planning holistically, Singapore hopes to solve its mobility challenges by embracing innovative concepts and learning from new technologies.

The government's ultimate aim is to fully and efficiently integrate all modes of transport, including autonomous vehicles, to support the anticipated future growth of the city-state. 


\section{Other considerations}

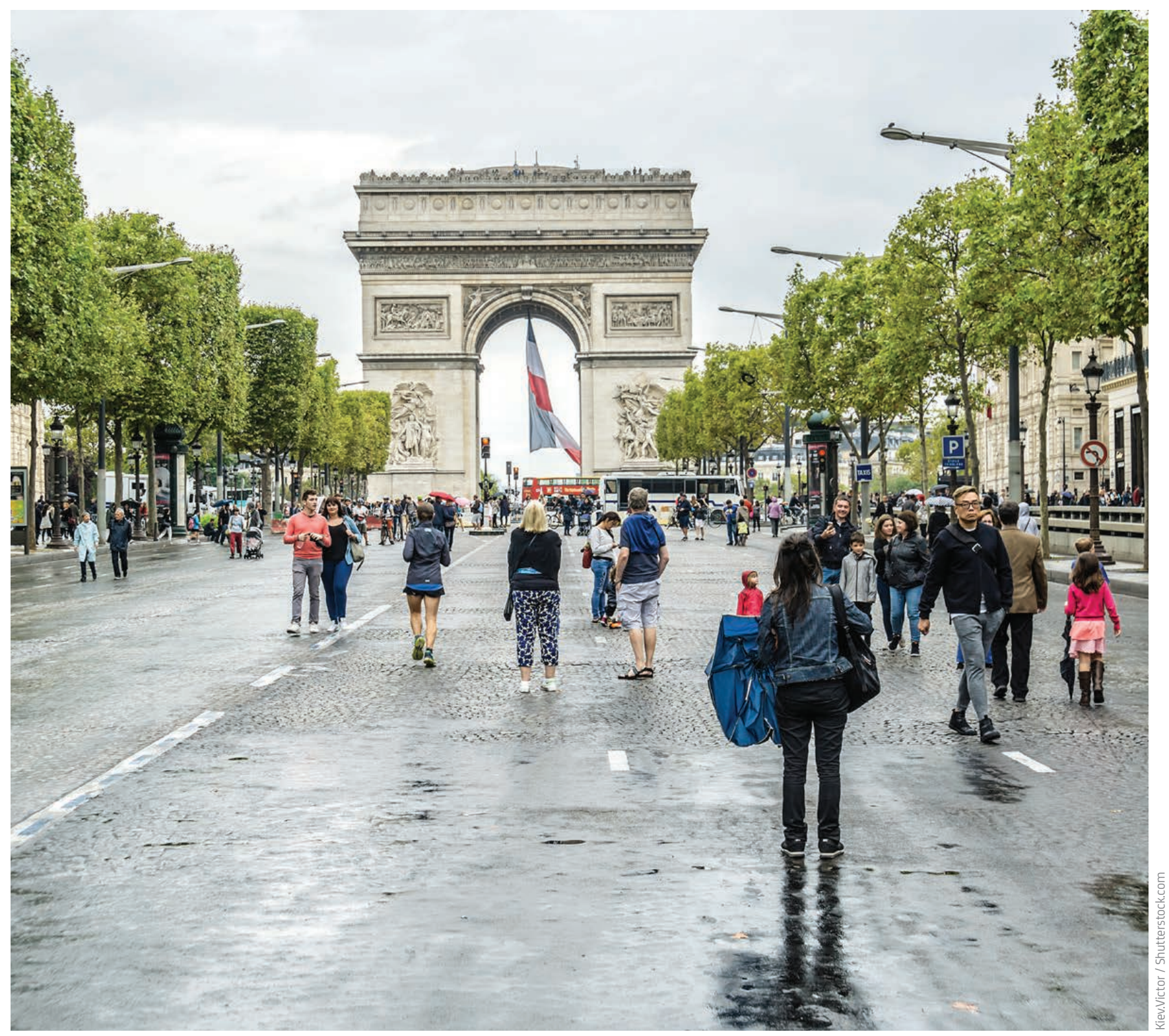

Paris, France is one city that has recently experimented with car-free days. This was in response to rising pollution levels, noting that in early 2015 it was the most polluted city in the world. ${ }^{66}$ Hamburg, Germany is another city where there are plans to significantly reduce vehicles in the city by $2034 .{ }^{67} \mathrm{~A}$ YouGov poll in 2015 found that the majority of Londoners would support a monthly one-day ban on motor vehicles in the city centre. ${ }^{68}$
Public health preferences from voters and legislators alike may also pose a challenge to the overall uptake of autonomous vehicles. A growth in autonomous vehicles for last mile solutions may decrease the use of active transport for mobility. One of the main inconvenience barriers to car sharing presently is the need to travel to where the car needs to be collected from. Autonomous vehicles represent the ability to break down that barrier and make car sharing more attractive. 


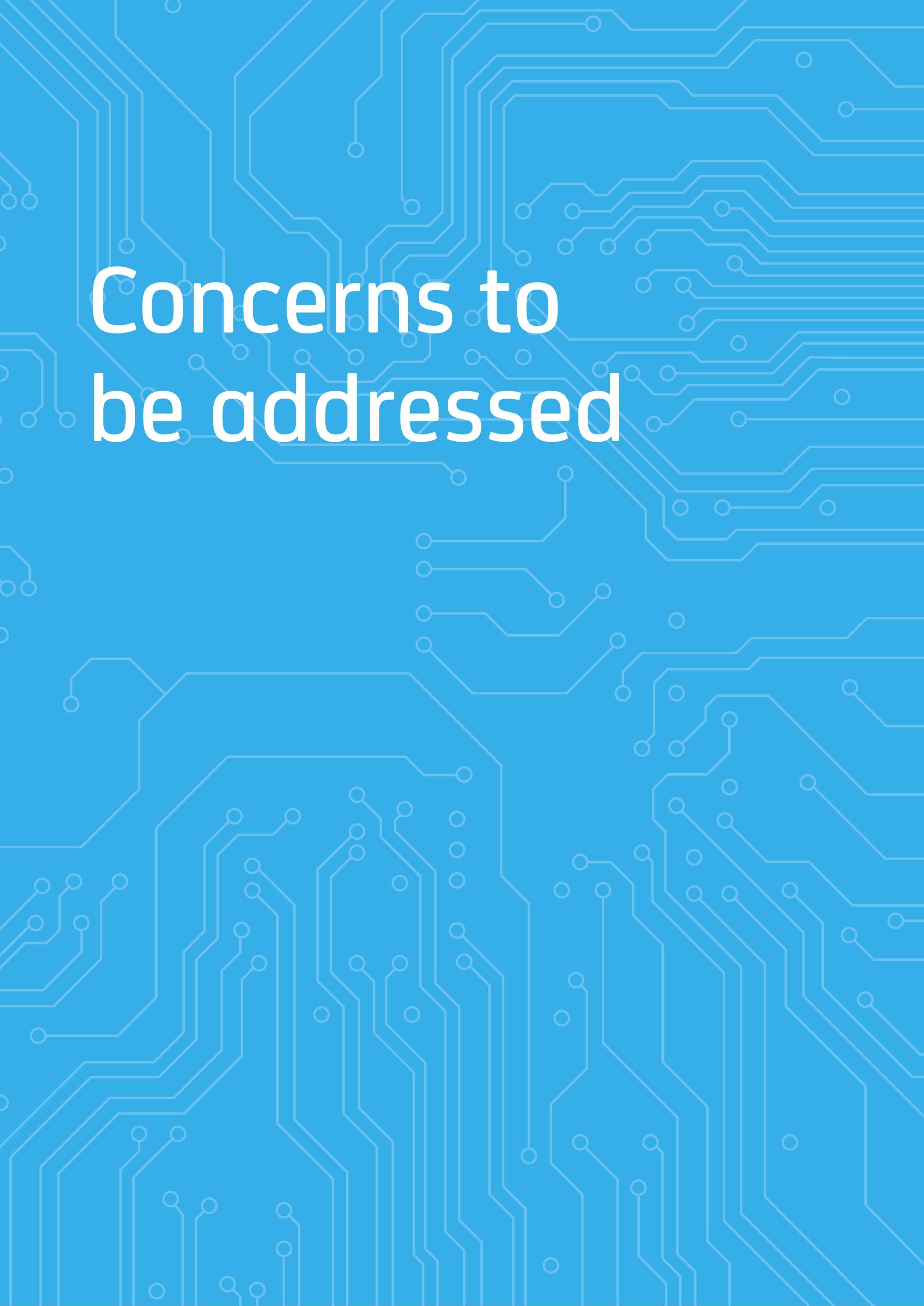




\section{Displacement and job losses}

Citizens are extremely wary of technology they see as being a threat to their business and employment. We are yet to have a frank conversation about the impact of new mobility on employment in the motoring industry in Australia.

"The best way to deal with structural change and people fearing for their jobs is to stick your head in the sand and pretend it won't happen," is how the founder of Australia's largest start-up, Atlassian, joked about the inability of governments to respond to technological and societal change. ${ }^{69}$

Societal attitudes to labour saving technology are often negative. It is common that media reporting in relation to technological changes often focuses on the number of job losses expected as a result. Often, society is slow to appreciate the new, more productive jobs that are created through the opportunities that new technological developments offer - both directly and indirectly.

If we perhaps look back to the horse and cart, as the predominant form of mobility prior to the mass introduction of the automobile, then we can imagine some of the jobs that may have existed, or existed in more numerous numbers than they do today. Farriers, blacksmiths, horse trainers, stable hands, coach builders, coach drivers - they are jobs that still exist today, but exist in significantly smaller numbers compared to 100 or so years ago. A move to motor vehicles created new jobs such as mechanics, automotive engineers, and component manufacturers.

Firms and occupations are only relevant if a demand for their services exists. It is possible that in the future the skills needed by mechanics will be highly complex electronic and software skills, vastly unlike the skill requirements of today. Traffic police, couriers, truck drivers, chauffers, taxi drivers and valets may also not be needed in the same numbers as today, but service technicians and digital programmers may grow in demand. The vehicle industry is not immune to technological disruption.
Once electric vehicles take over from petroleum drive train technology as the most common vehicle type, we expect that electrical engineers will begin to displace motor mechanics, and electric charging stations will begin to replace petrol stations.

Professional heavy vehicle driver job losses will be among the most pronounced, with heavy vehicle operators alone representing 1.5 per cent of the Australian workforce. Goldman Sachs estimates that the impact of autonomous technology on heavy vehicle driver roles will be as high as 7.5 per cent per annum.

Following the launch of Uber Freight in May, Tesla has flagged September 2017 for the launch of its semitrailer concept.

\section{CSIRO Hot Metal Carrier Vehicle ${ }^{70}$}

Hot metal carriers are a specialised forklift and are designed to carry molten metal from pot lines to cast machines inside foundries and smelters. The operation of the hot metal carrier is a dangerous task.

Australia's CSIRO has created an autonomous hot metal carrier that is capable of carrying out the operations of a manned vehicle and responding intelligently in the event of any issues or problems it may face.

The operation of the vehicle allows humans to be removed from this hazardous line of work.

While this may result in job losses, it also allows the business to redeploy the former operator elsewhere in the business to conduct a safer task.

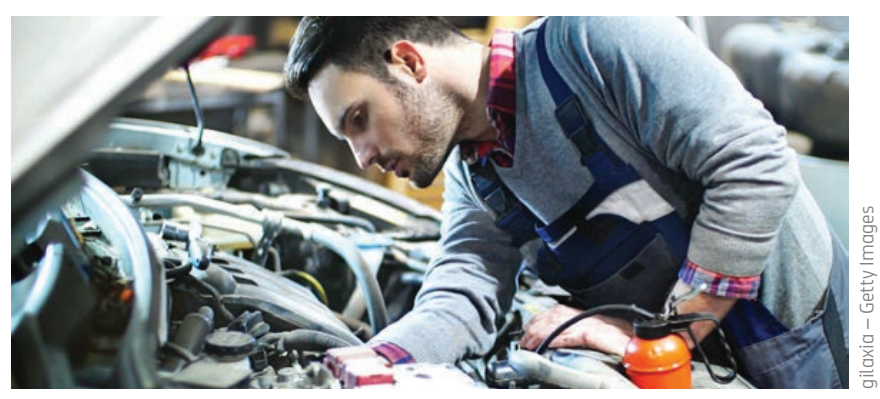




\section{Do autonomous vehicle trials require a driver?}

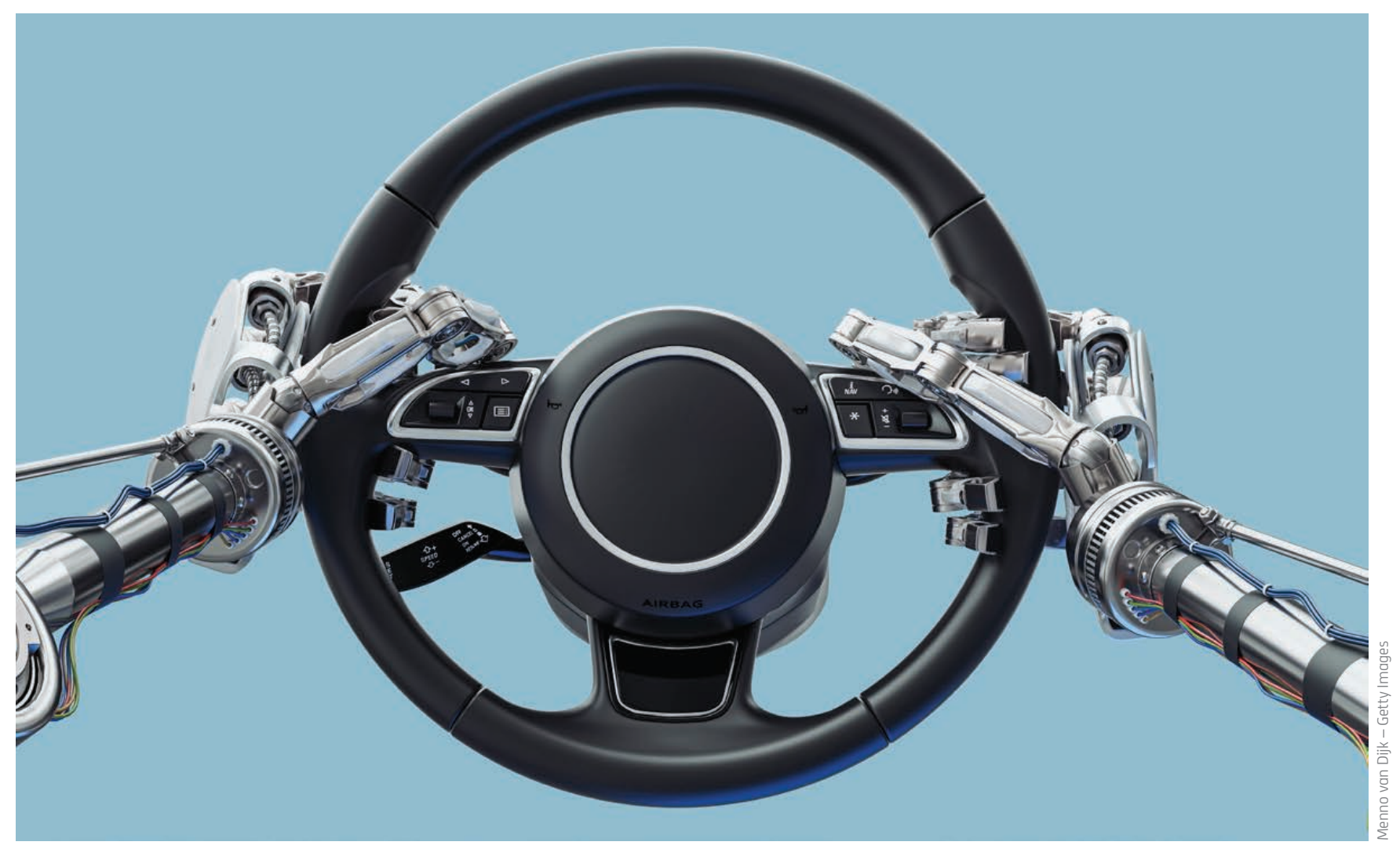

One major problem in safety that has been foreshadowed by OEM executives is the requirement, at present, to have someone still in the driver's seat ready to take over during a trial if the autonomous vehicle looks as if it is going to crash. This could actually undermine safety benefits, and stall the ability for the autonomous vehicle to safely learn behaviours if it is being overruled by a cautious tester.

Noting that driver error causes 94 per cent of vehicle crashes, the whole objective of autonomous vehicle technology is to eliminate the need for a driver. While having this requirement in trials when the technology is still new has sound policy merit, the only death to occur in an autonomous vehicle has so far been attributed to driver error in ignoring warnings to take control of the autonomous vehicle.

It would perhaps be plausible to take a soft approach to informing consumers of the benefits of autonomy by giving manufacturers the flexibility to test autonomous vehicles on roads with citizen-led trials.

One company pioneering this approach is Volvo. In 2017, Volvo will conduct a citizen-led autonomous vehicle trial named Drive Me, which will see citizen volunteers travel in an autonomous vehicle. The trial is not actually about testing the technology per se, rather it is about showing consumers how autonomous vehicles can enhance their lives. The first Drive Me trial will be in Gothenburg, Sweden, with plans to trial the concept in the United Kingdom and China after the first Drive Me pilot is completed.

It would be prudent for Australian governments to be proactive and encourage a similar type of citizen-led trial on Australian roads. 


\section{Insurance and liability}

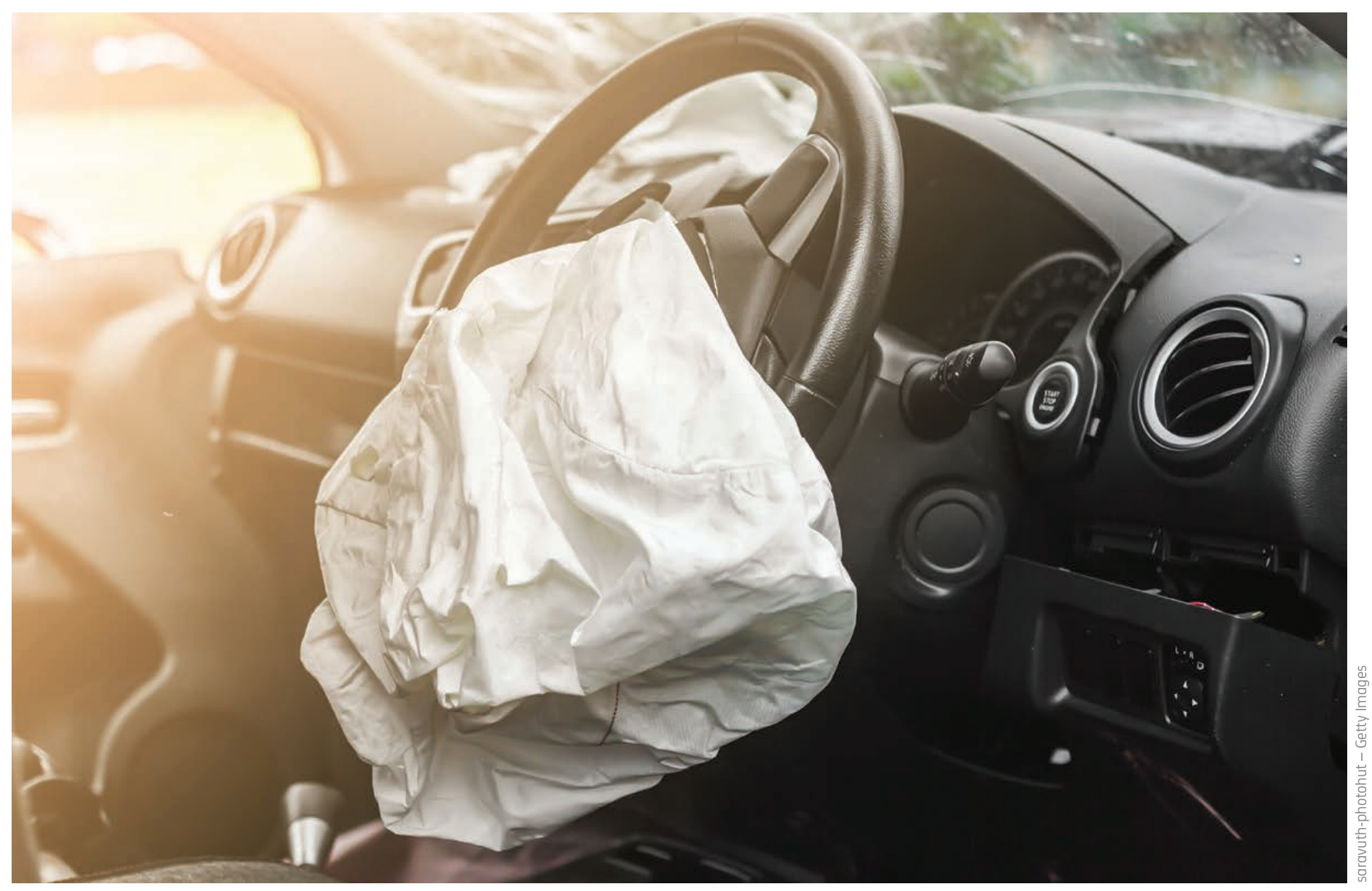

Liability questions are a major stumbling block to both trials and the introduction of autonomous vehicles on public roads. Because liability is such a crucial topic, it is perhaps the topic within the overall autonomous vehicle discussion with the largest amount of available literature. While the introduction of autonomous vehicles will potentially reduce accident numbers, there are presently well established liability principles in all states around motor vehicle accidents.

Some of the key issues around liability are:

- Misalignment between the various state and territory Compulsory Third Party insurance schemes.

- Liability surrounding partially autonomous vehicles.

- Liability when autonomous technology does not account for a novel incident.

- 'No fault' v 'At fault' liability.
Volvo have put a stake in the ground suggesting that they would be happy to take on liability for any crash where an autonomous Volvo was at fault, and suggested that governments should legislate for this. Volvo's focus on safety has been a defining part of their brand for the past two decades. Volvo were also the first manufacturer to test an autonomous vehicle in Australia by trialling a number of autonomous XC90s in 2015.

The United Kingdom Department of Transport has recently canvassed the idea that in the future, car owners will need to take out dual insurance policies for the use of autonomous vehicles. 


\section{Security and privacy}

Significant issues relating to privacy and data will need to be resolved before the new mobility future can be fully realised. OEMs currently have little incentive to allow external access to the vast amounts of data they collect on driver and trip usage (even to the user), which is no different to that of current ride share apps such as Uber.

However, as technology progresses and a greater need for data becomes mandatory for proper autonomous operation and interaction, consumers will become more and more wary about what information is collected, and what transpires as a result. The NRMA strongly supports the notion that consumers own their data and should be free to choose where it is stored and how it is used.

In Canada, as the government begins to study regulatory options pertaining to autonomous vehicles, the Privacy Commissioner, Mr Daniel Therrien, raised the following data access concern:

"Modern cars are more than simply vehicles. They have become smartphones on wheels - mobile sensor networks, capable of gathering information about, and communicating with, their internal systems, other vehicles on the road, and local infrastructure."

The main concerns expressed by the Privacy Commissioner are that there is no real accountability for the flow of data. ${ }^{71}$

The Australian Productivity Commission released a report entitled Data Availability and Use in May 2017 which also raised issues concerning consumer data. Presenting a number of recommendations, the Commission ultimately found that reforms to data availability and use are overdue. As a key point of its report, the Commission proposes that future reforms are aimed at moving from a system based on risk aversion and avoidance, to one based on transparency and confidence in data processes..$^{72}$

In the medium to long term, as car ownership begins to decline and subscription-based services become the norm, concerns relating to privacy and data access will turn into concerns about the amount of data collected, and the amount of information held or retained.

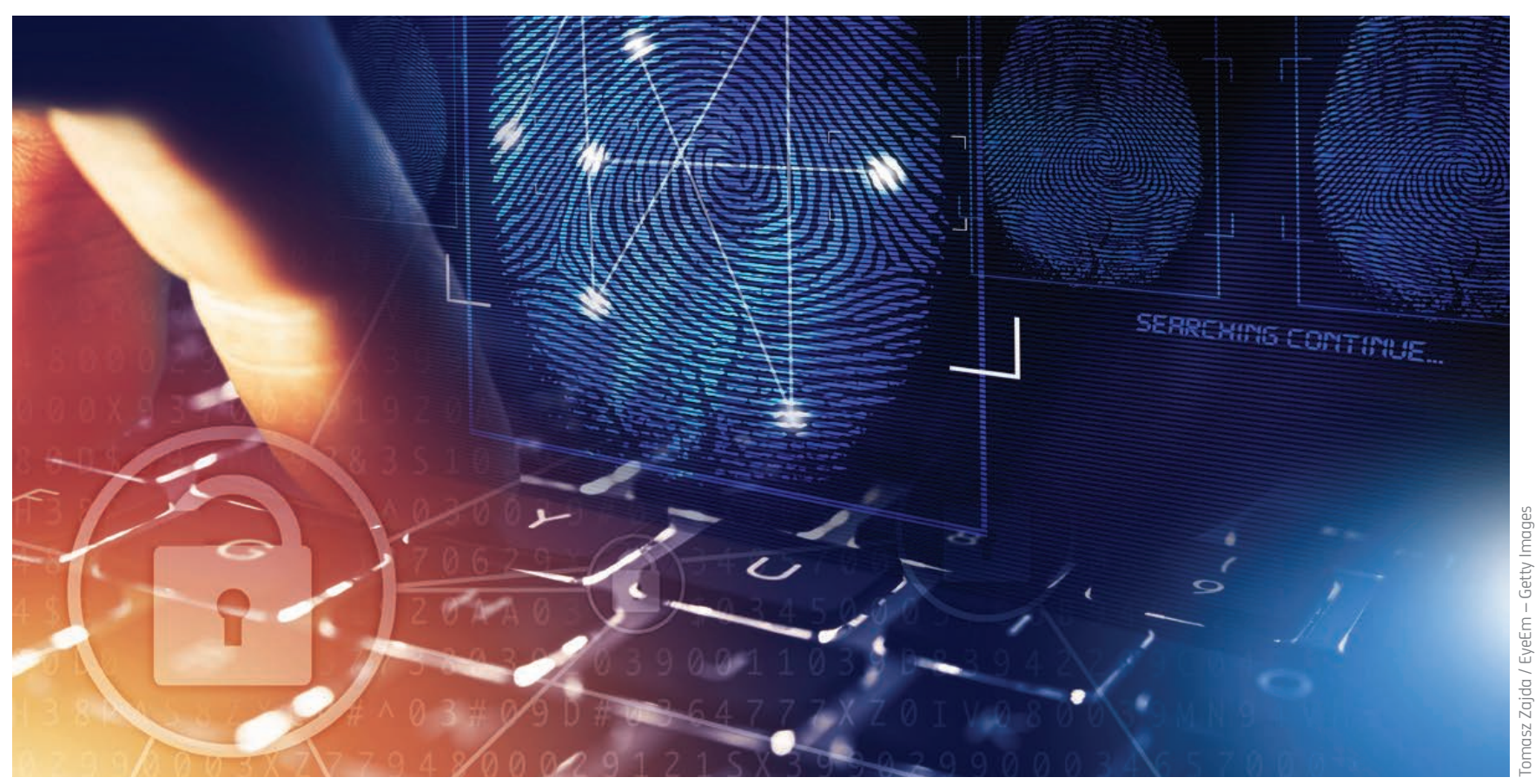

71. http://betakit.com/privacy-commissioner-of-canada-concerned-about-data-collection-in-connected-cars/ 72. http://www.pc.gov.au/inquiries/completed/data-access/thedraft/data-access-overview-draft.pdf 


\section{Beyond}

autonomous

vehicles 
What is beyond autonomy on the road? The following pages show two ideas that demonstrate anything is possible in the not so distant future.

Predicting dates and future technological advances is extremely difficult as progression and shifts in thinking are beginning to happen at exponential rates. However, it is important to consider where transport technology is heading, and how it will transform how we move around.
When the horse and cart were first put to use, it is reasonable to assume that nobody envisaged the motor car as we know it today. When the motor car did arrive, there was no immediate thought of removing the driver. Such a thought would have almost seemed ridiculous. We have come a long way very quickly in terms of mobility, so who really knows how we will all be getting around in $20,30,40$ or 50 years?

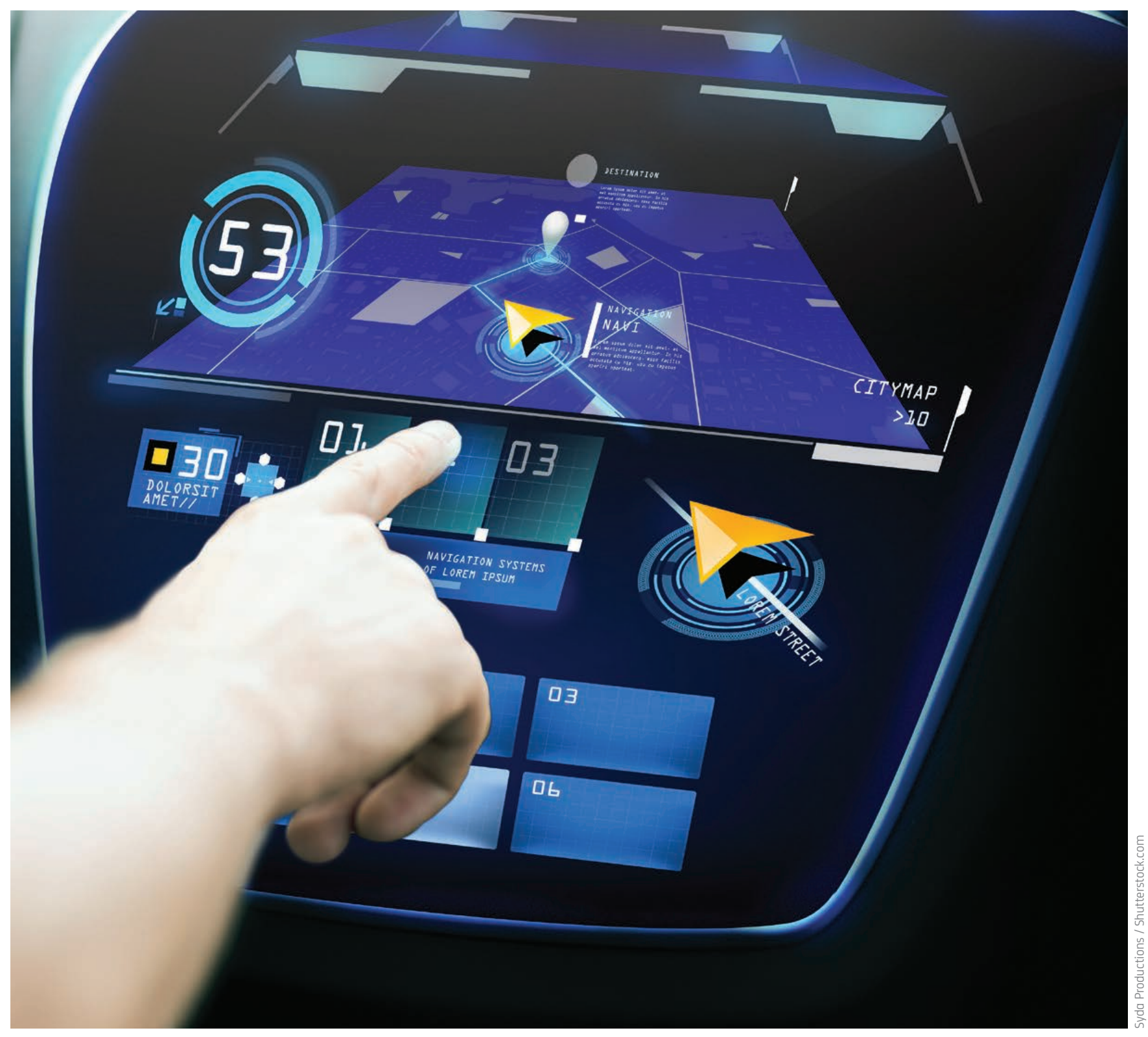




\section{Hyperloop}

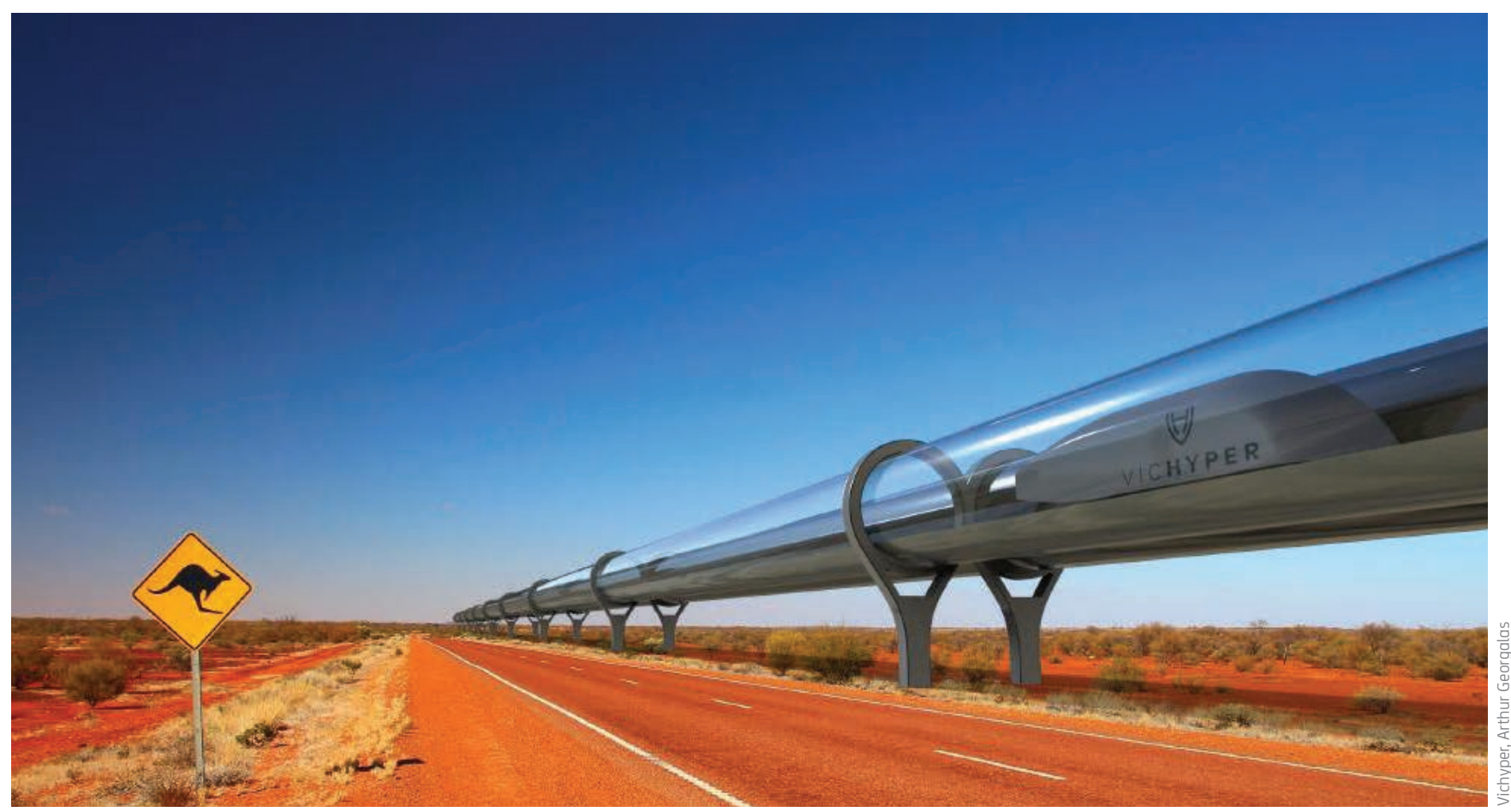

Hyperloop is a proposed mode of transport aimed at freight and passenger movement. The concept was first created by Elon Musk, the CEO of SpaceX and Tesla, in 2012.

Hyperloop is essentially the propulsion of a pod or trainlike vehicle inside a low pressure tube. The pod uses passive magnetic levitation to glide through the tube at speeds which can exceed current airliners. Although in its infancy in terms of development, the proposal has gained a significant amount of interest and investment since 2013. The governments of the UAE, India and South Korea have committed to the deployment of the new transport mode by as early as 2021 .

Musk conceptualised the proposal as a 'fifth mode of transport.' Ultimately, Hyperloop would be a low power mode of transport that is fast, automated and immune to weather events.

Although designs and concepts slightly resemble that of a modern bullet train, Hyperloop proposes several advantages:
- $\quad$ Speed - While the Maglev bullet train is capable of reaching over $600 \mathrm{~km} / \mathrm{h}$, commercial services currently operate at just over $400 \mathrm{~km} / \mathrm{h} .{ }^{73}$ With the use of frictionless technology, Hyperloop proposes to transport passengers at over $1,200 \mathrm{~km} / \mathrm{h} .^{74}$

- Frequency - Hyperloop pods are expected to arrive every 30 to 120 seconds, presenting travellers and commuters with an unrivalled service.

- Cost - While construction and potential ticket pricing is still speculative, Hyperloop aims to offer travellers and commuters reduced prices. If initial construction costs are comparable to high speed rail, Hyperloop should, in theory, present a favourable alternative given its benefits.

- Last Mile - Hyperloop proposes to adopt elements of autonomous vehicle technology with small 1-10 person pods meeting commuters at their origin. These pods then travel to the Hyperloop terminal before joining other similar pods and self-loading onto a Hyperloop for high-speed, long-distance travel. 


\section{Flying cars}

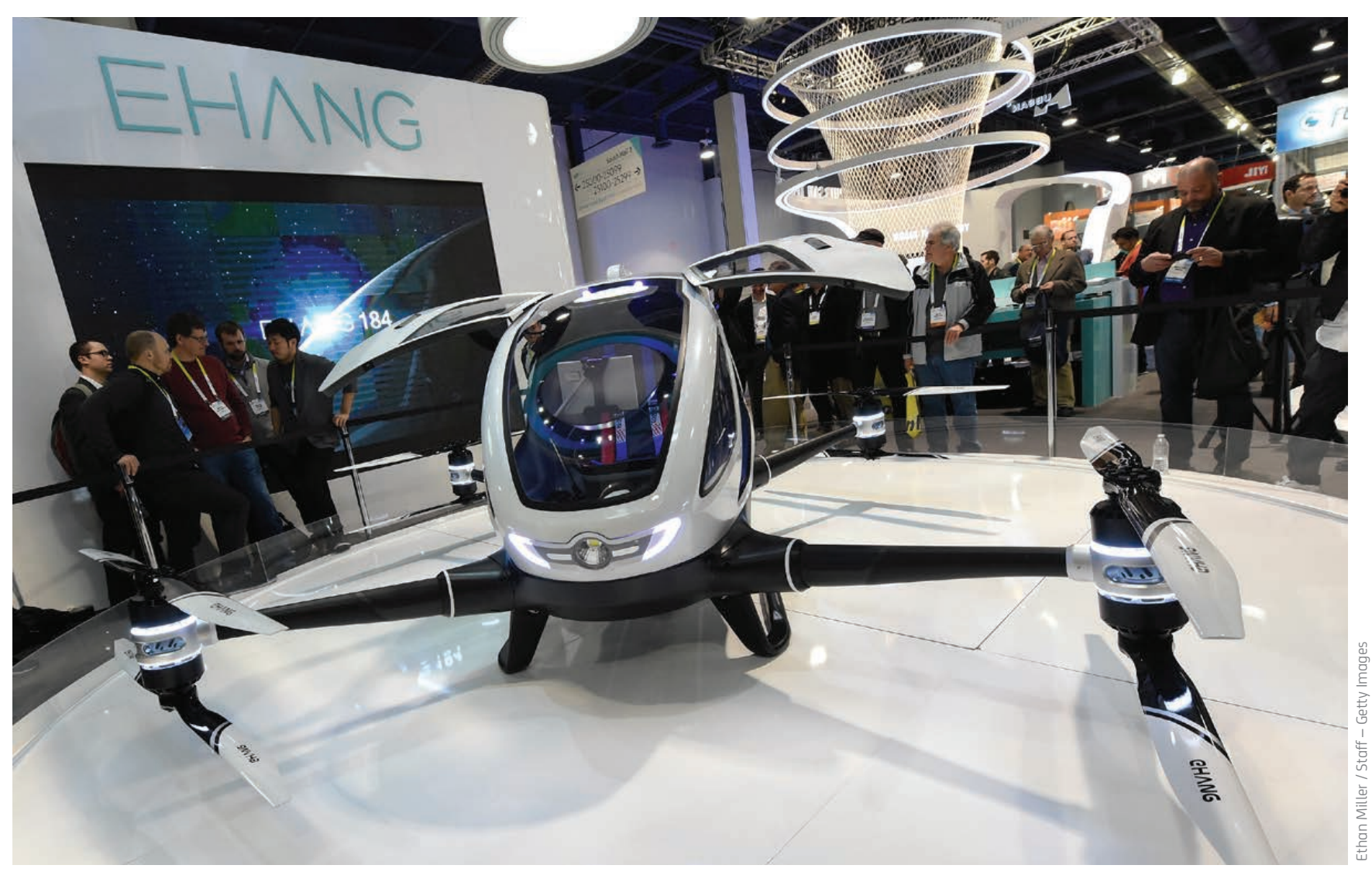

The flying car has been in our minds for some time, and was in fact flagged publicly by Henry Ford in 1940.

Since that time, prototypes have been developed and many science-fiction films have pitched the flying car as the ultimate future transport vehicle. Who wouldn't want a small and personal jet-like contraption to fly around in?

In the past decade, a number of proposals and concepts have been put forward by companies and inventors around the world, and many of these approach the issue with varying technological solutions.

More recently, several prototypes have even taken to the skies, proving that a personal vehicle capable of road and air travel could potentially exist.

In February 2017, the Chinese made EHang 184, a self-flying air taxi. Having already completed over
100 successful test flights, EHang 184 will make its commercial debut in Dubai in 2017.

In June 2017, Toyota revealed a working prototype of its take on the flying car. While still in its infancy, it's Toyota's goal to have a version ready by 2020 that is capable of lighting the torch at the opening ceremony of the 2020 Olympic Games in Tokyo.

Dutch company Pal-V propose to launch a commercial flying car in 2018 which is in line with both air and road regulations. ${ }^{75}$ They hope to produce 50 to 100 models in 2019, and a few hundred by $2020 .{ }^{76}$ The basic Pal-V model is expected to cost more than $\$ 500,000$ when it goes on sale.

AeroMobil and Terrafugia, who use plane-like propulsion systems for their flying car concepts, hope to release products prior to 2021 . 


\section{Conclusion}

Industries across the globe are currently going through some of the biggest changes since the industrial revolution, and the global vehicle industry will not be immune from this phenomena.

OEMs are responding aggressively to these changes, with significant investment in technology and alternative business models to future-proof their existence. Whether it is the rise of car share and ride sharing, electric vehicles or autonomous vehicles, the way we think about auto mobility has changed, and the car, as the most well-known and convenient form of mobility, will undergo significant transition.

The motor vehicle has transformed itself since 1885 , but its reason to exist remains unchanged: people need to get from A to B. But the way the car is used, owned and communicates with the road network will never be the same again.

The development of autonomous vehicles, combined with the growth in ride and car sharing, has seen the car industry pivot towards a future where fleet managers, OEMs and technology companies retain ownership of vehicles, and the use of assets is driven by on-demand, subscription-based services. It is this structural shift, from auto mobility to Mobility-as-aService (MaaS) that starts revolutionary thinking on mobility. At its core, however, remains the need for customised, convenient and efficient transportation services to support a range of journeys.

As OEMs and technology companies move the industry towards an autonomous, shared mobility future where vehicle ownership is obsolete, there is still uncertainty around how and when this transformation will take place, and how connected and shared mobility systems will interact with each other. Analysis of OEM technological investments and predictions tends to suggest the transition could be closer than we think, with drivers no longer needed by 2020 and cars with no steering wheels from 2025 onwards.
While we may not know exactly when major change will occur, one thing is for certain - change is coming, and in some instances the technology is already here. It is perhaps underestimated how close we are to a fully autonomous future, which is understandable given the car as we know it has been central to the Australian way of life for the best part of 60 years. Members of the community who see car ownership and driving as a symbol of independence, fun and freedom will remain, regardless of what technology is forthcoming.

A future mobility solution built around autonomy will only be possible if the community has confidence in autonomous technology.

Autonomous vehicle trials are needed to appropriately prepare, test and develop public confidence in the technology and improve our understanding of how these vehicles will interact with our road network. Road user charging, autonomous parking and the insurance implications of a transitional and fully autonomous future are all key considerations in supporting this technology.

While progress has been made to harmonise thinking around the regulatory framework needed to support autonomous vehicles, progression has been slow considering some jurisdictions have already established targets to end driven vehicles by 2025 .

As a mobility-focused organisation, the NRMA is committed to remaining abreast of emerging trends and developments in the industry. We will continue to inform our Members of new developments as information comes to light, and continue to advocate for advancements that keep our Members moving. 
Notes 


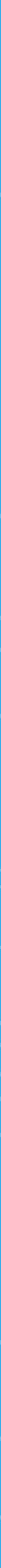




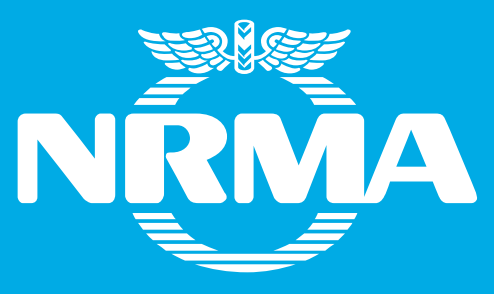

\section{NRMA}

PO Box 1026

Strathfield NSW 2135

Email: Public.Policy@mynrma.com.au

Web: mynrma.com.au 